TI 2018-064/VI

Tinbergen Institute Discussion Paper
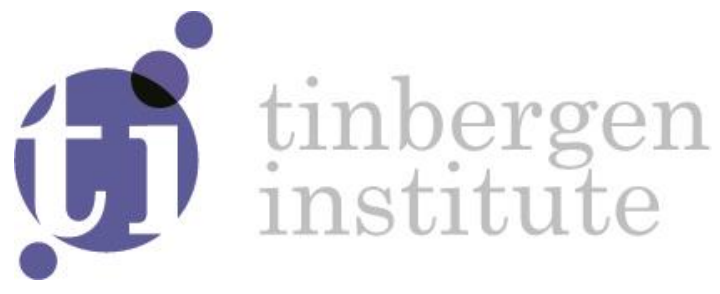

\title{
Optimal Income Taxation in Unionized Labor Markets
}

\author{
Albert Jan Hummel ${ }^{1}$ \\ Bas (B.) Jacobs ${ }^{1}$
}

${ }^{1}$ Erasmus School of Economics, Erasmus University Rotterdam 
Tinbergen Institute is the graduate school and research institute in economics of Erasmus University Rotterdam, the University of Amsterdam and VU University Amsterdam.

Contact: discussionpapers@tinbergen.nl

More TI discussion papers can be downloaded at http://www.tinbergen.nl

Tinbergen Institute has two locations:

Tinbergen Institute Amsterdam

Gustav Mahlerplein 117

1082 MS Amsterdam

The Netherlands

Tel.: +31(0)205984580

Tinbergen Institute Rotterdam

Burg. Oudlaan 50

3062 PA Rotterdam

The Netherlands

Tel.: +31(0)10408 8900 


\title{
Optimal Income Taxation in Unionized Labor Markets*
}

\author{
Albert Jan Hummel** \\ Bas Jacobs ${ }^{* * *}$
}

July 29, 2018

\begin{abstract}
This paper extends the Diamond (1980) model with labor unions to study optimal income taxation and to analyze whether unions can be desirable for income redistribution. Unions bargain with firms over wages in each sector and firms unilaterally determine employment. Unions raise the efficiency costs of income redistribution, because unemployment benefits and income taxes raise wage demands and thereby generate involuntary unemployment. Optimal unemployment benefits and optimal income taxes are lower in unionized labor markets. We show that unions are socially desirable only if they represent (low-income) workers whose participation is subsidized on a net basis. By creating implicit taxes on work, unions alleviate the labor-market distortions caused by income taxation. Numerical simulations demonstrate that optimal taxes and transfers are much less redistributive in unionized labor markets than in competitive labor markets.
\end{abstract}

Keywords: optimal taxation, unions, wage bargaining, labor participation

JEL classification: $\mathrm{H} 21, \mathrm{H} 23, \mathrm{~J} 51, \mathrm{~J} 58$

${ }^{*}$ We would like to thank Thomas Gaube, Pieter Gautier, Aart Gerritsen, Egbert Jongen, Pim Kastelein, Rick van der Ploeg, Dominik Sachs, Kevin Spiritus and seminar and congress participants at Erasmus School of Economics, CPB Netherlands Bureau for Economic Policy Analysis, Max Planck Institute for Law and Public Finance, European University Institute, Taxation Theory Conference 2016 Toulouse, IIPF Congress 2016 Lake Tahoe, APET Meeting 2017 Paris, and Norwegian-German Seminar Public Economics 2017 Munich for useful comments and suggestions.

**Erasmus University Rotterdam and Tinbergen Institute. E-mail: hummel@ese.eur.nl.

*** Erasmus University Rotterdam, Tinbergen Institute, and CESifo. E-mail: bjacobs@ese.eur.nl. Corresponding author: Erasmus School of Economics, Erasmus University Rotterdam, PO box 1738, 3000 DR Rotterdam, The Netherlands. Phone: +31-10-4081452/1441. Homepage: http:/personal.eur.nl/bjacobs. 


\section{Introduction}

Unions play a dominant role in modern labor markets. Figure 1 plots union membership and coverage rates among three groups of OECD-countries over the period 1960-2011. While union membership has shown a steady downward trend since the early 1980s, the fraction of labor contracts covered by collective agreements has decreased by much less and remains high, especially in continental European and Nordic countries.

Despite their importance, surprisingly little is known about the impact of unions on the optimal design of redistributive policies. This paper aims to close this gap by studying optimal income redistribution in unionized labor markets. It asks two main questions: 'How should the government optimize income redistribution if labor markets are unionized?' And: 'Can labor unions be socially desirable if the government wants to redistribute income?' Although some papers have analyzed optimal taxation in unionized labor markets, no paper has, to the best of our knowledge, studied the desirability of unions for income redistribution.

To answer these questions, we extend the extensive-margin models of Diamond (1980), Saez (2002), and Choné and Laroque (2011) with unions. ${ }^{1}$ Workers are heterogeneous with respect to their costs of participation and the sector (or occupation) in which they can work. Workers choose whether or not to participate, and supply labor on the extensive margin if they succeed in finding a job. In our model, we abstract from an intensive labor-supply margin. The extensive margin is often considered empirically more relevant compared to the intensive margin, especially at the lower part of the income distribution. ${ }^{2}$ Workers within a sector are represented by a union, which maximizes the expected utility of its members. Firm-owners own a stock of capital and employ different labor types to produce a final consumption good. Our baseline is the canonical right-to-manage (RtM) model of Nickell and Andrews (1983). The wage in each sector is determined through bargaining between (representatives of) firm-owners and unions. Firm-owners, in turn, unilaterally determine how many workers to hire. ${ }^{3}$ Finally, there is a government which sets income taxes, unemployment benefits and profit taxes to maximize a utilitarian social welfare function. Our main findings are the following.

First, we answer the question how income taxes should be adjusted in unionized labor markets. We show that optimal participation tax rates (i.e., the sum of income taxes and unemployment benefits as a fraction of the wage) are lower if unions are more powerful. ${ }^{4}$ Intuitively, high income taxes and unemployment benefits worsen the inside option of workers relative to their outside option. Hence, higher participation tax rates induce unions to bid up wages above market-clearing levels. This results in involuntary unemployment, which generates a welfare loss. Alternatively, involuntary unemployment creates an implicit tax, which exacer-

\footnotetext{
${ }^{1}$ Saez (2002) analyzes a model with both an extensive margin and an occupational-choice margin, which is referred to as the intensive margin.

${ }^{2}$ See, for instance, Heckman (1993), Eissa and Liebman (1996), and Meyer (2002).

${ }^{3}$ The RtM-model nests both the monopoly-union (MU) model of Dunlop (1944) and the competitive model as special cases. We analyze the efficient bargaining (EB) model of McDonald and Solow (1981) in an extension. Together with the RtM-model, these are the canonical union models, see Layard et al. (1991), Booth (1995), Boeri and Van Ours (2008).

${ }^{4}$ Because participation no longer equals employment if there is involuntary unemployment, Jacquet et al. (2014) and Kroft et al. (2017) prefer the term employment tax over the term participation tax. In line with most of the literature, we use the term 'participation tax', keeping this caveat in mind.
} 


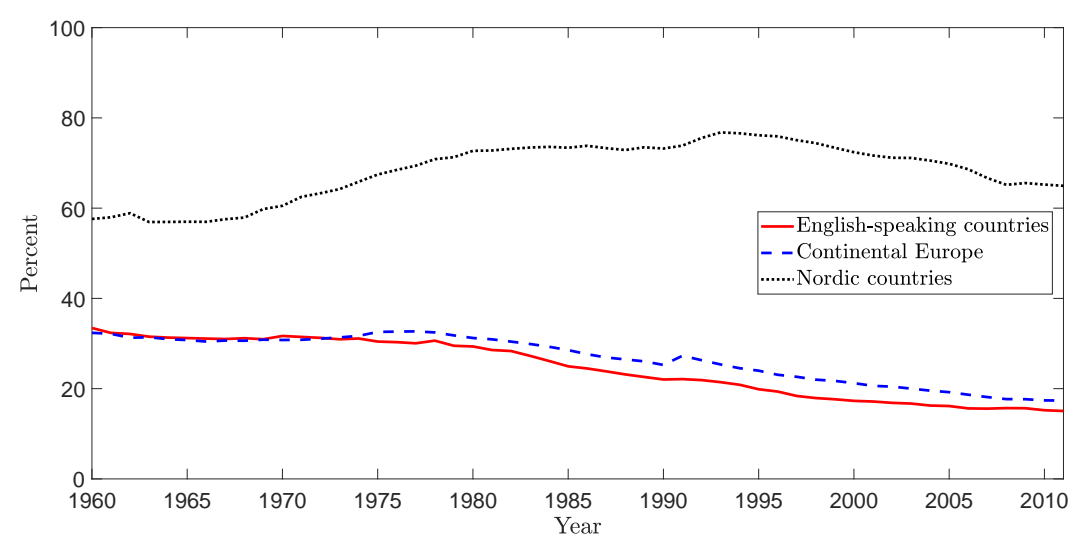

(a) Union membership



(b) Union coverage

Figure 1: Union membership (a) and union coverage (b). Data are obtained from the ICTWSS Database version 5.1 (ICTWSS, 2016). Membership is measured as the fraction of wage earners in employment who are member of a union, and coverage as the fraction of employees covered by collective bargaining agreements. Missing observations are linearly interpolated. The countries included are: Australia, Canada, the United Kingdom, the United States ('English-speaking countries'), Austria, Belgium, France, Germany, the Netherlands, Switzerland ('Continental Europe'), Denmark, Finland, Norway and Sweden ('Nordic countries'). Averages are computed using population weights, which are obtained from the OECD database (OECD, 2018a).

bates the explicit tax on labor participation. Consequently, optimal participation tax rates are lowered. Moreover, it may be optimal to subsidize participation even for workers whose welfare weight is below one, which never occurs if labor markets are competitive, cf. Diamond (1980), Saez (2002), and Choné and Laroque (2011). EITC programs are therefore more likely to be desirable if unions are more powerful.

Second, we answer the question whether unions are desirable for income redistribution. We show that, if taxes are optimally set and labor rationing is efficient, then unions are desirable only if they represent workers whose social welfare weight is above one. ${ }^{5}$ Intuitively, in sectors where the workers' welfare weight exceeds one, participation is subsidized on a net basis, see also Diamond (1980), Saez (2002), and Choné and Laroque (2011). Consequently, labor partici-

\footnotetext{
${ }^{5}$ Efficient rationing in our model means that the burden of unemployment is borne by the workers with the highest participation costs.
} 
pation is distorted upwards. Unions alleviate the distortions on labor participation by reducing employment. Hence, involuntary unemployment acts as an implicit tax, which partially off-sets the explicit subsidy on labor participation. ${ }^{6}$ Consequently, EITC policies and labor unions are complementary instruments to raise the net incomes of the low-skilled. The reverse is also true: unions are never desirable if the social welfare weights of workers are below one, since labor participation is then taxed on a net basis. ${ }^{7}$ In that case, implicit taxes from involuntary unemployment exacerbate explicit taxes on labor participation. Therefore, our results imply that it is socially optimal to let low-income workers organize themselves in a labor union, whereas labor markets for workers with higher incomes should remain competitive.

In our numerical application, we calculate the optimal tax-benefit system for the Netherlands based on a sufficient-statistics approach recently introduced by Kroft et al. (2017). For plausible values of labor-demand and participation elasticities, the optimal tax-benefit system is much less redistributive if unions are more powerful. In particular, for workers with the lowest educational attainment optimal participation tax rates vary from around $30 \%$ in the absence of unions to $-4 \%$ if there are monopoly unions. The reduction in participation tax rates is brought about by lower income taxes, but mostly by a sharp decline in unemployment benefits. Furthermore, the welfare weight of the lowest-income workers is below one in most of our simulations, which implies that unions are generally not desirable. However, this finding is sensitive to changing the redistributive preferences of the government. It could easily be reversed if the government attaches a higher social welfare weight to the working poor, for example, because the low-income workers are considered to be 'more deserving' than the unemployed workers.

We also analyze the robustness of our findings by relaxing a number of important assumptions: i) if the government cannot (fully) tax profits, ii) if there are general-equibrium effects on the distribution of wages, iii) if labor rationing is not fully efficient, iv) if a national union bargains over all sectoral wages with the aim to compress the wage distribution, and v) if unions and firms bargain over wages and employment, as in the efficient bargaining model of McDonald and Solow (1981). First, we show that all our results continue to hold if profits cannot be fully taxed, if there are general-equilibrium effects on wages, and if there is a national union aiming to compress the wage distribution. Second, we find that if labor rationing is inefficient (so that the burden of unemployment is not necessarily borne by the workers with the highest participation costs), our results are slightly modified. Optimal participation tax rates are higher compared to case with efficient rationing, because participation taxes replace involuntary by voluntary unemployment. Further, we show that unions are desirable only if the social welfare weight of the low-income workers sufficiently exceeds one, since unions create more distortions if rationing is inefficient. Finally, in the efficient bargaining model, optimal participation tax rates are no longer necessarily lower in unionized labor markets, since employment is no longer unambiguously distorted downwards. However, we still find that unions are desirable only if

\footnotetext{
${ }^{6}$ This finding echoes the results of Lee and Saez (2012) and Gerritsen and Jacobs (2018), who show that, if labor rationing is efficient, a binding minimum wage raises social welfare if the welfare weight of the workers for whom the minimum wage binds exceeds one. Intuitively, labor participation is then distorted upwards, and by reducing employment, the minimum wage alleviates this distortion.

${ }^{7}$ The net tax on participation is the sum of the participation tax and the implicit tax on labor. As indicated above, it is possible to have an explicit participation subsidy even if the social welfare weight is below one. This is the case if the implicit tax is larger than the explicit subsidy on labor.
} 
they represent workers whose welfare weight exceeds one.

The remainder of this paper is organized as follows. Section 2 discusses the related literature. Section 3 outlines the basic structure of the model, characterizes general equilibrium, and discusses the comparative statics. Section 4 analyzes how participation tax rates, unemployment benefits, and profit taxes should optimally be set. Section 5 analyzes the desirability of labor unions. Section 6 investigates the robustness of the results by exploring the implications of inefficient rationing, efficient-bargaining, and national unions. Section 7 presents our simulations. Section 8 concludes. Finally, an Appendix contains the proofs and provides additional details on the simulations.

\section{Related literature}

Our paper relates to several branches in the literature. First, there is an extensive literature, which analyzes the impact of taxation on wages and employment in union models, but does not analyze optimal taxation as in our paper, see, e.g., Lockwood and Manning (1993), Bovenberg and van der Ploeg (1994), Koskela and Vilmunen (1996), Fuest and Huber (1997), Sørensen (1999), Fuest and Huber (2000), Lockwood et al. (2000), Bovenberg (2006), Aronsson and Sjögren (2004), Sinko (2004), van der Ploeg (2006), and Aronsson and Wikström (2011). In these papers, high unemployment benefits and high income taxes (i.e., high average tax rates) improve the position of the unemployed relative to the employed, which raises wage demands and lowers employment. Moreover, high marginal tax rates (for given average tax rates) moderate wage demands and boost employment, since wage increases are taxed at higher rates. If, however, individuals can also adjust their working hours, the impact of higher marginal tax rates on overall employment (i.e., total hours worked) becomes ambiguous (Sørensen, 1999, Fuest and Huber, 2000, Aronsson and Sjögren, 2004, and Koskela and Schöb, 2012). Since we focus on extensive labor-supply responses, we abstract from the wage-moderating effect of tax-rate progressivity.

Second, there is also a literature on optimal taxation in unionized labor markets to which we contribute. Palokangas (1987), Fuest and Huber (1997), and Koskela and Schöb (2002) analyze models with exogenous labor supply. They show that the first-best optimum can be achieved, provided that the government can tax profits and it can prevent unions from setting above market-clearing wages via income or payroll taxes. This is not possible in our model, because labor supply is endogenous. Aronsson and Sjögren (2003), Aronsson and Sjögren (2004), and Kessing and Konrad (2006) study labor supply on the intensive margin, which also prevents a first-best outcome. These studies find that the impact of unions on optimal taxes is ambiguous, because higher marginal tax rates moderate wage demands, and thus reduce unemployment, but they also increase labor-supply distortions on the intensive margin. ${ }^{8}$ Instead, in our model labor supply responds only on the extensive margin. Consequently, optimal income taxes are unambiguously lower because higher taxes induce unions to bid up wages, which generates involuntary unemployment.

\footnotetext{
${ }^{8}$ For instance, Aronsson and Sjögren (2004) show that the optimal labor income tax might be either progressive or regressive depending on whether working hours are determined by the union or by workers themselves.
} 
Third, our paper is related to Diamond (1980), Saez (2002), and Choné and Laroque (2011), who analyze optimal redistributive income taxation with extensive labor-supply responses. Christiansen (2015) extends these analyses by allowing for imperfect substitutability between different labor types, so that wages are endogenous. These studies show that participation subsidies (EITCs) are optimal for low-income workers whose social welfare weight exceeds one. We extend these analyses to settings where wages are determined endogenously through bargaining between unions and firm-owners. Our model nests Diamond (1980), Saez (2002), and Choné and Laroque (2011) if labor types are perfect substitutes and it nests Christiansen (2015) if there are no unions. We find that optimal income taxes are less progressive, and benefits are lower if unions create involuntary unemployment. In addition, we show that participation subsidies may be optimal even for workers whose social welfare weight is below one.

Fourth, our study is related to Christiansen and Rees (2018), who study optimal taxation in a model with occupational choice and a single union, which is concerned with wage compression. In contrast to our paper, they abstract from involuntary unemployment and focus instead on the misallocation generated by wage compression. They show that unions have an ambiguous effect on optimal taxes, because wage compression alters both the distortions and the distributional benefits of income taxes. In contrast to Christiansen and Rees (2018), we find in an extension of our model that optimal tax rules - expressed in sufficient statistics - do not change if unions are concerned with wage compression.

\section{Model}

We consider an economy, which includes workers, unions, firm-owners and a government. The basic structure of the model follows Diamond (1980), except that we consider a finite number of labor types which are imperfect substitutes in production. Within each sector (or occupation), workers are represented by a single labor union that negotiates wages with firm-owners. The latter exogenously supply capital and produce a final consumption good using the labor input of workers in different sectors. The government aims to maximize social welfare by redistributing income between unemployed workers, employed workers, and firm-owners. We assume that each union takes tax policy as given and does not internalize the impact of its decisions on the government budget.

\section{$3.1 \quad$ Workers}

Workers differ in two dimensions: their participation costs and the sector in which they can work. There is a discrete number of $I$ sectors. A worker of type $i \in \mathcal{I} \equiv\{1, \cdots, I\}$ can work only in sector $i$, where she earns wage $w_{i}$. We denote by $N_{i}$ the mass of workers of type $i$. When working, every worker incurs a monetary participation $\operatorname{cost} \varphi$, which is private information, and has domain $[\underline{\varphi}, \bar{\varphi}]$, with $\underline{\varphi}<\bar{\varphi} \leq \infty$. The cumulative distribution function of participation costs of workers is denoted by $G(\varphi)$, which is assumed to be identical across sectors. ${ }^{9}$

Each worker is endowed with one indivisible unit of time and decides whether she wants to

\footnotetext{
${ }^{9}$ It is straightforward to allow for a type-specific distribution of participation $\operatorname{costs} G_{i}(\varphi)$, but none of our results would change.
} 
work or not. All workers derive utility from consumption net of participation costs. ${ }^{10}$ Their utility function $u(\cdot)$ is strictly concave. The net consumption of an employed worker in sector $i$ with participation costs $\varphi$ equals labor income $w_{i}$, minus income taxes $T_{i}$ and participation costs $\varphi: c_{i, \varphi}=w_{i}-T_{i}-\varphi$. Unemployed workers consume $c_{u}$, which equals an unemployment benefit of $-T_{u}$, hence $c_{u}=-T_{u}$. An individual in sector $i$ with participation costs $\varphi$ is willing to work if

$$
u\left(c_{i, \varphi}\right)=u\left(w_{i}-T_{i}-\varphi\right) \geq u\left(-T_{u}\right)=u\left(c_{u}\right) .
$$

For each sector $i$, equation (1) defines a cut-off $\varphi_{i}^{*}$ at which individuals are indifferent between working and not working: $\varphi_{i}^{*}=w_{i}-T_{i}+T_{u}$. Higher wages $w_{i}$, lower income taxes $T_{i}$, and lower unemployment benefits $-T_{u}$ all raise the cut-off $\varphi_{i}^{*}$, and, thus, raise labor participation in sector $i$. Workers are said to be involuntarily unemployed if condition (1) is satisfied, but they are not employed.

\section{$3.2 \quad$ Firms}

There is a unit mass of firm-owners, who inelastically supply $K$ units of capital, and employ all types of labor to produce a final consumption good. ${ }^{11}$ We distinguish between individual firmowners who take wages as given, and representatives of firm-owners who bargain with sectoral unions over the sectoral wage. The production technology is described by a constant-returnsto-scale production function:

$$
F\left(K, L_{1}, \cdots, L_{I}\right), \quad F_{K}(\cdot), F_{i}(\cdot)>0, \quad F_{K K}(\cdot), F_{i i}(\cdot),-F_{K i}(\cdot) \leq 0 .
$$

Here, the subscripts refer to the partial derivatives with respect to capital and labor in sector $i$. We assume that capital and labor have positive, non-increasing marginal returns. Moreover, capital and labor in sector $i$ are co-operant production factors $\left(F_{K i} \geq 0\right)$. In addition, in most of what follows we make the following assumption.

Assumption 1. (Independent labor markets) Marginal labor productivity in sector $i$ is unaffected by the amount of labor employed in sector $j \neq i$, i.e., $F_{i j}(\cdot)=0$ for all $i \neq j$.

Under Assumption 1, a change in employment in one sector does not affect the marginal productivity of workers in other sectors. Hence, there are no spillover effects between different sectors in the labor market. Section 6.1 shows that all our main results carry over to a setting in which labor markets are interdependent.

Profits equal output minus wage costs:

$$
\pi=F\left(K, L_{1}, \cdots, L_{I}\right)-\sum_{i} w_{i} L_{i}
$$

Firm-owners maximize profits taking sectoral wages $w_{i}$ as given. The first-order condition for

\footnotetext{
${ }^{10}$ For analytical convenience, we model participation costs as a pecuniary cost rather than a utility cost, see also Choné and Laroque (2011). Utility is then a function of consumption net of participation costs.

${ }^{11}$ Alternatively, we could assume there are sector-specific firms producing a single, final consumption good. As long as the government is able to observe (and tax) profits of all firms, none of our results change.
} 
profit maximization in each sector $i$ is given by:

$$
w_{i}=F_{i}\left(K, L_{1}, \cdots, L_{I}\right)
$$

Firms demand labor until its marginal product is equal to the wage. Under Assumption 1, the demand for labor in sector $i$ is only a function of the wage in sector $i$ : $L_{i}=L_{i}\left(w_{i}\right)$, where $L_{i}^{\prime}(\cdot)=1 / F_{i i}(\cdot)$. The labor-demand elasticity $\varepsilon_{i}$ in sector $i$ is defined as $\varepsilon_{i} \equiv-F_{i}(\cdot) /\left(L_{i} F_{i i}(\cdot)\right)>$ 0 and depends only $L_{i}$.

Firm-owners consume their profits net of taxes. Their utility is given by $u\left(c_{f}\right)=u\left(\pi-T_{f}\right)$, where $T_{f}$ denotes the profit tax. Note that the profit tax is non-distortionary, since it affects none of the firms' decisions.

\subsection{Unions and labor-market equilibrium}

In each sector $i$, all workers are organized in a union, which aims to maximize the expected utility of its members. ${ }^{12}$ We characterize labor-market equilibrium in sector $i$ using a version of the Right-to-Manage (RtM) model due to Nickell and Andrews (1983). In this model, the wage $w_{i}$ is determined through bargaining between the union in sector $i$ and (representatives of) firm-owners. Individual firm-owners in each sector take the negotiated wage $w_{i}$ as given and have the 'right to manage' how much labor to employ. The RtM-model nests both the competitive equilibrium (CE) as well as the monopoly-union (MU) model of Dunlop (1944) as special cases.

Because union members differ in their participation costs, we have to make an assumption on the rationing schedule: which workers become unemployed if the wage is set above the market-clearing level? In most of what follows, we assume that labor rationing is efficient (cf. Lee and Saez, 2012, Gerritsen, 2017, and Gerritsen and Jacobs, 2018).

Assumption 2. (Efficient Rationing) The incidence of involuntary unemployment is borne by the workers with the highest participation costs.

If labor markets are competitive, there is no involuntary unemployment and Assumption 2 is trivially satisfied. However, if there is involuntary unemployment, there is no reason to believe that only individuals with the highest participation costs bear the burden of unemployment, see also Gerritsen (2017). The assumption of efficient rationing clearly biases our results in favor of unions and will be relaxed in Section 6.2.

Let $E_{i} \equiv L_{i} / N_{i}$ denote the employment rate for workers in sector $i$. Under Assumption 2 , workers with participation costs $\varphi \in\left[\underline{\varphi}, \hat{\varphi}_{i}\right]$, where $\hat{\varphi}_{i} \equiv G^{-1}\left(E_{i}\right)$, are employed, whereas those with participation costs $\varphi \in\left(\hat{\varphi}_{i}, \bar{\varphi}\right]$ are not employed. Workers with participation costs $\varphi \in\left(\hat{\varphi}_{i}, \varphi_{i}^{*}\right]$ are involuntarily unemployed, since they participate in the labor market, but cannot find employment. Workers with participation costs $\varphi \in\left(\varphi_{i}^{*}, \bar{\varphi}\right]$ do not participate ('voluntary unemployment'). Because participation is voluntary, the fraction of workers willing to participate is weakly larger than the rate of employment: $E_{i}=G\left(\hat{\varphi}_{i}\right) \leq G\left(\varphi_{i}^{*}\right)$.

\footnotetext{
${ }^{12}$ The qualitative predictions of the model are robust to changing the union objective as long as the union cares about unemployment, and as long as the negotiated wage extends to the non-union members. For example, we could allow for different degrees of union membership across workers with varying participation costs.
} 




Figure 2: Labor market equilibria in the right-to-manage model

If union $i$ maximizes the expected utility of its members, and labor rationing is efficient, then the union's objective function can be written as:

$$
\Lambda_{i}=\int_{\underline{\varphi}}^{\hat{\varphi}_{i}} u\left(c_{i, \varphi}\right) \mathrm{d} G(\varphi)+\int_{\hat{\varphi}_{i}}^{\bar{\varphi}} u\left(c_{u}\right) \mathrm{d} G(\varphi)=E_{i} \overline{u\left(c_{i}\right)}+\left(1-E_{i}\right) u\left(c_{u}\right),
$$

where $\overline{u\left(c_{i}\right)} \equiv \int_{\varphi}^{\hat{\varphi}_{i}} u\left(c_{i, \varphi}\right) \mathrm{d} G(\varphi) / E_{i}$ denotes the average utility of employed workers in sector $i$.

To characterize equilibrium, we employ a version of the RtM-model that allows for any intermediate degree of union power. This is graphically illustrated in Figure 2. The competitive equilibrium lies at the intersection of the labor-supply curve and the labor-demand curve. The MU-outcome, in turn, lies at the point where the union's indifference curve is tangent to the labor-demand curve. In our characterization of labor-market equilibrium, any point on the bold part of the labor-demand curve corresponds to an equilibrium in the RtM-model. The higher (lower) is union power, the closer is the outcome to the monopoly-union outcome (competitive outcome). Therefore, the monopoly-union outcome and the competitive outcome represent the two polar cases in our analysis.

We refer to the monopoly-union (MU) model if the union in sector $i$ has full bargaining power. In this case, the union chooses the combination of the wage $w_{i}$ and the rate of employment $E_{i}$, which maximizes its objective (5) subject to the labor-demand equation (4). This leads to the following (implicit) wage-demand equation:

$$
1=\varepsilon_{i} \frac{u\left(\hat{c}_{i}\right)-u\left(c_{u}\right)}{\overline{u^{\prime}\left(c_{i}\right)} w_{i}}
$$

where $u\left(\hat{c}_{i}\right)$ denotes the utility of of the marginally employed worker (i.e., the worker with participation costs $\left.\hat{\varphi}_{i}\right)$, and $\overline{u^{\prime}\left(c_{i}\right)}$ is the average marginal utility of employed workers in sector 
$i$. If the union has full bargaining power, it demands a wage $w_{i}$ in sector $i$ such that marginal benefit of raising the wage for the employed with one euro (left-hand side) equals the marginal cost of higher unemployment (right-hand side). The marginal cost of setting the wage above the market-clearing level equals the elasticity of labor demand multiplied with the marginal worker's monetized utility gain of finding employment as a fraction of the wage: $\frac{u\left(\hat{c}_{i}\right)-u\left(c_{u}\right)}{\overline{u^{\prime}\left(c_{i}\right)} w_{i}}$. Importantly, because rationing is efficient, the costs of setting a higher wage depend only on the utility loss of the marginally employed workers, since they lose their jobs following an increase in the wage. Furthermore, equation (6) implies that an increase in either the income tax $T_{i}$ or the unemployment benefit $-T_{u}$ raises wage demands. Intuitively, higher income taxes $T_{i}$ or unemployment benefits $-T_{u}$ make the outside option more attractive relative to the inside option of the worker.

The polar opposite case is competitive outcome, where unions have no bargaining power at all. In this case, the wage is driven to the point where the marginally employed worker is indifferent between participating and not participating, i.e., $u\left(\hat{c}_{i}\right)=u\left(c_{u}\right)$. Hence, the labormarket outcome corresponds to the competitive outcome, where labor demand equals labor supply:

$$
E_{i}=G\left(\varphi_{i}^{*}\right)
$$

Since there is no involuntary unemployment, we have $\hat{\varphi}_{i}=\varphi_{i}^{*}=w_{i}-T_{i}+T_{u}$. A reduction in either the income tax $T_{i}$ or the unemployment benefit $-T_{u}$ leads to higher employment and, through the labor-demand equation (4), to a lower wage. The reduction in the wage comes about through an increase in labor participation, rather than through a reduction in the union's wage demand.

For an intermediate degree of union power in the RtM-model, a common approach to characterize the equilibrium is to solve the Nash bargaining problem between the union and the firm. Here, we choose a different approach. Rather than using bargaining weights, we introduce a union power parameter $\rho_{i} \in[0,1]$, which determines directly which equilibrium is reached in the negotiations. In particular, we modify the wage-demand equation (6) and characterize labor-market equilibrium as:

$$
\rho_{i}=\varepsilon_{i} \frac{u\left(\hat{c}_{i}\right)-u\left(c_{u}\right)}{\overline{u^{\prime}\left(c_{i}\right)} w_{i}} .
$$

Intuitively, the union power parameter $\rho_{i}$ determines which point on the labor-demand curve between $M U$ and $C E$ is reached in the wage negotiations. If $\rho_{i}=1$, the outcome corresponds to the equilibrium in the MU-model. And, if $\rho_{i}=0$, the outcome corresponds to the CE. Consequently, $\rho_{i} \in(0,1)$ corresponds to any intermediate degree of union bargaining power in the RtM-model. The higher (lower) is $\rho_{i}$, the higher (lower) is the negotiated wage. In Appendix A, we formally demonstrate that there exists a monotonic relationship between $\rho_{i}$ and the union's Nash bargaining parameter. Hence, using $\rho_{i}$ as a measure for union power is without loss of generality, while it allows us to avoid technical complications, which would arise if we instead assumed Nash bargaining. 


\subsection{Government}

The government is assumed to maximize a utilitarian social welfare function: ${ }^{13}$

$$
\mathcal{W} \equiv \sum_{i} N_{i}\left(E_{i} \overline{u\left(c_{i}\right)}+\left(1-E_{i}\right) u\left(c_{u}\right)\right)+u\left(c_{f}\right)
$$

The government observes the employment status of all workers, all sectoral wages, and the firms' profits. Tax policy cannot be conditioned on participation costs $\varphi$, which are private information. Consequently, the government cannot redistribute income between workers in the same sector with different participation costs. Furthermore, the government is unable to distinguish between workers who chose not to participate and those who are involuntarily unemployed. This results in a second-best problem, where the government needs to resort to distortionary taxes and transfers to redistribute income. In line with our informational assumptions, the government can set income taxes $T_{i}$, as well as a profit tax $T_{f}$ to finance an unemployment benefit $-T_{u}$ and an exogenous revenue requirement $R$. The government's budget constraint is then given by:

$$
\sum_{i} N_{i}\left(E_{i} T_{i}+\left(1-E_{i}\right) T_{u}\right)+T_{f}=R
$$

\subsection{Elasticity concepts}

Before characterizing optimal taxes, we first introduce the behavioral elasticities of wages and employment with respect to the tax instruments $T_{i}$ and $T_{u}$. To simplify the exposition, we assume that income effects at the union level are absent in most of what follows.

Assumption 3. (No income effects at the union level) Equilibrium wages and employment respond symmetrically to an increase in the income tax $T_{i}$ or an increase in the unemployment benefit $-T_{u}: \frac{\partial w_{i}}{\partial T_{i}}=-\frac{\partial w_{i}}{\partial T_{u}}$ and $\frac{\partial E_{i}}{\partial T_{i}}=-\frac{\partial E_{i}}{\partial T_{u}}$.

Under Assumption 3, giving both the employed and the unemployed an additional euro does not result in a change in union behavior. Hence, a simultaneous increase in the income tax and a reduction in the unemployment benefit such that the participation $\operatorname{tax} T_{i}-T_{u}$ remains unaffected, does not affect equilibrium in the labor-market. We show in Appendix C.3 that allowing for income effects at the union level does not yield any additional substantive insights. ${ }^{14}$ By Assumption 3, the equilibrium wage and employment rate in sector $i$ can be written solely as a function of the participation tax rate $t_{i} \equiv\left(T_{i}-T_{u}\right) / w_{i}$, i.e., $w_{i}=w_{i}\left(t_{i}\right)$ and $E_{i}=E_{i}\left(t_{i}\right)$. The behavioral elasticities are then given in the following Lemma.

Lemma 1. If Assumptions 1 (independent labor markets), 2 (efficient rationing), and 3 (no income effects at the union level) are satisfied, then the wage and employment elasticities with

\footnotetext{
${ }^{13}$ The utilitarian specification is without loss of generality. One can easily allow for stronger redistributional desires by adopting a concave cardinalization of the utility function, or a concave transformation of individual utilities, or by introducing Pareto weights for each individual.

${ }^{14}$ This is an assumption on the shape of the individual utility function $u(\cdot)$. Appendix C.3 shows that a sufficient condition for income effects to be absent is that $u(\cdot)$ is of the CARA-type.
} 
respect to the participation tax rate $t_{i}$ are given by:

$$
\begin{aligned}
\kappa_{i} & \equiv \frac{\partial w_{i}}{\partial t_{i}} \frac{1-t_{i}}{w_{i}}=\frac{u_{u}^{\prime} w_{i}\left(1-t_{i}\right)}{\hat{u}_{i}^{\prime} \varepsilon_{i} E_{i} / g\left(\hat{\varphi}_{i}\right)+u_{u}^{\prime} w_{i}\left(1-t_{i}\right)-\left(\hat{u}_{i}-u_{u}\right)\left(1+\varepsilon_{i} \varepsilon_{\varepsilon_{i}}+\varepsilon_{i} \frac{\left(\overline{u_{i}^{\prime}}-\hat{u}_{i}^{\prime}\right)}{\overline{u_{i}^{\prime}}}\right)}, \\
\eta_{i} & \equiv-\frac{\partial E_{i}}{\partial t_{i}} \frac{1-t_{i}}{E_{i}}=\frac{\varepsilon_{i} u_{u}^{\prime} w_{i}\left(1-t_{i}\right)}{\hat{u}_{i}^{\prime} \varepsilon_{i} E_{i} / g\left(\hat{\varphi}_{i}\right)+u_{u}^{\prime} w_{i}\left(1-t_{i}\right)-\left(\hat{u}_{i}-u_{u}\right)\left(1+\varepsilon_{i} \varepsilon_{\varepsilon_{i}}+\varepsilon_{i} \frac{\left(\overline{u_{i}^{\prime}}-\hat{u}_{i}^{\prime}\right)}{\overline{u_{i}^{\prime}}}\right)},
\end{aligned}
$$

where $\varepsilon_{\varepsilon_{i}} \equiv \frac{\partial \varepsilon_{i}}{\partial E_{i}} \frac{E_{i}}{\varepsilon_{i}}=-\left(1+\frac{1}{\varepsilon_{i}}+\frac{E_{i} F_{i i i}}{F_{i i}}\right)$ is the elasticity of the labor-demand elasticity with respect to employment. The employment and wage elasticity are related via $\eta_{i}=\varepsilon_{i} \kappa_{i}$, and satisfy $\eta_{i}>0$ and $0<\kappa_{i}<1$.

Proof. See Appendix B.

According to Lemma 1, an increase in the participation tax rate (resulting from either an increase in the income tax or the unemployment benefit) raises the union's wage demand, which reduces labor demand, and thus lowers employment.

\section{Optimal taxation}

The government optimally chooses participation tax rates $t_{i}$, the unemployment benefit $-T_{u}$, and profit taxes $T_{f}$ in order to maximize its social welfare (9), subject to the budget constraint (10), and taking into account the behavioral responses summarized in Lemma 1. We characterize optimal tax policy in terms of elasticities and social welfare weights. Social welfare weights of workers in sector $i$, the unemployed, and the firm-owners are denoted by $b_{i} \equiv \frac{\overline{u^{\prime}\left(c_{i}\right)}}{\lambda}, b_{u} \equiv \frac{u^{\prime}\left(c_{u}\right)}{\lambda}$, and $b_{f} \equiv \frac{u^{\prime}\left(c_{f}\right)}{\lambda}$, respectively, where $\lambda$ is the multiplier on the government budget constraint. The social welfare weight of each group measures the monetized increase in social welfare resulting from a one unit increase in the income of that group. The following Proposition characterizes optimal tax policy.

Proposition 1. Suppose Assumptions 1 (independent labor markets), 2 (efficient rationing), and 3 (no income effects at the union level) hold, then the optimal unemployment benefit $-T_{u}$, profit taxes $T_{f}$, and participation tax rates $t_{i}$ are determined by:

$$
\begin{gathered}
\omega_{u} b_{u}+\sum_{i} \omega_{i} b_{i}=1, \\
b_{f}=1, \\
\left(\frac{t_{i}+\tau_{i}}{1-t_{i}}\right) \eta_{i}=\left(1-b_{i}\right)+\left(b_{i}-1\right) \kappa_{i},
\end{gathered}
$$

where $\omega_{i} \equiv \frac{N_{i} E_{i}}{\sum_{j} N_{j}}$ and $\omega_{u} \equiv \frac{\sum_{i} N_{i}\left(1-E_{i}\right)}{\sum_{j} N_{j}}$ are the employment shares of workers of type $i$ and the unemployed, and $\tau_{i} \equiv \frac{u\left(\hat{c}_{i}\right)-u\left(c_{u}\right)}{\lambda w_{i}}=\frac{\rho_{i} b_{i}}{\varepsilon_{i}}$ is the union wedge.

Proof. See Appendix C.1. 
Equation (13) states that a weighted average of the welfare weights of the employed and unemployed workers should sum to one. Intuitively, the government uniformly raises transfers to all individuals until the marginal utility benefits of a marginally higher transfer (left-hand side) are equal to the unit marginal costs (right-hand side). ${ }^{15}$ Because the welfare weight of the unemployed always exceeds the welfare weights of the employed, it must be that $b_{u}>1$. For condition (13) to be valid, there must be at least one sector $i$ where $b_{i}<1$. Depending on the redistributive preferences of the government, there may also be employed workers whose welfare weight is above one, see also Diamond (1980), Saez (2002), and Choné and Laroque (2011). In the remainder, we refer to workers for whom $b_{i}>1$ as low-income, or low-skilled workers.

Condition (14) for optimal profit taxes states that the government taxes firm-owners until their welfare weight equals one. Since the profit tax is a non-distortionary tax, the government raises profit taxes until it is indifferent between raising firm-owners' consumption with one unit and receiving a unit of public funds.

The first-order condition for optimal participation tax rates is given by equation (15). The left-hand side of this expression captures the marginal distortions and the right-hand side captures the marginal redistributional gains (or losses) of raising the participation tax rate in sector $i$. The total wedge on labor participation is $\frac{t_{i}+\tau_{i}}{1-t_{i}}$ and consists of the explicit tax on participation $t_{i}$ and the union wedge $\tau_{i}$. The latter is the monetized loss in social welfare as a fraction of the wage if the marginal worker in sector $i$ loses employment. Therefore, $\tau_{i}$ acts as an implicit tax on labor participation. The union wedge $\tau_{i}$ is proportional to union power $\rho_{i}$ and inversely related to the labor-demand elasticity $\varepsilon_{i}$. Hence, $\tau_{i}=0$ if either the union has no bargaining power $\left(\rho_{i}=0\right)$, or if labor demand is infinitely elastic $\left(\varepsilon_{i} \rightarrow \infty\right)$. In the latter case, unions refrain from demanding a wage above the market-clearing level, since doing so would result in a complete breakdown of employment.

Equation (15) shows that - for given distributional benefits on the right-hand side - optimal participation tax rates $t_{i}$ are lower in sectors where the welfare costs of involuntary unemployment are high, i.e., in sectors where $\tau_{i}$ is large. Hence, optimal participation tax rates are lower if unions are stronger. Low participation tax rates induce unions to moderate their wage demands, and thereby alleviate the welfare costs of unemployment. The total wedge on labor participation $\frac{t_{i}+\tau_{i}}{1-t_{i}}$ is weighted by the employment elasticity with respect to the participation tax rate $\eta_{i}$. Therefore, if $\eta_{i}$ is large, the optimal participation tax rate is lower. This is in line with the findings from Diamond (1980) and Saez (2002).

Turning to the marginal distributional benefits (or costs) on the right-hand side of equation (15), the first term captures the direct distributional effect of raising the participation tax rate. It equals the marginal value of raising one unit of revenue minus the utility loss if workers in sector $i$ pay one unit more tax. Participation tax rates also indirectly redistribute resources from firm-owners to workers by affecting equilibrium wages, as captured by the second term. This redistribution of income is socially desirable if the workers in sector $i$ have a higher social welfare weight than the firm-owners $\left(b_{i}>1\right)$. Moreover, this distributional effect is stronger, the higher is the elasticity of wages with respect to participation tax rates $\kappa_{i}$.

\footnotetext{
${ }^{15}$ This confirms Jacobs (2018), who shows that the marginal cost of public funds equals one in the policy optimum even under distortionary taxation.
} 
Like in Diamond (1980), Saez (2002), and Choné and Laroque (2011) we find that it is optimal to subsidize participation, i.e., setting $t_{i}<0$, for low-income workers whose welfare weight is above one, i.e., if $b_{i}>1$. However, and in contrast to these papers, in unionized labor markets subsidizing participation can also be optimal for workers whose welfare weight is below one $\left(b_{i}<1\right)$. This occurs if the welfare cost of involuntary unemployment is high, so that the implicit tax $\tau_{i}$ is large. Intuitively, explicit subsidies on participation can be desirable to offset the distortions from implicit taxes on participation even if $b_{i}<1$.

Our optimal tax formula nests the one derived in Saez (2002) without an occupational-choice margin as a special case. In a model with exogenous wages, he shows that optimal participation tax rates satisfy:

$$
\frac{t_{i}}{1-t_{i}}=\frac{1-b_{i}}{\gamma_{i}}, \quad \gamma_{i} \equiv \frac{\partial G\left(\varphi_{i}^{*}\right)}{\partial \varphi_{i}^{*}} \frac{\varphi_{i}^{*}}{G\left(\varphi_{i}^{*}\right)},
$$

where $\gamma_{i}$ denotes the participation elasticity in sector $i$. If labor demand is infinitely elastic (i.e., if labor types are perfect substitutes in production), equations (15) and (16) coincide. In this case, unions always refrain from demanding above market-clearing wages. The result from Saez (2002) also holds if labor types are imperfect substitutes in production and there are no unions (i.e., $\rho_{i}=0$ for all $i$ ). The same result is derived as well in Christiansen (2015). If labor markets are perfectly competitive, labor-demand considerations are therefore irrelevant for the characterization of optimal participation tax rates. See also Diamond and Mirrlees (1971a,b), who show that optimal taxes are the same in partial as in general equilibrium. ${ }^{16}$

Up to this point, we assumed that the government has access to a perfect profit tax. Earlier studies on (optimal) taxation in unionized labor markets have explicitly considered restrictions on profit taxation, either to prevent a first-best outcome or to analyze rent appropriation by unions. ${ }^{17}$ How does a potential restriction on profit taxation affect the design of optimal participation tax rates? The following Corollary provides the answer.

Corollary 1. If Assumptions 1 (independent labor markets), 2 (efficient rationing), and 3 (no income effects at the union level) are satisfied, and profit taxes $T_{f}$ are exogenously determined, then optimal unemployment benefits $-T_{u}$ and participation tax rates $t_{i}$ are determined by:

$$
\begin{gathered}
\omega_{u} b_{u}+\sum_{i} \omega_{i} b_{i}=1 \\
\left(\frac{t_{i}+\tau_{i}}{1-t_{i}}\right) \eta_{i}=\left(1-b_{i}\right)\left(1+\frac{t_{i}}{1-t_{i}} \kappa_{i}\right)+\left(\frac{b_{i}-b_{f}}{1-t_{i}}\right) \kappa_{i} .
\end{gathered}
$$

Proof. See Appendix C.2.

Compared to Proposition 1, the expression for the optimal unemployment benefit is unaffected. The restriction on profit taxes modifies the optimal participation tax rate in two ways. First, if profits cannot be taxed, wage increases (resulting from an increase in the participation tax rate) are taxed. The welfare effect is proportional to $1-b_{i}$ and is stronger the higher is the wage elasticity with respect to the participation tax $\kappa_{i}$. This is captured by the modification of the first term on the right-hand side of equation (18). Second, higher participation tax rates

\footnotetext{
${ }^{16} \mathrm{Saez}(2004)$ refers to this finding as the 'tax-formula result'.

${ }^{17}$ See, among others, Fuest and Huber (1997), Koskela and Schöb (2002), and Aronsson and Sjögren (2004).
} 
indirectly redistribute resources from firm-owners to workers by motivating unions to raise their wage demands. This is captured by the second term on the right-hand side of equation (18). The associated welfare effect is proportional to $b_{i}-b_{f}$ and is weighted by the elasticity of wages with respect to the participation tax rate $\kappa_{i}$. With a binding restriction on profit taxes, the welfare weight of the firm-owners falls short of one, i.e., $b_{f}<1$. The more binding is the restriction on profit taxation (i.e., the lower is $b_{f}$ ), the higher should participation tax rates be set to correct for the absence of the profit tax and to indirectly redistribute income from firm-owners to workers. The finding that income taxes are adjusted to indirectly redistribute income from firms to workers has been established as well in Fuest and Huber (1997) and Aronsson and Sjögren (2004).

\section{Desirability of unions}

The previous Section analyzed the optimal tax-benefit system in unionized labor markets. In this Section we ask the question: can it be socially desirable to allow workers to organize themselves in a union? And, if so, under which conditions? The following Proposition answers both questions.

Proposition 2. If Assumption 2 (efficient rationing) is satisfied, and taxes are set optimally as in Proposition 1, then increasing union power $\rho_{i}$ in sector $i$ raises social welfare if and only if the welfare weight of the workers in sector $i$ exceeds one: $b_{i}>1$.

Proof. See Appendix D.

According to Proposition 2, unions are desirable if they represent low-income workers for whom $b_{i}>1$. To understand why, consider a marginal increase in union power $\rho_{i}$, starting from a competitive labor market (i.e., $\rho_{i}=0$ ). If $b_{i}>1$, participation is subsidized on a net basis in the policy optimum without unions, see Diamond (1980) and equation (16). Consequently, labor participation is distorted upwards: too many low-skilled workers decide to participate. Unions alleviate this distortion by offsetting the explicit subsidy on participation with an implicit tax $\tau_{i}$ on participation. The implicit tax $\tau_{i}$ lowers employment, and, hence, raises government revenue. Moreover, the rise in the equilibrium wage transfers income from firm-owners (whose welfare weight is one) to employed workers in sector $i$ (whose welfare weight is above one), which again raises social welfare. Finally, starting from a competitive labor market, a marginal increase in unemployment does not lead to a utility loss of the workers who lose their job, since labor rationing is efficient. As a result, the introduction of a union unambiguously raises social welfare if the social welfare weight of the workers in this sector is larger than one $\left(b_{i}>1\right)$. This result bears resemblance to Lee and Saez (2012), who show that a minimum wage is desirable if the welfare weight of the workers subject to the minimum wage is larger than one. Intuitively, the minimum wage reduces upward participation distortions from participation subsidies by generating unemployment, see also Gerritsen and Jacobs (2018).

For the same reasons, there is no role for a union in sector $i$ if workers have social welfare weights that are smaller than one, i.e., $b_{i}<1$. In this case, labor participation is distorted downwards. Higher union power exacerbates these distortions. Moreover, higher union power 
results in redistributional losses, because the welfare weight of firm-owners is larger than the welfare weight of workers. Hence, unions cannot meaningfully complement an optimal tax system. ${ }^{18}$

Another way to understand the efficiency-enhancing role of unions is through the following thought experiment. Below we employ this policy experiment to analyze the desirability of unions in more complicated settings, including the case with inefficient rationing. Consider a marginal increase in union power $\rho_{i}$ starting from an optimized tax-benefit system. Furthermore, suppose that jointly with the increase in union power $\rho_{i}$, the government off-sets the upward pressure on the wage $w_{i}$ by lowering the participation tax rate $t_{i}$ in sector $i$. To keep the budget balanced, the profit tax $T_{f}$ can be increased. ${ }^{19}$ This joint policy reform of raising union power, lowering the participation tax rate, and raising the profit tax thus keeps the equilibrium wage and employment fixed, and only brings about a transfer in income from firm-owners (whose welfare weight is one) to low-skilled workers (whose welfare weight exceeds one). Hence, raising union power $\rho_{i}$ is welfare-enhancing if and only if $b_{i}>1$.

Proposition 2 holds irrespective of whether there are income effects at the union level and whether labor markets are independent. Importantly, Proposition 2 also generalizes to a setting where profits cannot be fully taxed, as formally demonstrated in Appendix D. At first sight, this result appears counter-intuitive, because increasing union power may seem desirable if profits cannot be taxed directly. The reason why a restriction on profit taxes does not affect the desirability condition of unions is that the government can already achieve indirect redistribution from firms to workers via the tax-benefit system. As was demonstrated in Corollary 1, participation tax rates should be raised if profits cannot be fully taxed - ceteris paribus. Unions are not helpful to achieve more income redistribution over and above what can already be achieved via the tax-transfer system.

Finally, we can use our model to characterize optimal union power in each sector in the next Corollary. ${ }^{20}$

Corollary 2. Let $\hat{\rho}_{i}$ be the union power such that the social welfare weight of workers in sector $i$ equals one: $\hat{\rho}_{i} \equiv\left\{\rho_{i}: b_{i}=1\right\}$. If Assumption 2 (efficient rationing) is satisfied, and taxes and transfers are set according to Proposition 1, then the optimal degree of union power in sector $i$ equals $\rho_{i}^{*}=\min \left[\hat{\rho}_{i}, 1\right]$ if $b_{i} \geq 1$, and $\rho_{i}^{*}=\max \left[\hat{\rho}_{i}, 0\right]$ if $b_{i} \leq 1$.

According to Corollary 2, for workers whose social welfare weight exceeds one (i.e., $b_{i} \geq 1$ ), the power of the union representing these workers should optimally be increased until their social welfare weight equals one. However, if this is not feasible (which can happen if workers have low wages $w_{i}$ ), the next best thing to do is to make the labor union a monopoly union, i.e., to set $\rho_{i}^{*}=1$. For workers whose social welfare weight is smaller than one $\left(b_{i}<1\right)$, the government

\footnotetext{
${ }^{18}$ In most OECD countries, participation is taxed on a net basis (OECD, 2018b). Hence, if the tax-benefit system is optimally set, an increase in union power reduces social welfare. We get back to this point in Section 7 .

${ }^{19}$ Increasing the profit tax is only one way to finance the decrease in the participation tax rate for workers in sector $i$. As long as the marginal cost of public funds equals one, the argument carries over to other instruments as well.

${ }^{20}$ Of course, it is not obvious how government can set union power. In this context, Hungerbühler and Lehmann (2009, p.475) remark that: "Whether and how the government can affect the bargaining power is still an open question". They suggest that changing the way how unions are financed and regulated can affect their bargaining power.
} 
would like to lower the power of the union representing them. However, the government cannot decrease union power below the competitive level.

\section{Robustness analysis}

In this Section, we investigate the robustness of our results by relaxing the assumptions of independent labor markets (Assumption 1) and efficient rationing (Assumption 2). In addition, we analyze two alternative bargaining structures: one in which a single, national union bargains with firm-owners over the entire distribution of wages, and one in which sectoral unions bargain with firms over wages and employment as in the efficient bargaining model of McDonald and Solow (1981).

\subsection{Interdependent labor markets}

If Assumption 1 is violated, and labor markets are interdependent (such that $F_{i j}(\cdot) \neq 0$ for all $i \neq j$ ), taxes levied in one sector also affect wages and employment in other sectors. Proposition 3 generalizes Proposition 1 and characterizes optimal tax policy if labor markets are interdependent.

Proposition 3. If Assumptions 2 (efficient rationing) and 3 (no income effects at the union level) are satisfied, then optimal unemployment benefits $-T_{u}$, optimal profit taxes $T_{f}$, and optimal participation tax rates $t_{i}$ are determined by:

$$
\begin{gathered}
\sum_{i} \omega_{i} b_{i}+\omega_{u} b_{u}=1, \\
b_{f}=1, \\
\sum_{j} \omega_{j}\left(\frac{t_{j}+\tau_{j}}{1-t_{j}}\right) \eta_{j i}=\omega_{i}\left(1-b_{i}\right)+\sum_{j} \omega_{j}\left(b_{j}-1\right) \kappa_{j i},
\end{gathered}
$$

where the (cross) elasticities of employment and wages in sector $j$ with respect to participation tax rates in sector $i$ are defined as:

$$
\begin{aligned}
\eta_{j i} & \equiv-\frac{\partial E_{j}}{\partial t_{i}} \frac{1-t_{i}}{E_{j}} \frac{w_{j}\left(1-t_{j}\right)}{w_{i}\left(1-t_{i}\right)}, \\
\kappa_{j i} & \equiv \frac{\partial w_{j}}{\partial t_{i}} \frac{1-t_{i}}{w_{j}} \frac{w_{j}\left(1-t_{j}\right)}{w_{i}\left(1-t_{i}\right)} .
\end{aligned}
$$

Proof. See Appendix E.

Equations (19)-(20) are identical to those stated in Proposition 1, and their explanation is not repeated here. Optimal participation tax rates $t_{i}$ in equation (21) are modified compared to their counterparts in Proposition 1. The left-hand side gives the marginal costs in the form of larger labor-market distortions, whereas the right-hand side gives the marginal distributional benefits (or losses) of higher participation tax rates. In contrast to Proposition 1, both the labor-market distortions and the distributional benefits are now summed over all sectors due to the complementarities of labor in production. In particular, the overall distortion of the 
participation tax rate in sector $i$ is given by the sum over all sectors of the total tax wedge in sector $j$ multiplied by the weighted (cross) elasticity of employment in sector $j$ with respect to the participation tax rate in sector $i$. If the participation tax rate in sector $i$ is increased, then the union in sector $i$ raises its wage demand. Ceteris paribus, this leads to a decrease in employment in sector $i$. If labor types are complementary (i.e., $F_{i j}(\cdot)>0$ for $i \neq j$ ), then the decrease in employment in sector $i$ lowers marginal productivity and thus labor demand in all other sectors $j \neq i$. Consequently, both employment and wages in all other sectors are reduced. The reduction in employment is larger if the (weighted) cross elasticity $\eta_{j i}$ of employment in sector $j$ with respect to the participation tax rate in sector $i$ is larger. If the sum of the explicit and implicit tax on participation is positive (negative), i.e., $\frac{t_{j}+\tau_{j}}{1-t_{j}}>0(<0)$, a higher participation tax rate in sector $i$ exacerbates (alleviates) labor-market distortions in sector $j$.

The right-hand side of equation (21) gives the sum of the marginal distributional benefits over all sectors of a higher participation tax rate in sector $i$. An increase in the participation tax rate $t_{i}$ directly redistributes income from workers in sector $i$ to the government. The associated welfare effect is proportional to $1-b_{i}$. Furthermore, the increase in the participation tax rate in sector $i$ redistributes income from firm-owners (whose welfare weight is one) to workers in sector $i$ (whose welfare weight is $b_{i}$ ) via a change in the wage $w_{i}$. In addition, there are indirect redistributional consequences in all other sectors $j \neq i$, because wages in all other sectors are reduced if participation tax rates in sector $i$ are raised. If the social welfare weight of workers in sector $j$ is larger than one, i.e., $b_{j}>1$, the reduction in the wage in sector $j$ due to higher participation tax rates in sector $i$ is socially costly, because the social welfare weight of the firm-owners is lower. However, if the social welfare weight of workers in sector $j$ is smaller than one, i.e., $b_{j}<1$, the reduction in the wage in sector $j$ is welfare-enhancing. This indirect welfare effect is weighted by $\kappa_{j i}$, which measures the change in the wage in sector $j$ with respect to the participation tax rate in sector $i$. If labor markets are independent, $\eta_{j i}=\kappa_{j i}=0$ for all $j \neq i$, and Proposition 1 applies.

Turning to the question whether or not unions are desirable if labor markets are interdependent, we find that Proposition 2 generalizes completely (see Appendix E for the proof). As in the case with independent labor markets, an increase in union power $\rho_{i}$ raises social welfare if and only if the social welfare weight of the workers in sector $i$ exceeds one, i.e., $b_{i}>1$. While increasing union power in sector $i$ puts upward pressure on the wage in sector $i$, this effect can be perfectly offset by lowering the participation tax rate $t_{i}$ in sector $i$, such that no change in the wage and employment in sector $i$ results. Therefore, if neither the wage nor employment in sector $i$ is affected by the policy reform, then wages and employment in all other sectors $j$ do not change, even if labor markets are interconnected. Hence, the logic of our earlier policy experiment to explore the desirability of unions fully extends to the case with interdependent labor markets.

\subsection{Inefficient rationing}

We have deliberately biased our findings in favor of unions by assuming that unemployment rationing is efficient: the burden of involuntary unemployment is borne by the workers with the highest participation costs. However, there are neither theoretical nor empirical reasons to 
expect that labor rationing is always efficient, see Gerritsen (2017) and Gerritsen and Jacobs (2018). In this Section, we analyze how the optimal tax formulas should be modified, and under which conditions unions are desirable if the assumption of efficient rationing is relaxed. We maintain the assumptions of independent labor markets and no income effects at the union level.

We follow Gerritsen (2017) and Gerritsen and Jacobs (2018) by defining the rationing schedule as a function

$$
e_{i}\left(E_{i}, \varphi_{i}^{*}, \varphi\right), \quad e_{i E_{i}}(\cdot),-e_{i \varphi_{i}^{*}}(\cdot)>0,
$$

which specifies the probability $e_{i} \in[0,1]$ that workers with participation $\operatorname{costs} \varphi \in\left[\underline{\varphi}, \varphi_{i}^{*}\right]$, find employment in sector $i$ for given employment $E_{i}$ and participation threshold $\varphi_{i}^{*}$. The probability $e_{i}(\cdot)$ of finding a job in sector $i$ increases in employment $E_{i}$ and decreases if labor participation rises, i.e., if $\varphi_{i}^{*}$ is lower. ${ }^{21}$ For all values of employment $E_{i}$ and the participation cut-off $\varphi_{i}^{*}$, the following relationship must hold:

$$
\int_{\underline{\varphi}}^{\varphi_{i}^{*}} e_{i}\left(E_{i}, \varphi_{i}^{*}, \varphi\right) \mathrm{d} G(\varphi)=E_{i}
$$

Integrating over all employment probabilities of the workers in sector $i$ (who differ in terms of their participation costs) yields sectoral employment. The following Proposition characterizes the optimal tax formulas if labor rationing is inefficient.

Proposition 4. If Assumptions 1 (independent labor markets), 3 (no income effects at the union level) are satisfied, and labor rationing is described by the rationing schedule (24), then optimal unemployment benefits $-T_{u}$, optimal profit taxes $T_{f}$, and optimal participation tax rates $t_{i}$ are determined by:

$$
\begin{gathered}
\omega_{u} b_{u}+\sum_{i} \omega_{i} b_{i}=1, \\
b_{f}=1, \\
\left(\frac{t_{i}+\hat{\tau}_{i}}{1-t_{i}}\right) \eta_{i}-\left(\frac{\psi_{i}}{1-t_{i}}\right) \gamma_{i}=\left(1-b_{i}\right)+\left(b_{i}-1\right) \kappa_{i},
\end{gathered}
$$

where the union wedge is redefined as

$$
\hat{\tau}_{i} \equiv \int_{\underline{\varphi}}^{\varphi_{i}^{*}} e_{i E_{i}}\left(E_{i}, \varphi_{i}^{*}, \varphi\right)\left(\frac{u\left(w_{i}\left(1-t_{i}\right)-T_{u}-\varphi\right)-u\left(-T_{u}\right)}{\lambda w_{i}}\right) \mathrm{d} G(\varphi),
$$

and $\psi_{i}$ denotes the rationing wedge, which is defined as

$$
\psi_{i} \equiv \frac{e_{i}\left(E_{i}, \varphi_{i}^{*}, \varphi_{i}^{*}\right)}{E_{i} / G\left(\varphi_{i}^{*}\right)} \int_{\underline{\varphi}}^{\varphi_{i}^{*}} \frac{e_{i \varphi_{i}^{*}}\left(E_{i}, \varphi_{i}^{*}, \varphi\right)}{\int_{\underline{\varphi}}^{\varphi_{i}^{*}} e_{i \varphi_{i}^{*}}\left(E_{i}, \varphi_{i}^{*}, \varphi\right) \mathrm{d} G(\varphi)}\left(\frac{u\left(w_{i}\left(1-t_{i}\right)-T_{u}-\varphi\right)-u\left(-T_{u}\right)}{\lambda w_{i}}\right) \mathrm{d} G(\varphi) .
$$

Proof. See Appendix F.1.

\footnotetext{
${ }^{21}$ An example of a rationing schedule that satisfies these criteria is a uniform rationing scheme. All participating workers then face the same probability of finding a job, i.e., $e_{i}\left(E_{i}, \varphi_{i}^{*}, \varphi\right) \equiv E_{i} / G\left(\varphi_{i}^{*}\right)$ for all values of $\varphi \in\left[\underline{\varphi}, \varphi_{i}^{*}\right]$.
} 
The expressions for the optimal unemployment benefit and profit tax are again identical to those stated in Proposition 1 and their explanation is not repeated here. The expression for the optimal participation tax rate in equation (28) equates the marginal distortionary costs of a higher participation tax rate (left-hand side) to the marginal distributional gains of a higher participation tax rate (right-hand side). The expression for the optimal participation tax rate is modified in two ways compared to the one with efficient rationing in equation (15). First, with a general rationing scheme, the union wedge $\hat{\tau}_{i}$ no longer measures the monetized utility loss of a marginal worker losing her job, but the expected utility loss of all rationed workers, i.e., the workers who lose their job if the wage is marginally increased. Second, in addition to the union wedge $\hat{\tau}_{i}$, there is a distortion associated with the inefficiency of the rationing scheme, which is captured by the rationing wedge $\psi_{i}$.

To understand the rationing wedge $\psi_{i}$, consider a decrease in the participation tax rate $t_{i}$. Moreover, suppose the union refrains from lowering its wage demand, so that employment remains unaffected. More people want to participate if the participation tax rate is lowered. A fraction $e_{i}\left(E_{i}, \varphi_{i}^{*}, \varphi_{i}^{*}\right)$ of the workers who are at the participation margin (i.e., those who are indifferent between employment and unemployment) will succeed in finding a job. However, if employment remains constant, other workers become unemployed. Since these workers are not indifferent between work and unemployment, a welfare loss occurs. The latter is captured by the term $\psi_{i}$, which measures the marginal welfare costs associated with an inefficient allocation of jobs over those who are willing to work. These costs are weighted by the participation elasticity $\gamma_{i}$.

According to equation (28), the higher is $\psi_{i}$, i.e., the more inefficient is the rationing scheme, the higher should be the optimal participation tax rate. The intuition is similar to Gerritsen (2017): by setting a higher participation tax rate, the workers who care least about finding a job opt out of the labor market. This, in turn, increases the employment prospects of the workers who experience a larger surplus from working. Consequently, the government replaces involuntary unemployment by voluntary unemployment, which reduces the inefficiency of labor market rationing.

The next Corollary gives the condition under which an increase in union power raises social welfare if rationing is no longer efficient.

Corollary 3. If Assumptions 1 (independent labor markets), 3 (no income effects at the union level) are satisfied, labor rationing is described by rationing schedule (24), and taxes and transfers are set according to Proposition 4 , then an increase in union power $\rho_{i}$ in sector $i$ raises social welfare if and only if

$$
b_{i}>1+\left(\frac{\psi_{i}}{1-t_{i}}\right) \gamma_{i}
$$

Proof. See Appendix F.2.

To understand whether it is optimal to increase union power, we consider again a policy reform starting from a situation where taxes are optimally set. We marginally raise union power $\rho_{i}$ in sector $i$, while simultaneously reducing the participation tax rate $t_{i}$ in sector $i$ such that the wage $w_{i}$, and hence employment $E_{i}$, is kept constant. The reduction in the participation tax rate $t_{i}$ is financed by an increase in the profit tax $T_{f}$ to ensure that the government budget remains 
balanced. The reform transfers income from firm-owners to workers in sector $i$. As before, the associated welfare effect is proportional to $b_{i}-1$. By construction, there are no welfare effects associated with changes in equilibrium wages and employment. However, the increase in net earnings raises participation of workers in sector $i$. If some of the (previously voluntarily) unemployed workers find a job, a welfare loss occurs because - with constant employment some participants who experience a surplus from working will not be able to find a job. The more inefficient is the rationing scheme, or the higher is the participation elasticity (i.e., the higher $\psi_{i}$ or $\gamma_{i}$ ), the higher should be the welfare weight of workers $b_{i}$ for unions in sector $i$ to be desirable - ceteris paribus. The welfare costs of inefficient rationing could be so large that they completely off-set the potential welfare gains of unions. Consequently, if rationing is inefficient, increasing union power in a sector where $b_{i}>1$ does not unambiguously raise social welfare.

\subsection{Bargaining over the wage distribution}

In our baseline model, bargaining takes place at the sectoral level and wages vary only across (and not within) sectors. Each sectoral union faces a trade-off between employment and wages, but does not care about the overall distribution of wages. There is, however, ample empirical evidence that a higher degree of unionization is associated with lower wage inequality. ${ }^{22}$ How do our results for optimal taxes and the desirability of unions change if unions care about the entire distribution of wages?

To answer this question, we now analyze a single union which bargains with firm-owners over all wages. To maintain tractability, we assume efficient rationing and we assume away income effects at the union level. The union has a utilitarian objective: it maximizes the sum of all workers' expected utilities. As in the RtM-model, wages are determined through bargaining between the national union and firms, while firms (unilaterally) determine employment. Since the utility function $u(\cdot)$ is concave, the union has an incentive to compress the wage distribution. Doing so is only possible if labor markets are interdependent, since in that case marginal productivity (and hence, the wage) for any group of workers depends on employment in other sectors. If labor markets would be independent, a national union would simply set the same wages in each sector as a sectoral union would, and our previous results apply.

We explicitly solve the Nash-bargaining problem to characterize labor-market equilibrium, where the national union's bargaining power is denoted by $\beta \in[0,1]$. Since there is only one union, we can no longer use a sector-specific measure of union power $\rho_{i}$ to analyze the union's desirability. However, under Nash-bargaining, equilibrium wages and employment also depend on profit taxes, which is not the case if we use $\rho_{i}$ to parameterize union power. To maintain comparability with our previous findings, we therefore assume that firm-owners are risk neutral. This ensures that equilibrium wages and employment can be written only in terms of participation tax rates, like before. In Appendix G.1, we set up the bargaining problem, characterize labor-market equilibrium, and extensively discuss its properties. Here, we only highlight its most important features.

First, if the union has no bargaining power at all $(\beta=0)$, the labor-market equilibrium

\footnotetext{
${ }^{22}$ See, for instance, Freeman (1980, 1993), Lemieux (1993, 1998), Machin (1997), Card (2001), DiNardo and Lemieux (1997), Card et al. (2004), Visser and Checchi (2011), and Western and Rosenfeld (2011).
} 
coincides with the competitive outcome. Second, if union power $\beta$ is sufficiently high, there is at least one group of workers whose wage is raised above the market-clearing level. This follows from the assumptions that, first, the union has an incentive to compress the wage distribution and, second, labor rationing is efficient. Hence, starting from the competitive labor-market outcome, a marginal increase in the bargained wage in the sector with the lowest wage compresses the wage distribution, but entails negligible welfare losses due to involuntary unemployment. Third, it may not be in the union's best interest to raise all wages above the market-clearing level. This is because an increase in the wage for high-skilled workers depresses the wages for low-skilled workers. A national union may therefore refrain from demanding an above market-clearing wage for high-skilled workers. The next proposition shows how taxes should be optimized if there is a single union, which bargains with firm-owners over the entire distribution of wages.

Proposition 5. If Assumptions 2 (efficient rationing), and 3 (no income effects at the union level) are satisfied, labor markets are interdependent, and a single union bargains over all wages $w_{i}$ in all sectors $i$, then the expressions for the optimal unemployment benefits $-T_{u}$, optimal profit taxes $T_{f}$, and optimal participation tax rates $t_{i}$ are the same as in Proposition 3.

Proof. In the absence of income effects, the reduced-form wage and employment equations can be written as $w_{i}=w_{i}\left(t_{1}, \ldots, t_{I}\right)$ and $E_{i}=E_{i}\left(t_{1}, \ldots, t_{I}\right)$. Since the optimal tax formulas from Proposition 3 are derived for any relationship between tax instruments and labor-market outcomes, they remain the same.

The reason why Proposition 3 generalizes to a national union bargaining over the entire wage distribution is that the optimal tax rules are expressed in terms of sufficient statistics and equilibrium wages and employment only depend on participation tax rates in both cases. ${ }^{23}$

How is the desirability condition for unions modified if the union negotiates the wages for all workers? Once more, we can answer this question by analyzing the welfare effects of a (marginal) increase in union power $\beta$ combined with a tax reform that leaves wages and employment in all sectors unaffected. To analyze the impact of such a reform, we need to keep track of the sectors where the wage is set above the market-clearing level. Denote by $k(\beta) \equiv\left\{i: G\left(w_{i}\left(1-t_{i}\right)\right)>E_{i}\right\}$ the set of sectors where the wage is raised above the market-clearing level. This set $k(\cdot)$ depends - among other things - on the union power $\beta \in[0,1]$. If the union has no power $(\beta=0)$, no wage is raised above the market-clearing level, and consequently $k(\cdot)$ is empty. On the other hand, $k(\beta)$ contains at least one element if $\beta=1$, since a utilitarian monopoly union always has an incentive to increase the wage for the workers in the sector earning the lowest wage. We assume that the set of sectors where wages are above market-clearing levels $k(\beta)$ does not change in response to a marginal increase in union power. ${ }^{24}$

The rise in union power puts upward pressure on the wages of workers $i \in k(\beta)$ for whom the wage already exceeds the market-clearing level (the 'direct' effect). Through spillovers in production, the wages for workers in other sectors $j \notin k(\beta)$ will be affected as well (the 'indirect'

\footnotetext{
${ }^{23}$ The optimal tax levels are not necessarily the same because the elasticities and wedges generally differ between the different bargaining structures.

${ }^{24}$ Assuming $k(\beta)$ does not change following a marginal change in $\beta$ is without loss of generality, since there is a discrete number of sectors.
} 
effect). Now, consider a tax reform that leaves all wages and employment levels unaffected. Such a tax reform only requires an adjustment in the participation tax rates $t_{i}$ for those workers whose wage exceeds the market-clearing level, i.e., for sectors $i \in k(\beta)$. Intuitively, if the adjustment in the tax system offsets the 'direct' effects, there will also be no 'indirect' effects. As before, the marginal changes in the participation tax rates can be financed by a marginal increase in the profit tax such that the government budget remains balanced. The tax reform that leaves equilibrium wages and employment constant is characterized by the solution to the following system of equations:

$$
\forall i \in k(\beta): \quad \sum_{j \in k(\beta)} \frac{\partial w_{i}\left(t_{1}, \ldots, t_{I}, \beta\right)}{\partial t_{j}} \mathrm{~d} t_{j}^{*}+\frac{\partial w_{i}\left(t_{1}, \ldots, t_{I}, \beta\right)}{\partial \beta} \mathrm{d} \beta=0 .
$$

Here, the functions $w_{i}=w_{i}\left(t_{1}, \ldots, t_{I}, \beta\right)$ are the reduced-form equations that solve the bargaining problem (see Appendix G.1 for details). The next Proposition derives the desirability condition for the national union.

Proposition 6. If Assumptions 2 (efficient rationing), and 3 (no income effects at the union level) are satisfied, there is a national utilitarian union bargaining with firm-owners over all wages, and the tax-benefit system is optimized according to Proposition 3, then an increase in union power $\beta$ increases social welfare if and only if

$$
\sum_{i \in k(\beta)} \omega_{i}\left(b_{i}-1\right)\left(-\mathrm{d} t_{i}^{*}\right)>0
$$

where the changes in participation tax rates $\mathrm{d} t_{i}^{*}$ follow from equation (32) and $k(\beta) \equiv\{i$ : $\left.G\left(w_{i}\left(1-t_{i}\right)\right)>E_{i}\right\}$.

Proof. See Appendix G.3

Proposition 6 is an intuitive counterpart of Proposition 2: an increase in union power raises social welfare if and only if doing so allows the government to increase the incomes of workers whose social welfare weight (on average) exceeds one. By the same logic as before, the joint increase in union power and the tax reform leaves all labor-market outcomes unaffected, while raising the net incomes for the low-skilled. Therefore, increasing union power raises social welfare if and only if the weighted average welfare weight of workers whose wage is above the market-clearing level exceeds one. The weight depends on the share $\omega_{i}$ of workers in sector $i$ and on the change in the participation tax rate $-\mathrm{d} t_{i}^{*}$ in the policy reform.

Since desirability condition remains unaltered, the union's desire to compress the wage distribution does not provide an additional reason why a welfarist government would like to raise union power. As was the case with a restriction on profit taxes, the government can achieve the same wage compression as the labor union through the tax-transfer system, without creating involuntary unemployment. Hence, unions cannot redistribute income via wage compression any better than the government can. 


\subsection{Efficient bargaining}

Up to this point, we have assumed that bargaining takes place in a right-to-manage setting. This bargaining structure generally leads to outcomes that are not Pareto efficient, because firm-owners - who take wages as given - do not take into account the impact of their hiring decisions on the union's objective (McDonald and Solow, 1981). This inefficiency can be overcome if unions and firm-owners bargain over both wages and employment. This Section explores whether our results generalize to a setting with efficient bargaining (EB), as in McDonald and Solow (1981). We maintain the assumptions of independent labor markets, efficient rationing, and no income effects at the union level.

We would like to emphasize from the outset that we consider the EB-model less appealing for two main reasons. First, the assumption that firms and unions can write contracts on both wages and employment is problematic with national or sectoral unions, since individual firm-owners then need to commit to employment levels that are not profit-maximizing (Boeri and Van Ours, 2008). Oswald (1993) argues that firms unilaterally set employment, even if bargaining takes place at the firm level. Second, employment is higher in the EB-model compared to the competitive outcome, since part of firm profits are converted into jobs. This property of the EB-model is difficult to defend empirically. Therefore, we maintain the RtMmodel as our baseline.

The key feature of the EB-model is that any potential equilibrium $\left(w_{i}, E_{i}\right)$ in sector $i$ lies on the contract curve, which is the line where the union's indifference curve and the firm's iso-profit curve are tangent:

$$
\frac{u\left(w_{i}-T_{i}-\hat{\varphi}_{i}\right)-u\left(-T_{u}\right)}{E_{i} \overline{u^{\prime}\left(w_{i}-T_{i}-\varphi\right)}}=\frac{w_{i}-F_{i}(\cdot)}{E_{i}} .
$$

Intuitively, if the equilibrium wage and employment level are on the contract curve, then it is impossible to raise either union $i$ 's utility while keeping firm profits constant, or vice versa.

The contract curve defines a set of potential labor-market equilibria $\left(w_{i}, E_{i}\right)$ in sector $i$. Which contract is negotiated depends on the power of union $i$ relative to that of the firm. We model union $i$ 's power as its ability to bargain for a wage that exceeds the marginal product of labor. In particular, let $\sigma_{i}$ denote the power of union $i$. We select the equilibrium in labor market $i$ using the following rent-sharing rule:

$$
w_{i}=\left(1-\sigma_{i}\right) F_{i}(\cdot)+\sigma_{i} \phi_{i}\left(E_{i}\right),
$$

where $\phi_{i}\left(E_{i}\right) \equiv \frac{\Phi_{i}\left(N_{i} E_{i}\right)}{N_{i} E_{i}}$ is the average productivity of a worker in sector $i$ and $\Phi_{i}$ is the contribution of sector $i$ to total output:

$$
\Phi_{i}\left(N_{i} E_{i}\right) \equiv F\left(K, N_{1} E_{1}, \cdots, N_{i} E_{i}, \cdots, N_{I} E_{I}\right)-F\left(K, N_{1} E_{1}, \cdots, 0, \cdots, N_{I} E_{I}\right) .
$$

If unions have zero bargaining power, i.e., $\sigma_{i}=0$, the outcome in the EB-model coincides with the competitive equilibrium: $w_{i}=F_{i}(\cdot)$. Efficiency then requires $\hat{\varphi}_{i}=\left(1-t_{i}\right) w_{i}=\varphi_{i}^{*}$. If, on the other hand, union $i$ has full bargaining power, i.e., $\sigma_{i}=1$, it can offer a contract which leaves no surplus to firm-owners. In the latter case, the wage equals average labor productivity and the firm makes zero profits from hiring workers in sector $i$ : $w_{i} N_{i} E_{i}=\Phi_{i}(\cdot)$. We refer to 


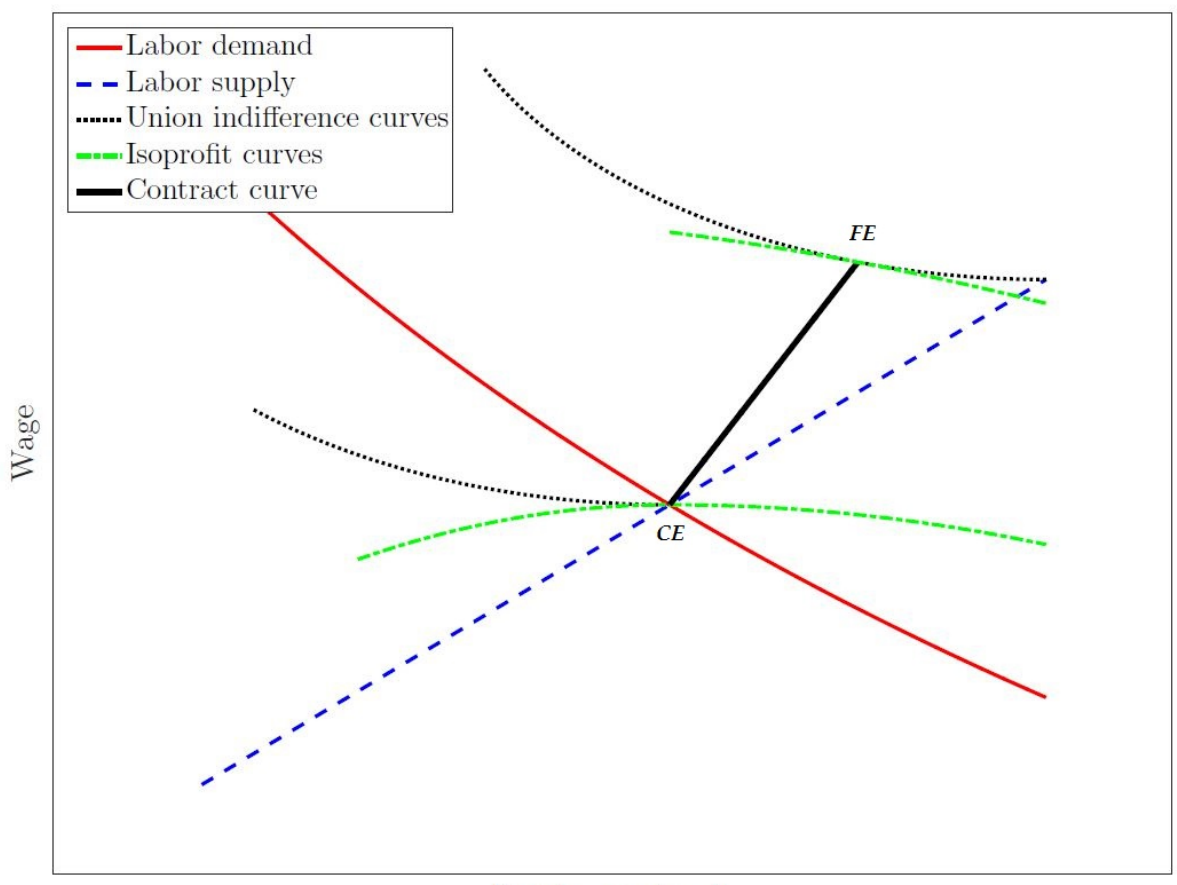

Employment rate

Figure 3: Labor market equilibria in the efficient bargaining model

this outcome as the full expropriation (FE) outcome.

The characterization of labor-market equilibrium is graphically illustrated in Figure 3. As in the RtM-model, the equilibrium coincides with the competitive outcome if the union has zero bargaining power. If union power increases, the equilibrium moves along the contract curve towards the FE-equilibrium, where the union has full bargaining power. Which equilibrium is selected depends on union power $\sigma_{i}$.

Figure 3 provides three important insights. First, as in the RtM-model, there is involuntary unemployment if union power $\sigma_{i}$ is positive. Without involuntary unemployment, unions are marginally indifferent to changes in employment, since labor rationing is efficient. Hence, unions are always willing to bargain for a slightly higher wage and accept some unemployment. Second, in contrast to the RtM-model, there is also a labor-demand distortion: the wage exceeds the marginal product of labor if $\sigma_{i}>0$, see equation (35). Consequently, the labor-market equilibrium is no longer on the labor-demand curve. Intuitively, if the wage equals the marginal product of labor, firms are indifferent to changes in employment, whereas unions are generally not. Hence, it is possible to negotiate a labor contract with a lower wage and higher employment, which benefits both parties. As a result, efficient bargaining results in implicit subsidies on labor demand. Third, and in stark contrast to the RtM-model, an increase in union power will not only result in a higher wage, but also in higher employment. As illustrated in Figure 3, the contract curve is upward sloping. The higher is union power, the larger is the share of the bargaining surplus that accrues to union members. Due to the concavity of the utility function $u(\cdot)$, this surplus is translated partly into higher wages, and partly into higher employment.

In the absence of income effects at the union level, and assuming independent labor markets, the contract curve (34) and the rent-sharing rule (35) jointly determine the equilibrium wage 
$w_{i}$ and employment $E_{i}$ in sector $i$ solely as a function of the participation tax rate $t_{i}$. If the participation tax rate increases, fewer workers want to participate. In terms of Figure 3, the labor-supply schedule shifts upward. As a result, the equilibrium wage (employment rate) will be higher (lower) following the increase in the participation tax rate. Therefore, the comparative statics are qualitatively the same as in the RtM-model. We replicate Lemma 1 for the EB-model in Appendix H.1. The following Proposition characterizes optimal taxes.

Proposition 7. If Assumptions 1 (independent labor markets), 2 (efficient rationing), and 3 (no income effects at the union level) are satisfied, and the efficient-bargaining equilibrium in labor market $i$ is determined by the contract curve (34) and the rent-sharing rule (35), then optimal unemployment benefits $-T_{u}$, profit taxes $T_{f}$, and participation tax rates $t_{i}$ are determined by:

$$
\begin{gathered}
\omega_{u} b_{u}+\sum_{i} \omega_{i} b_{i}=1, \\
b_{f}=1, \\
\left(\frac{t_{i}+\tau_{i}-m_{i}}{1-t_{i}}\right) \eta_{i}=\left(1-b_{i}\right)+\left(b_{i}-1\right) \kappa_{i},
\end{gathered}
$$

where $m_{i} \equiv \frac{w_{i}-F_{i}}{w_{i}}=\sigma_{i}\left(\frac{\phi_{i}-F_{i}}{w_{i}}\right)$ is the implicit subsidy on labor demand. The wage and employment elasticities with respect to the participation tax rate $t_{i}$ are given by:

$$
\begin{gathered}
\kappa_{i}=\frac{u_{u}^{\prime} w_{i}\left(1-t_{i}\right)\left(\frac{\left(1-m_{i}\right)\left(1-\sigma_{i}\right)}{\varepsilon_{i}}+m_{i}\right)}{\frac{\hat{u}_{i}^{\prime} E_{i}}{g\left(\hat{\varphi}_{i}\right)}+u_{u}^{\prime} w_{i}\left(1-t_{i}\right)\left(\frac{\left(1-m_{i}\right)\left(1-\sigma_{i}\right)}{\varepsilon_{i}}+m_{i}\right)+\left(\hat{u}_{i}-u_{u}\right)\left(\frac{\left(1-m_{i}\right)}{m_{i}} \frac{\left(1-\sigma_{i}\right)}{\varepsilon_{i}}-1+\frac{\left(\hat{u}_{i}^{\prime}-\overline{u_{i}^{\prime}}\right)}{\bar{u}_{i}^{\prime}}\right)}>0, \\
\eta_{i}=\frac{-u_{u}^{\prime} w_{i}\left(1-t_{i}\right)}{\frac{\hat{u}_{i}^{\prime} E_{i}}{g\left(\hat{\varphi}_{i}\right)}+u_{u}^{\prime} w_{i}\left(1-t_{i}\right)\left(\frac{\left(1-m_{i}\right)\left(1-\sigma_{i}\right)}{\varepsilon_{i}}+m_{i}\right)+\left(\hat{u}_{i}-u_{u}\right)\left(\frac{\left(1-m_{i}\right)}{m_{i}} \frac{\left(1-\sigma_{i}\right)}{\varepsilon_{i}}-1+\frac{\left(\hat{u}_{i}^{\prime}-\overline{u_{i}^{\prime}}\right)}{\overline{u_{i}^{\prime}}}\right)}>0 .
\end{gathered}
$$

Proof. See Appendix H.2.

The optimality conditions in the EB-model are very similar to their counterparts in the RtM-model, see Proposition 1. Except from differences in the definitions of the elasticities, the main difference is the implicit subsidy on labor demand $m_{i}$ in the expression for the optimal participation tax rate $t_{i}$ in equation (39). Since the equilibrium wage exceeds the marginal product of labor, a decrease in employment in sector $i$ positively affects the firm's profits, which the government can tax without generating distortions. The higher is the implicit subsidy on labor demand $m_{i}$, the higher should optimal participation tax rates be set - ceteris paribus.

The optimal participation tax rate $t_{i}$ aims to redistribute income and to counter the implicit taxes on labor participation $\tau_{i}$ and the implicit subsidies on labor demand $m_{i}$. The equilibrium is neither on the labor-supply nor on the labor-demand curve if the union has some bargaining power. On the one hand, employment is too low, because unions generate involuntary unemployment (as captured by the union wedge $\tau_{i}$ ), which calls for lower participation tax rates. On the other hand, employment is too high, because unions generate implicit subsidies on labor 
demand (as captured by $m_{i}$ ), which calls for higher participation tax rates. Hence, it is no longer unambiguously true that participation tax rates should optimally be lower in unionized labor markets. This result contrasts with our finding from the RtM-model.

How is the desirability condition for unions affected if we assume efficient bargaining? The next Proposition answers this question.

Proposition 8. If Assumption 2 (efficient rationing) is satisfied, the equilibrium in labor market $i$ is determined by the contract curve (34) and the rent-sharing rule (35), and taxes and transfers are set according to Proposition 7 , then increasing union power $\sigma_{i}$ in sector $i$ raises social welfare if and only if $b_{i}>1$.

Proof. See Appendix H.3.

According to Proposition 8, the condition under which an increase union power in sector $i$ is desirable is the same as in the RtM-model. Therefore, the question whether unions are desirable or not does not depend on the bargaining structure. This might seem surprising, given that - unlike in the RtM-model - employment increases in union power in the EB-model. However, also unemployment increases in union power, since the contract curve is steeper than the labor-supply curve. Intuitively, the union trades off employment and wages, which is not the case at the individual level. Only the effect on unemployment is critical to assess the desirability of unions. Stronger unions still generate more involuntary unemployment. Hence, an increase in union power is desirable only if there is too much employment as a result of net subsidies on participation. Therefore, the intuition for the desirability of unions in the RtMmodel carries over to the EB-model: unions are only useful only if net participation subsidies lead to overemployment.

\section{Numerical simulations}

We illustrate numerically how the presence of unions affects the optimal tax-benefit system and we explore the desirability of unions. To do so, we employ the sufficient-statistics approach developed by Kroft et al. (2017) and apply it to the Netherlands, where $84.8 \%$ of all employees in 2013 were covered by collective labor agreements (OECD, 2017). Our theoretical model captures important featurs of the bargaining process in the Netherlands. In particular, unions and representatives of firms bargain over wages (mainly) at the sectoral level and employment is unilaterally determined by firms. To calculate the optimal tax-benefit system, we need to specify the structure of the labor market and preferences for redistribution. Moreover, we require measures of the wage distribution, the current tax-benefit system and unemployment rates by earnings level, and the current tax-benefit system.

\subsection{Baseline calibration}

Our baseline is the RtM-model with independent labor markets, efficient rationing, and no income effects at the union level. In our simulations, we assume the labor-market equilibrium 
relationships are described by the following reduced-form equations:

$$
\begin{aligned}
& E_{i}=\xi_{i} w_{i}^{-\varepsilon_{i}}, \quad \xi_{i}, \varepsilon_{i}>0, \\
& E_{i}=\zeta_{i}\left(w_{i}\left(1-t_{i}\right)\right)^{\gamma_{i}^{e}}, \quad \zeta_{i}, \gamma_{i}^{e}>0 .
\end{aligned}
$$

Equation (42) gives the standard labor-demand schedule, where $\varepsilon_{i}$ denotes the labor-demand elasticity. Equation (43) is the 'effective' labor-supply schedule. The effective labor-supply schedule differs from the standard 'notional' labor-supply schedule due to the unemployment created by unions. The union mark-up equation (8) implicitly defines the effective labor-supply schedule for a given labor-demand elasticity $\varepsilon_{i}$, union power $\rho_{i}$, and participation tax rate $t_{i}$. $\gamma_{i}^{e}$ is the effective labor-supply elasticity, which in the absence of unions corresponds to the participation elasticity $\gamma_{i}$. Hence, in the absence of unions, effective and notional labor supply coincide.

Equilibrium employment and wages can be written as functions of the participation tax rates only, i.e., $E_{i}=E_{i}\left(t_{i}\right)$ and $w_{i}=w_{i}\left(t_{i}\right)$, with corresponding elasticities $\eta_{i}$ and $\kappa_{i}$. The latter are related to the effective supply and demand elasticities through $\eta_{i}=\frac{\gamma_{i}^{e} \varepsilon_{i}}{\gamma_{i}^{e}+\varepsilon_{i}}$ and $\kappa_{i}=\frac{\gamma_{i}^{e}}{\gamma_{i}^{e}+\varepsilon_{i}}$. We assume a labor-demand elasticity of $\varepsilon_{i}=0.3$, which is constant. This value is well within the range of common estimates, see, e.g., Lichter et al. (2015) for a recent overview. We proxy the effective labor-supply elasticity $\gamma_{i}^{e}$ by an estimate for the participation elasticity $\gamma_{i}$. In particular, we set $\gamma_{i}^{e}=0.16$ based on estimates for the Netherlands provided in Mastrogiacomo et al. (2013). We conduct sensitivity analyses for $\varepsilon_{i}=0.6$ and $\gamma_{i}^{e}=0.32$. We use three different degrees of union power: i) the competitive labor market $\left(\rho_{i}=0\right)$, ii) an intermediate degree of union power $\left(\rho_{i}=0.5\right)$, iii) monopoly unions $\left(\rho_{i}=1\right)$.

We assume a constant elasticity of inequality aversion $\nu \geq 0$ to write the social welfare weights as:

$$
b_{i} \equiv \frac{1}{\lambda\left(w_{i}\left(1-t_{i}\right)-T_{u}\right)^{\nu}}, \quad b_{u} \equiv \frac{1}{\lambda\left(-T_{u}\right)^{\nu}} .
$$

The government is non-redistributive if $\nu=0$ and Rawlsian if $\nu \rightarrow \infty$. Our baseline value is $\nu=1$. The social welfare weights only depend on consumption and do not account for participation costs, as in Saez (2002) and Kroft et al. (2017). The social welfare weights of the employed workers are therefore underestimated relative to the unemployed workers - ceteris paribus. In a robustness check, we analyze how our results are affected if the social welfare weight of the unemployed is scaled downwards.

Ideally, we like to use sectoral data on wage and unemployment rates to calibrate our model. However, this is empirically challenging, since we cannot observe sectoral unemployment rates. The latter requires assigning a specific sector to the unemployed workers. Therefore, we follow Kroft et al. (2017) and associate an earnings level with a particular level of education. This allows us to measure employment rates by earnings level. Data on wages, taxes, and unemployment rates for five education levels are obtained from CPB Netherlands Bureau for Economic Policy Analysis. ${ }^{25}$ The value of the uemployment benefit is set equal to 12,000 euros. ${ }^{26}$

\footnotetext{
${ }^{25} \mathrm{CPB}$ Netherlands Bureau for Economic Policy Analysis calculated the statistics reported in Table 1. These are based on the Labor Market Panel from Statistics Netherlands, which is a rich administrative household panel dataset covering the period 2006-2009. For more details, see Jongen et al. (2014).

${ }^{26}$ This corresponds to a monthly benefit of 1,000 euros, which lies between the social-assistance benefit for
} 
All simulation inputs are summarized in Table 1. Optimal participation tax rates and unemployment benefits are calculated by solving the optimal tax formulas in sufficient statistics, see Proposition 1. Since there is no clear-cut empirical counterpart of the pure profit tax $T_{f}$, we decided to ignore firm-owners in our simulations. This is without much loss of generality, since the revenue from the profit tax can be interpreted equivalently as a lower revenue requirement for the government. Hence, as the revenue requirement only affects the multiplier on the government budget constraint $\lambda$, the profit tax only implies a different cardinalization of the social preference for income redistribution. For further details on the simulations, see Appendix I.

Table 1: Labor-market statistics and tax-benefit system by education level

\begin{tabular}{lccccc}
\hline & $\begin{array}{c}(1) \\
\text { Primary } \\
\text { education }\end{array}$ & $\begin{array}{c}(2) \\
\text { Lower } \\
\text { secondary } \\
\text { education }\end{array}$ & $\begin{array}{c}(3) \\
\text { Upper } \\
\text { secondary } \\
\text { education }\end{array}$ & $\begin{array}{c}\text { Bachelor } \\
\text { degree }\end{array}$ & $\begin{array}{c}\text { Master } \\
\text { degree }\end{array}$ \\
Wage $\left(w_{i}\right.$, euro $)$ & 22,912 & 25,430 & 30,661 & 42,344 & 59,886 \\
Employment rate $\left(E_{i}\right)$ & 0.646 & 0.771 & 0.879 & 0.927 & 0.917 \\
Income tax $\left(T_{i}\right.$, euro $)$ & 5,471 & 6,771 & 9,120 & 14,587 & 22,423 \\
Unemployment benefit $\left(-T_{u}\right.$, euro) & 12,000 & 12,000 & 12,000 & 12,000 & 12,000 \\
Labor force shares $\left(N_{i} / \sum_{j} N_{j}\right)$ & 0.081 & 0.230 & 0.432 & 0.174 & 0.083 \\
\hline
\end{tabular}

Data are obtained from CPB Netherlands Bureau of Economic Policy Analysis and are calculated from the Labor Panel of Statistics Netherlands, see Jongen et al. (2014).

\subsection{Optimal taxes}

Figure 4 shows our most important finding: optimal participation tax rates are substantially lower in unionized labor markets. In the baseline simulation, optimal participation tax rates at the bottom of the income distribution vary from around 30\% without unions to approximately $-4 \%$ if there are monopoly unions. The reduction in participation tax rates is brought about mostly by a sharp reduction in the optimal unemployment benefit, which is lowered from around 11,800 euros if unions are absent (close to the current value of 12,000 euros) to less than 3,000 euros with monopoly unions. The reason why participation tax rates are lowered by such a large amount is that the union wedge $\tau_{i}$ is high if unions are more powerful and the labor-demand elasticity $\varepsilon_{i}$ is low, as in our simulations. Hence, the distortions generated by unions (in the form of higher unemployment) are large. The government then optimally lowers participation tax rates to moderate wage demands and to reduce involuntary unemployment.

Figure 5 plots the social welfare weights by income. The social welfare weight for the unemployed is much higher if unions are strong, since the optimal unemployment benefit is much lower. Moreover, all workers have a social welfare weight that is smaller than one. Hence, participation is never subsidized on a net basis, which implies that the explicit subsidy on participation is never larger than the implicit tax on participation created by unions. However, it is still possible that participation is subsidized. In particular, Figure 4 shows that subsidizing participation (i.e., setting a negative participation tax rate) for low-income workers is optimal

singles (approximately 600 euro), single parents (approximately 850 euro), and couples (approximately 1,200 euro) for the period 2006-2009 in the Netherlands. 


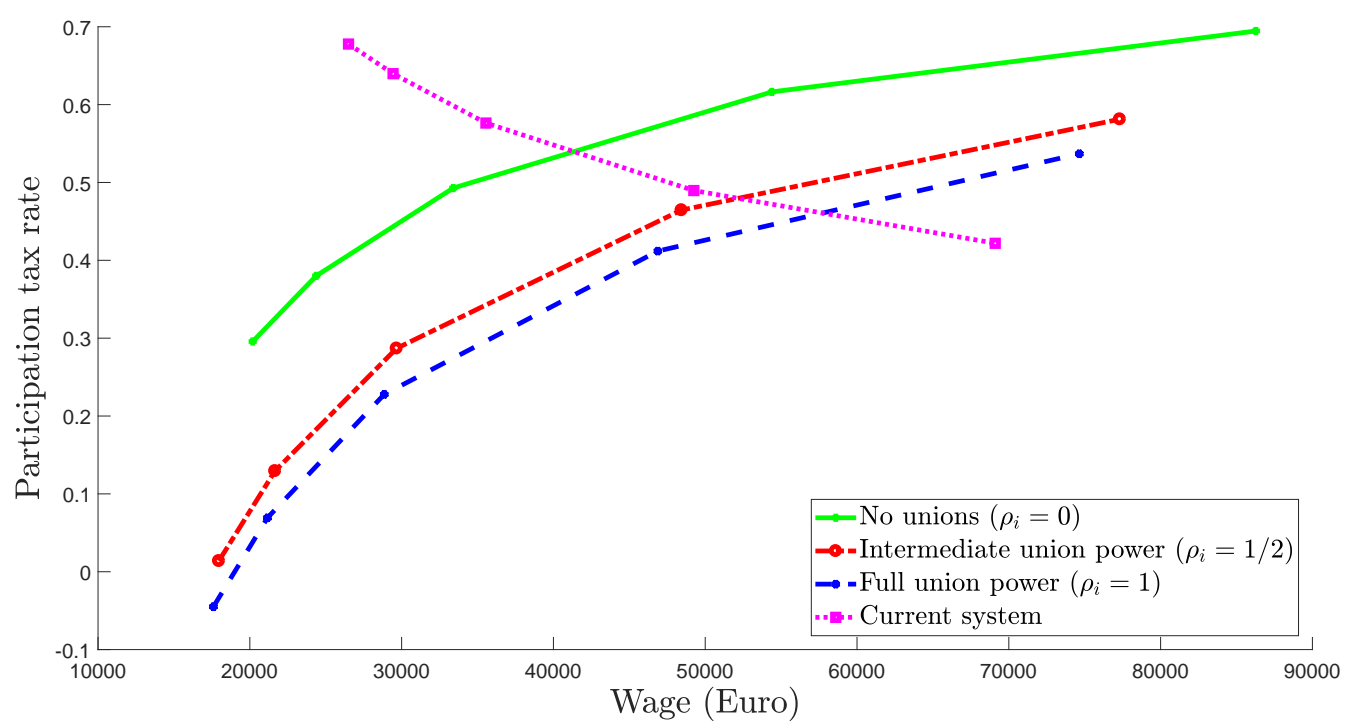

Figure 4: Optimal participation tax rates (baseline)

if union power is sufficiently close to one $\left(\rho_{i} \approx 1\right)$, i.e., if the union is close to a monopoly union. Hence, if the costs of unemployment are sufficiently high, then the government may subsidize participation even if the welfare weight of the working poor falls short of one (see Proposition 1). This can never occur if labor markets are competitive, as in Diamond (1980) and Saez (2002).

Furthermore, since the social welfare weights of all working individuals are below one, Proposition 2 immediately implies that an increase in union power in any sector reduces social welfare, irrespective of the degree of initial union power. Therefore, even starting from a competitive labor market, introducing a union for low-income workers is not socially desirable. However, this result should be interpreted with caution, since it heavily relies on the specification for the social welfare weights, as we show below.

\subsection{Sensitivity Analysis}

In this Section, we analyze how our numerical results are affected if some of the key underlying parameters or assumptions are changed. The corresponding figures can be found in Appendix I. First, we double the labor-demand elasticity from to $\varepsilon_{i}=0.3$ to to $\varepsilon_{i}=0.6$. There is no empirical consensus on the value of the labor-demand elasticity. Based on an extensive meta-regression analysis, Lichter et al. (2015) give a preferred estimate of around 0.25, close to our baseline value of 0.3. However, they argue that there is substantial heterogeneity in the reported estimates, with higher estimates for lower-income workers, and over longer time horizons. Figure 6 shows optimal participation tax rates if the labor demand elasticity is doubled. Optimal participation tax rates are still lower if unions have more power. However, the reduction is less pronounced than with relatively inelastic labor demand, because the union wedge decreases in the labordemand elasticity (see Proposition 1).

Turning to the participation elasticity, Figure 8 shows the optimal tax rates if the participation elasticity is doubled from a baseline value of $\gamma^{e}=0.16$ to a value of $\gamma^{e}=0.32$. As 


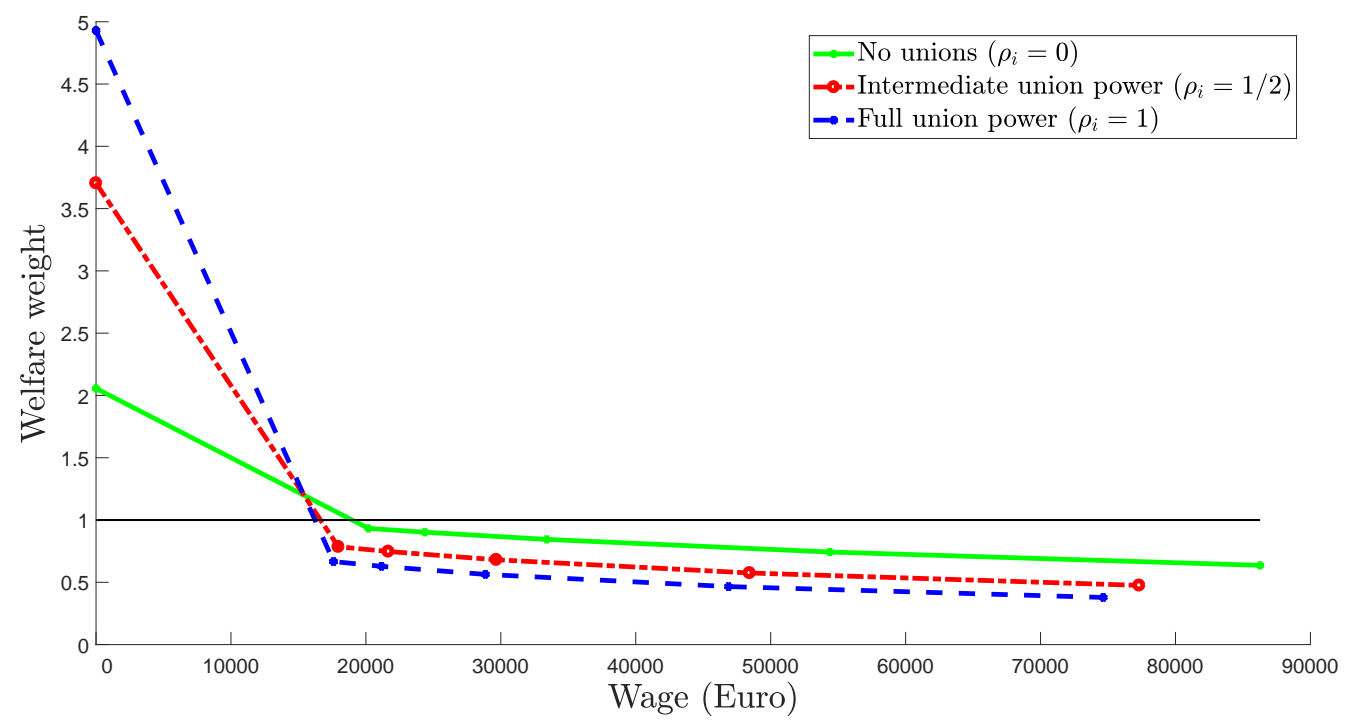

Figure 5: Social welfare weights (baseline)

expected, a higher participation elasticity reduces optimal participation tax rates, in line with the theoretical findings from Diamond (1980), see Figures 4 and 8. The reduction in optimal participation tax rates due to unions is of a similar magnitude as before. Intuitively, the union wedge only depends on the labor-demand elasticity and not on the participation elasticity.

Next, we consider a reduction in the social welfare weight of the unemployed relative to the employed workers. Our baseline specification of the social welfare weights ignores participation costs, which generates an upward bias in the social welfare weight of the unemployed. Furthermore, there might be other (non-welfarist) motives why the government attaches a higher social welfare weight to the working poor, for instance because the government considers the working poor more deserving than the non-working poor. Figure 10 shows the optimal participation tax rates if the social welfare weight of the unemployed is scaled down with a factor 2.25. Not surprisingly, optimal participation tax rates are lower compared to the baseline. The reduction in optimal participation tax rates is brought about mostly by a reduction in the unemployment benefit. Therefore, equilibrium social welfare weights of the unemployed do not change much, despite the downward scaling of their weight, see Figures 5 and 11. Furthermore, Figure 11 shows that the social welfare weight of the working poor is now raised to a level slightly above one if there are monopoly unions. Hence, the conclusions on the desirability of unions are sensitive to the choice of the social welfare function. If sufficient weight is attached to the working poor relative to the non-working poor, an increase in union power for the low-income workers can be welfare-improving.

Finally, we analyze the case with interdependent labor markets. This case is theoretically analyzed in Section 6.1. In the presence of general-equilibrium spill-over effects on wages, the equilibrium in sector $i$ depends on all tax instruments: $E_{i}=E_{i}\left(t_{1}, \cdots, t_{I}\right)$ and $w_{i}=$ $w_{i}\left(t_{1}, \cdots, t_{I}\right)$. To calculate optimal taxes with the sufficient-statistics approach, we require knowledge on all the behavioral elasticities (i.e., on all $\eta_{i j}$ 's and $\kappa_{i j}$ 's). However, as argued by Kroft et al. (2017), there is hardly any direct evidence on these cross-elasticities. Hence, we 
impose structure on the production technology, which implies how the own- and cross-elasticities are related. In particular, we assume the production function is Cobb-Douglas:

$$
F\left(K, L_{1}, \cdots, L_{I}\right)=A K^{1-\sum_{i} \alpha_{i}} \prod_{i} L_{i}^{\alpha_{i}}
$$

Labor demand in each sector $i$ is then given by:

$$
w_{i}=\alpha_{i} \frac{A K^{1-\sum_{j} \alpha_{j}} \prod_{j} L_{j}^{\alpha_{j}}}{L_{i}},
$$

which replaces the labor-demand equations (42) in our baseline simulation. The employment and wage elasticities with respect to the participation tax rates depend on the share parameters $\alpha_{i}$. To obtain an estimate for $\alpha_{i}$, we exploit the property that workers in sector $i$ receive a fraction $\alpha_{i} / \sum_{j} \alpha_{j}$ of the total wage bill, which can be calculated from Table 1. Combined with an estimate of the aggregate labor income share $\sum_{j} \alpha_{j}$, this allows us to pin down the $\alpha_{i}$ for each sector $i$. We set $\sum_{j} \alpha_{j}=0.75$, which is approximately an average of the aggregate labor share over the period 2006-2009 in the Netherlands. ${ }^{27}$

Figure 12 shows optimal participation tax rates in interdependent labor markets. The pattern of optimal participation tax rates is the same as before: they are increasing in income and lower if unions are stronger. The reduction of optimal participation tax rates in unionized labor markets is less pronounced than in the baseline, because the labor-demand elasticity is significantly higher. The own labor-demand elasticity equals $1 /\left(1-\alpha_{i}\right)$, which always exceeds one, cf. equation (46). ${ }^{28}$ If labor demand is more elastic, unions refrain from demanding high wages and the welfare costs of involuntary unemployment are lower. As a result, labor-market distortions are lower, and optimal participation tax rates are reduced less if the impact of unions is taken into account.

\section{Conclusions}

The aim of this paper has been to answer two questions concerning optimal income redistribution in unionized labor markets. Our first question was: 'How should the government optimize income redistribution if labor markets are unionized?' Our most important finding is that the optimal tax-benefit system is much less redistributive than in competitive labor markets. Intuitively, the tax system is not only used to redistribute income, but also to alleviate the distortions induced by unions. Lower income taxes and lower benefits motivate unions to moderate their wage demands, which results in less involuntary unemployment. We show that participation tax rates should be lower the larger are the welfare gains from lowering involuntary unemployment. Therefore, it may be optimal to subsidize participation even for workers whose social welfare weight falls short of one, which cannot happen if labor markets are competitive (see, e.g., Diamond, 1980, Saez, 2002, and Choné and Laroque, 2011). Our simulations suggest

\footnotetext{
${ }^{27}$ See estimates of the labor income share ('arbeidsinkomensquote') from Statistics Netherlands (Statistics Netherlands, 2017).

${ }^{28}$ The labor-demand elasticity lies between 1.03 and 1.44 in the simulations, with an unweighted average of 1.19 .
} 
that optimal participation tax rates are substantially lower if unions are more powerful. Hence, the optimal tax-benefit system may feature a strong EITC-component.

Our second question was: 'Can labor unions be socially desirable if the government wants to redistribute income?' We show that increasing the power of the unions representing workers whose social welfare weight exceeds one is welfare-enhancing, while the opposite holds true for workers whose social welfare weight is below one. Since Diamond (1980), it is well known that participation is optimally subsidized for workers with a social welfare weight larger than one, i.e., they receive an income transfer which exceeds the unemployment benefit. Consequently, participation for these workers is distorted upwards, which results in overemployment. By bidding up wages, unions create implicit taxes on employment, which reduce the upward distortions from participation subsidies. However, in the typical case that participation is taxed on a net basis, employment is distorted downwards, and increasing union power only exacerbates labormarket distortions. Whether unions are desirable thus depends critically on the preference for redistribution and, in particular, whether low-income workers are subsidized or taxed on a net basis.

We have made some assumptions that warrant further research. First, we assumed throughout that the government is the Stackelberg leader relative to firms and unions. However, unions may internalize some of the macro-economic and fiscal impacts of their decisions in wage negotiations, see also Calmfors and Driffill (1988). For future research, it would be interesting to generalize our model to a setting where unions and the government interact strategically. Second, we have abstracted from labor supply on the intensive margin and from a wage-moderating effect of tax progressivity. It would be interesting to extend the model to include an intensive margin and to analyze how our results are affected if the union's decisions would be influenced by marginal tax rates.

\section{References}

Aronsson, T. and T. Sjögren (2003). Income Taxation, Commodity Taxation and Provision of Public Goods under Labor Market Distortions. FinanzArchiv 59(3), 347-370.

Aronsson, T. and T. Sjögren (2004). Is the Optimal Labor Income Tax Progressive in a Unionized Economy? Scandinavian Journal of Economics 106(4), 661-675.

Aronsson, T. and M. Wikström (2011). Optimal Tax Progression: Does it Matter if Wage Bargaining is Centralized or Decentralized? mimeo, Umeå University.

Boeri, T. M. and J. C. Van Ours (2008). The Economics of Imperfect Labor Markets. Princeton: Princeton University Press.

Booth, A. L. (1995). The Economics of the Trade Union. Cambridge, UK: Cambridge University Press.

Bovenberg, A. L. (2006). Tax Policy and Labor Market Performance. In J. Agell and P. B. Sørensen (Eds.), Tax Policy and Labor Market Performance, Chapter 1, pp. 3-74. Cambridge, MA: MIT Press. 
Bovenberg, A. L. and F. van der Ploeg (1994). Effects of the Tax and Benefit System on Wage Formation and Unemployment. mimeo, Tilburg University and University of Amsterdam.

Calmfors, L. and J. Driffill (1988). Bargaining Structure, Corporatism and Macroeconomic Performance. Economic Policy 3(6), 13-61.

Card, D. E. (2001). The Effect of Unions on Wage Inequality in the U.S. Labor Market. Industrial and Labor Relations Review 54 (2), 296-315.

Card, D. E., T. Lemieux, and W. C. Riddell (2004). Unions and Wage Inequality. Journal of Labor Research 25(4), 519-559.

Choné, P. and G. Laroque (2011). Optimal Taxation in the Extensive Model. Journal of Economic Theory 146(2), $425-453$.

Christiansen, V. (2015). Optimal Participation Taxes. Economica 82(328), 595-612.

Christiansen, V. and R. Rees (2018). Optimal Taxation in a Unionised Economy. CESifo Working Paper No. 6954, Munich: CESifo.

Diamond, P. A. (1980). Income Taxation with Fixed Hours of Work. Journal of Public Economics 13(1), 101-110.

Diamond, P. A. and J. A. Mirrlees (1971a). Optimal Taxation and Public Production I: Production Efficiency. American Economic Review 61(1), 8-27.

Diamond, P. A. and J. A. Mirrlees (1971b). Optimal Taxation and Public Production II: Tax Rules. American Economic Review 61(3), 261-278.

DiNardo, J. E. and T. Lemieux (1997). Diverging Male Wage Inequality in the United States and Canada, 1981-1988: Do Institutions Explain the Difference? Industrial and Labor Relations Review 50(4), 629-651.

Dunlop, J. T. (1944). Wage Determination under Trade Unions. London: Macmillan.

Eissa, N. and J. B. Liebman (1996). Labor Supply Response to the Earned Income Tax Credit. Quarterly Journal of Economics 111(2), 605-637.

Freeman, R. B. (1980). Unionism and the Dispersion of Wages. Industrial and Labor Relations Review 34(1), 3-23.

Freeman, R. B. (1993). How Much has De-Unionisation Contributed to the Rise in Male Earnings Inequality? In S. Danziger and P. Gottschalk (Eds.), Uneven Tides: Rising Inequality in America, Chapter 4, pp. 133-164. New York: Russel Sage.

Fuest, C. and B. Huber (1997). Wage Bargaining, Labor-Tax Progression, and Welfare. Journal of Economics 66(2), 127-150.

Fuest, C. and B. Huber (2000). Is Tax Progression Really Good for Employment? A Model with Endogenous Hours of Work. Labour Economics 7(1), 79-93. 
Gerritsen, A. A. F. (2017). Equity and Efficiency in Rationed Labor Markets. Journal of Public Economics 153, 56-68.

Gerritsen, A. A. F. and B. Jacobs (2018). Is a Minimum Wage an Appropriate Instrument for Redistribution? mimeo, Erasmus University Rotterdam.

Heckman, J. J. (1993). What Has Been Learned About Labor Supply in the Past Twenty Years? American Economic Review 83(2), 116-121.

Hungerbühler, M. and E. Lehmann (2009). On the Optimality of a Minimum Wage: New Insights from Optimal Tax Theory. Journal of Public Economics 93(3), 464-481.

ICTWSS (2016). ICTWSS: Database on Institutional Characteristics of Trade Unions, Wage Setting, State Intervention and Social Pacts in 51 countries between 1960 and 2014. http: //www.uva-aias.net/en/ictwss.

Jacobs, B. (2018). The Marginal Cost of Public Funds is One at the Optimal Tax System. International Tax and Public Finance. Forthcoming.

Jacquet, L. M., E. Lehmann, and B. Van der Linden (2014). Optimal Income Taxation with Kalai Wage Bargaining and Endogenous Participation. Social Choice and Welfare 42(2), $381-402$.

Jongen, E. L. W., H. W. De Boer, and P. Dekker (2014). MICSIM-A Behavioural Microsimulation Model for the Analysis of Tax-benefit Reform in the Netherlands. CPB Background Document, The Hague: CPB Netherlands Bureau for Economic Policy Analysis.

Kessing, S. G. and K. A. Konrad (2006). Union Strategy and Optimal Direct Taxation. Journal of Public Economics 90(1), 393-402.

Koskela, E. and R. Schöb (2002). Optimal Factor Income Taxation in the Presence of Unemployment. Journal of Public Economic Theory 4 (3), 387-404.

Koskela, E. and R. Schöb (2012). Tax Progression under Collective Wage Bargaining and Individual Effort Determination. Industrial Relations 51(3), 749-771.

Koskela, E. and J. Vilmunen (1996). Tax Progression is Good for Employment in Popular Models of Trade Union Behaviour. Labour Economics 3(1), 65-80.

Kroft, K., K. J. Kucko, E. Lehmann, and J. F. Schmieder (2017). Optimal Income Taxation with Unemployment and Wage Responses: A Sufficient Statistics Approach. CEPR Discussion Paper No. 12328, London: CEPR.

Layard, P. R. G., S. J. Nickell, and R. Jackman (1991). Unemployment: Macroeconomic Performance and the Labour Market. Oxford: Oxford University Press.

Lee, D. S. and E. Saez (2012). Optimal Minimum Wage Policy in Competitive Labor Markets. Journal of Public Economics 96(9), 739-749. 
Lemieux, T. (1993). Unions and Wage Inequality in Canada and the United States. In D. E. Card and R. B. Freeman (Eds.), Small Differences that Matter: Labor Markets and Income Maintenance in Canada and the United States, Chapter 3, pp. 69-108. Chicago: University of Chicago Press.

Lemieux, T. (1998). Estimating the Effects of Unions on Wage Inequality in a Panel Data Model with Comparative Advantage and Nonrandom Selection. Journal of Labor Economics 16(2), 261-291.

Lichter, A., A. Peichl, and S. Siegloch (2015). The Own-Wage Elasticity of Labor Demand: A Meta-Regression Analysis. European Economic Review 80, 94-119.

Lockwood, B. and A. Manning (1993). Wage Setting and the Tax System: Theory and Evidence for the United Kingdom. Journal of Public Economics 52(1), 1-29.

Lockwood, B., T. Sløk, and T. Tranæs (2000). Progressive Taxation and Wage Setting: Some Evidence for Denmark. Scandinavian Journal of Economics 102(4), 707-723.

Machin, S. (1997). The Decline of Labour Market Institutions and the Rise in Wage Inequality in Britain. European Economic Review 41(3), 647-657.

Mastrogiacomo, M., N. M. Bosch, M. D. A. C. Gielen, and E. L. W. Jongen (2013). A Structural Analysis of Labour Supply Elasticities in the Netherlands. CPB Discussion Paper No. 235, The Hague: CPB Netherlands Bureau for Economic Policy Analysis.

McDonald, I. M. and R. M. Solow (1981). Wage Bargaining and Employment. American Economic Review 71(5), 896-908.

Meyer, B. D. (2002). Labor Supply at the Extensive and Intensive Margins: The EITC, Welfare, and Hours Worked. American Economic Review 92(2), 373-379.

Nickell, S. J. and M. J. Andrews (1983). Unions, Real Wages and Employment in Britain 1951-79. Oxford Economic Papers 35, 183-206.

OECD (2017). OECD Employment Outlook. Paris: OECD.

OECD (2018a). OECD Statistics. http://stats.oecd.org/Index.aspx?DataSetCode=POP_ FIVE_HIST.

OECD (2018b). Tax and Benefit Systems: OECD Indicators. http://www.oecd.org/els/ soc/benefits-and-wages.htm.

Oswald, A. J. (1993). Efficient Contracts are on the Labour Demand Curve: Theory and Facts. Labour Economics 1(1), 85-113.

Palokangas, T. K. (1987). Optimal Taxation and Employment Policy with a Centralized Wage Setting. Oxford Economic Papers 39(4), 799-812.

Saez, E. (2002). Optimal Income Transfer Programs: Intensive versus Extensive Labor Supply Responses. Quarterly Journal of Economics 117(3), 1039-1073. 
Saez, E. (2004). Direct or Indirect Tax Instruments for Redistribution: Short-Run versus LongRun. Journal of Public Economics 88(3), 503-518.

Sinko, P. (2004). Progressive Taxation under Centralised Wage Setting. VATT Discussion Papers No. 349, Helsinki: VATT.

Sørensen, P. B. (1999). Optimal Tax Progressivity in Imperfect Labour Markets. Labour Economics 6(3), 435-452.

Statistics Netherlands (2017). Herziening Methode Arbeidsinkomensquote. The Hague: Statistics Netherlands.

van der Ploeg, F. (2006). Do Social Policies Harm Employment and Growth? Second-best Effects of Taxes and Benefits on Employment. In J. Agell and P. B. Sørensen (Eds.), Tax Policy and Labor Market Performance, Chapter 3, pp. 97-144. Cambridge, MA: MIT Press.

Visser, J. and D. Checchi (2011). Inequality and the Labor Market: Unions. In B. Nolan, W. Salverda, and T. Smeeding (Eds.), The Oxford Handbook of Economic Inequality, Chapter 10, pp. 230-256. Oxford: Oxford University Press.

Western, B. P. and J. Rosenfeld (2011). Unions, Norms and the Rise in U.S. Wage Inequality. American Sociological Review 76(4), 513-537.

\section{A Derivation of $\rho_{i}$ from the right-to-manage model}

In this Appendix, we derive the relationship between our measure of union power $\rho_{i}$ and the bargaining power in the Nash product that is more commonly used to characterize equilibrium in the RtM-model (see, for instance, Boeri and Van Ours, 2008). In particular, the Nash bargaining problem is given by:

$$
\begin{aligned}
\max _{w_{i}, E_{i}} \Omega_{i} & =\beta_{i} \log \left(\int_{\underline{\varphi}}^{G^{-1}\left(E_{i}\right)}\left(u\left(w_{i}-T_{i}-\varphi\right)-u\left(-T_{u}\right)\right) \mathrm{d} G(\varphi)\right) \\
& +\left(1-\beta_{i}\right) \log \left(u\left(F(\cdot)-\sum_{i} w_{i} N_{i} E_{i}-T_{f}\right)-u\left(\left.F(\cdot)\right|_{E_{i}=0}-\sum_{j \neq i} w_{j} N_{j} E_{j}-T_{f}\right)\right) \\
\text { s.t. } & w_{i}=F_{i}(\cdot) \\
& \quad G\left(w_{i}-T_{i}+T_{u}\right)-E_{i} \geq 0
\end{aligned}
$$

where $\beta_{i} \in[0,1]$ is the weight attached to the union's payoff in the Nash product, and $\left.F(\cdot)\right|_{E_{i}=0}$ is the firm's output if it does not reach an agreement with the union in sector $i$, and, hence, none of the workers in sector $i$ find employment. The payoffs are taken in deviation from the payoff associated with the disagreement outcome. It is important to take the voluntary participation constraint in equation (47) explicitly into account, as it will bind for small values of $\beta_{i}$. If $\beta_{i}$ is close to zero, labor-market equilibrium is characterized by the final two conditions, which jointly define the competitive equilibrium. 
The Lagrangian reads as:

$$
\begin{aligned}
\mathcal{L} & =\beta_{i} \log \left(\int_{\underline{\varphi}}^{G^{-1}\left(E_{i}\right)}\left(u\left(w_{i}-T_{i}-\varphi\right)-u\left(-T_{u}\right)\right) \mathrm{d} G(\varphi)\right) \\
& +\left(1-\beta_{i}\right) \log \left(u\left(F(\cdot)-\sum_{i} w_{i} N_{i} E_{i}-T_{f}\right)-u\left(\left.F(\cdot)\right|_{E_{i}=0}-\sum_{j \neq i} w_{j} N_{j} E_{j}-T_{f}\right)\right) \\
& +\vartheta_{i}\left(w_{i}-F_{i}(\cdot)\right)+\mu_{i}\left(G\left(w_{i}-T_{i}+T_{u}\right)-E_{i}\right) .
\end{aligned}
$$

The first-order conditions are given by:

$$
\begin{aligned}
w_{i} & : \frac{\beta_{i}}{\left(\overline{u_{i}}-u_{u}\right)} \overline{u_{i}^{\prime}}-\frac{\left(1-\beta_{i}\right)}{\left(u_{f}-u_{f}^{-i}\right)} u_{f}^{\prime} N_{i} E_{i}+\vartheta_{i}+\mu_{i} G_{i}^{\prime}=0, \\
E_{i} & : \frac{\beta_{i}}{\left(\overline{u_{i}}-u_{u}\right)} E_{i}\left(\hat{u}_{i}-u_{u}\right)-\vartheta_{i} F_{i i}-\mu_{i}=0, \\
\vartheta_{i} & : w_{i}-F_{i}=0, \\
\mu_{i} & : \mu_{i}\left(G_{i}-E_{i}\right)=0,
\end{aligned}
$$

where the bars indicate averages over all employed workers in sector $i$, and $\hat{u}_{i}$ is the utility of the marginal worker in sector $i, u_{f}^{-i} \equiv u\left(\left.F(\cdot)\right|_{E_{i}=0}-\sum_{j \neq i} w_{j} N_{j} E_{j}-T_{f}\right)$ is the utility of firm-owners if they fail to reach an agreement with the union in sector $i$. If $\beta_{i}=1$, equations (49)-(50) imply that $\mu_{i}=0$, and we find the equilibrium of the monopoly-union model. For small values of $\beta_{i}$, the constraint $G_{i}=E_{i}$ becomes binding, and the labor-market equilibrium coincides with the competitive outcome. This can be verified by setting $\beta_{i}=0$. Equations (49)-(50) then imply that $\mu_{i}>0$. This is the case for all values of $\beta_{i} \in\left[0, \beta_{i}^{*}\right]$, where $\beta_{i}^{*} \in(0,1)$ solves:

$$
\frac{\beta_{i}^{*}}{1-\beta_{i}^{*}}=\frac{E_{i}\left(\overline{u_{i}}-u_{u}\right)}{\left(u_{f}-u_{f}^{-i}\right)} \frac{u_{f}^{\prime} N_{i}}{\overline{u_{i}^{\prime}}} .
$$

This equation is obtained by setting $G_{i}=E_{i}$ and $\mu_{i}=0$ in the system of first-order conditions in equations (49)-(52). The reason is that, at exactly this value of $\beta_{i}$, the constraint $G_{i}=E_{i}$ becomes binding. For values of $\beta_{i} \in\left[\beta_{i}^{*}, 1\right]$, we thus have $\mu_{i}=0$. Combining equations (49)-(50) then leads to:

$$
1-\left(\frac{1-\beta_{i}}{\beta_{i}}\right) \frac{E_{i}\left(\overline{u_{i}}-u_{u}\right)}{\left(u_{f}-u_{f}^{-i}\right)} \frac{u_{f}^{\prime} N_{i}}{\overline{u_{i}^{\prime}}}=\varepsilon_{i} \frac{\left(\hat{u}_{i}-u_{u}\right)}{\overline{u_{i}^{\prime}} w_{i}} .
$$

Defining the left-hand side of this equation as:

$$
\rho_{i} \equiv 1-\left(\frac{1-\beta_{i}}{\beta_{i}}\right) \frac{E_{i}\left(\overline{u_{i}}-u_{u}\right)}{\left(u_{f}-u_{f}^{-i}\right)} \frac{u_{f}^{\prime} N_{i}}{\overline{u_{i}^{\prime}}},
$$

we arrive at our equilibrium condition in the RtM-model, as given by equation (8). Clearly, if $\beta_{i}=1$, we have $\rho_{i}=1$, so that the MU-model applies. If $\beta_{i}=\beta_{i}^{*}$, from equation (53) it follows that $\rho_{i}=0$, and the equilibrium coincides with the competitive outcome. Hence, there exists a direct relationship between our measure of union power $\rho_{i}$ and the Nash-bargaining parameter 
$\beta_{i}$ :

$$
\rho_{i}= \begin{cases}0 & \text { if } \quad \beta_{i} \in\left[0, \beta_{i}^{*}\right), \\ 1-\frac{\left(1-\beta_{i}\right)}{\beta_{i}} \frac{E_{i}\left(\overline{u_{i}}-u_{u}\right)}{\left(u_{f}-u_{f}^{-i}\right)} \frac{u_{f}^{\prime} N_{i}}{\overline{u_{i}^{\prime}}} & \text { if } \quad \beta_{i} \in\left[\beta_{i}^{*}, 1\right] .\end{cases}
$$

\section{B Derivation elasticities}

This appendix derives the elasticities of wages and employment rates with respect to the tax instruments. If Assumption 1 is satisfied, and income effects at the union level are absent, we have $\partial E_{i} / \partial T_{i}=-\partial E_{i} / \partial T_{u}$ and $\partial w_{i} / \partial T_{i}=-\partial w_{i} / \partial T_{u}$. The equilibrium wage and employment rate in sector $i$ can then be written solely as a function of the participation tax rate $t_{i} \equiv$ $\left(T_{i}-T_{u}\right) / w_{i}$. Hence, we can write $E_{i}=E_{i}\left(t_{i}\right)$ and $w_{i}=w_{i}\left(t_{i}\right)$. The elasticities can then be derived using the labor-market equilibrium conditions:

$$
\begin{gathered}
w_{i}=F_{i}\left(E_{i}\right) \\
\rho_{i} \overline{u^{\prime}\left(w_{i}\left(1-t_{i}\right)-T_{u}-\varphi\right)} w_{i}=\varepsilon_{i}\left(E_{i}\right)\left(u\left(w_{i}\left(1-t_{i}\right)-T_{u}-G^{-1}\left(E_{i}\right)\right)-u\left(-T_{u}\right)\right),
\end{gathered}
$$

where

$$
\overline{u^{\prime}\left(w_{i}\left(1-t_{i}\right)-T_{u}-\varphi\right)}=E_{i}^{-1} \int_{\underline{\varphi}}^{G^{-1}\left(E_{i}\right)} u\left(w_{i}\left(1-t_{i}\right)-T_{u}-\varphi\right) \mathrm{d} G(\varphi),
$$

denotes the average marginal utility of the employed workers.

Without income effects, $T_{u}$ affects $E_{i}$ and $w_{i}$ only through its impact on $t_{i}$. Formally, this implies that the derivative of equation (58) with respect $T_{u}$, while keeping $t_{i}$ constant, is zero:

$$
-\rho_{i} \overline{u^{\prime \prime}\left(w_{i}\left(1-t_{i}\right)-T_{u}-\varphi\right)} w_{i}=-\varepsilon_{i}\left(E_{i}\right)\left(u^{\prime}\left(w_{i}\left(1-t_{i}\right)-T_{u}-G^{-1}\left(E_{i}\right)\right)-u^{\prime}\left(-T_{u}\right)\right) .
$$

See also the derivation for the case with income effects in Appendix C.3.

To obtain an expression for the elasticities, we log-linearize the labor-market equilibrium conditions around an initial equilibrium:

$$
\begin{aligned}
\frac{\mathrm{d} E_{i}}{E_{i}} & =-\varepsilon_{i} \frac{\mathrm{d} w_{i}}{w_{i}}, \\
\frac{\mathrm{d} \overline{u_{i}^{\prime}}}{\overline{u_{i}^{\prime}}}+\frac{\mathrm{d} w_{i}}{w_{i}} & =\frac{\mathrm{d} \varepsilon_{i}}{\varepsilon_{i}}+\frac{\mathrm{d}\left(\hat{u}_{i}-u_{u}\right)}{\hat{u}_{i}-u_{u}} .
\end{aligned}
$$

Using equation (60), we can linearize the parts of the last equation:

$$
\begin{aligned}
\frac{\mathrm{d} \overline{u_{i}^{\prime}}}{\overline{u_{i}^{\prime}}} & =\frac{\overline{u_{i}^{\prime \prime}} w_{i}\left(1-t_{i}\right)}{\overline{u_{i}^{\prime}}}\left(\frac{\mathrm{d} w_{i}}{w_{i}}-\frac{\mathrm{d} t_{i}}{1-t_{i}}\right)+\frac{\left(\hat{u}_{i}^{\prime}-\overline{u_{i}^{\prime}}\right)}{\overline{u_{i}^{\prime}}} \frac{\mathrm{d} E_{i}}{E_{i}}, \\
\frac{\mathrm{d} \varepsilon_{i}}{\varepsilon_{i}} & =\varepsilon_{\varepsilon_{i}} \frac{\mathrm{d} E_{i}}{E_{i}}, \\
\frac{\mathrm{d}\left(\hat{u}_{i}-u_{u}\right)}{\hat{u}_{i}-u_{u}} & =\frac{\hat{u}_{i}^{\prime} w_{i}\left(1-t_{i}\right)}{\hat{u}_{i}-u_{u}}\left(\frac{\mathrm{d} w_{i}}{w_{i}}-\frac{\mathrm{d} t_{i}}{1-t_{i}}\right)-\frac{\hat{u}_{i}^{\prime} E_{i}}{g\left(\hat{\varphi}_{i}\right)\left(\hat{u}_{i}-u_{u}\right)} \frac{\mathrm{d} E_{i}}{E_{i}},
\end{aligned}
$$


where $\varepsilon_{\varepsilon_{i}}$ is the elasticity of the labor-demand elasticity with respect to the rate of employment:

$$
\varepsilon_{\varepsilon_{i}} \equiv \frac{\partial \varepsilon_{i}}{\partial E_{i}} \frac{E_{i}}{\varepsilon_{i}}=-\left(1+\frac{1}{\varepsilon_{i}}+\frac{E_{i} F_{i i i}}{F_{i i}}\right)
$$

We find the relative changes in wages and employment in sector $i$ as functions of the changes in the participation tax rates by solving equations (61) and (62) and substituting equations (63)-(65):

$$
\begin{aligned}
\frac{\mathrm{d} w_{i}}{w_{i}} & =\frac{u_{u}^{\prime} w_{i}\left(1-t_{i}\right)}{\hat{u}_{i}^{\prime} \varepsilon_{i} E_{i} / g\left(\hat{\varphi}_{i}\right)+u_{u}^{\prime} w_{i}\left(1-t_{i}\right)-\left(\hat{u}_{i}-u_{u}\right)\left(1+\varepsilon_{i} \varepsilon_{\varepsilon_{i}}+\varepsilon_{i} \frac{\left(\overline{u_{i}^{\prime}}-\hat{u}_{i}^{\prime}\right)}{\overline{u_{i}^{\prime}}}\right)} \frac{\mathrm{d} t_{i}}{1-t_{i}}, \\
\frac{\mathrm{d} E_{i}}{E_{i}} & =-\frac{\varepsilon_{i} u_{u}^{\prime} w_{i}\left(1-t_{i}\right)}{\hat{u}_{i}^{\prime} \varepsilon_{i} E_{i} / g\left(\hat{\varphi}_{i}\right)+u_{u}^{\prime} w_{i}\left(1-t_{i}\right)-\left(\hat{u}_{i}-u_{u}\right)\left(1+\varepsilon_{i} \varepsilon_{\varepsilon_{i}}+\varepsilon_{i} \frac{\left(\overline{u_{i}^{\prime}}-\hat{u}_{i}^{\prime}\right)}{\overline{u_{i}^{\prime}}}\right)} \frac{\mathrm{d} t_{i}}{1-t_{i}} .
\end{aligned}
$$

\section{Optimal taxation}

\section{C.1 Full optimum}

The Lagrangian associated with the government's optimization problem can be written as:

$$
\begin{aligned}
\mathcal{L} & =\sum_{i} N_{i}\left(\int_{\underline{\varphi}}^{G^{-1}\left(E_{i}\right)} u\left(w_{i}\left(1-t_{i}\right)-T_{u}-\varphi\right) \mathrm{d} G(\varphi)+\int_{G^{-1}\left(E_{i}\right)}^{\bar{\varphi}} u\left(-T_{u}\right) \mathrm{d} G(\varphi)\right) \\
& +u\left(F\left(K, E_{1} N_{1}, \cdots, E_{I} N_{I}\right)-\sum_{i} w_{i} N_{i} E_{i}-T_{f}\right)+\lambda\left(\sum_{i} N_{i}\left(T_{u}+E_{i} t_{i} w_{i}\right)+T_{f}-R\right) .
\end{aligned}
$$

When differentiating with respect to the policy instruments, we have to take into account the dependency of $w_{i}$ and $E_{i}$ on $t_{i}$. The first-order conditions are given by:

$$
\begin{aligned}
T_{u}: & -\sum_{i} N_{i} E_{i} \overline{u_{i}^{\prime}}-\sum_{i} N_{i}\left(1-E_{i}\right) u_{u}^{\prime}+\lambda \sum_{i} N_{i}=0, \\
T_{f}: & -u_{f}^{\prime}+\lambda=0 \\
t_{i}: & -N_{i} E_{i} w_{i}\left(\overline{u_{i}^{\prime}}-\lambda\right)+\frac{\partial E_{i}}{\partial t_{i}}\left(N_{i}\left(\hat{u}_{i}-u_{u}\right)+\lambda N_{i} t_{i} w_{i}\right) \\
& +\frac{\partial w_{i}}{\partial t_{i}}\left(N_{i} E_{i} \overline{u_{i}^{\prime}}\left(1-t_{i}\right)-N_{i} E_{i} u_{f}^{\prime}+\lambda N_{i} E_{i} t_{i}\right)=0,
\end{aligned}
$$

where it should be noted that $\frac{\partial G^{-1}\left(E_{i}\right)}{\partial E_{i}} g\left(\hat{\varphi}_{i}\right)=1$, since $\frac{\partial G^{-1}\left(E_{i}\right)}{\partial E_{i}}=\frac{\partial \hat{\varphi}_{i}}{\partial E_{i}}=\frac{1}{g\left(\hat{\varphi}_{i}\right)}$. To obtain the first result of Proposition 1, divide equation (70) by $\lambda \sum_{i} N_{i}$ and use the definitions $b_{i} \equiv \overline{u^{\prime}\left(c_{i}\right)} / \lambda$, $b_{u} \equiv u^{\prime}\left(c_{u}\right) / \lambda, \omega_{i} \equiv N_{i} E_{i} / \sum_{j} N_{j}$ and $\omega_{u} \equiv \sum_{i} N_{i}\left(1-E_{i}\right) / \sum_{j} N_{j}$. The second result can be found by dividing equation (71) by $\lambda$ and using $b_{f} \equiv u^{\prime}\left(c_{f}\right) / \lambda$. The final result can be found as follows. First, substitute $u_{f}^{\prime}=\lambda$ in equation (72) and divide by $\lambda N_{i} w_{i}$. Next, use the definition $b_{i} \equiv \overline{u^{\prime}\left(c_{i}\right)} / \lambda$, the union wedge $\tau_{i} \equiv \frac{u\left(\hat{c}_{i}\right)-u\left(c_{u}\right)}{\lambda w_{i}}$, as well as the wage elasticity $\kappa_{i}$ and the employment elasticity $\eta_{i}$ from equations (11)-(12), and rearrange. 


\section{C.2 Restricted profit taxation}

To derive the optimal participation tax rate in the presence of a restriction on profit taxation (i.e., if $b_{f}<1$ ), divide equation $(72)$ by $\lambda N_{i} w_{i}$ and use the definitions of the welfare weights $b_{i} \equiv \overline{u^{\prime}\left(c_{i}\right)} / \lambda$ and $b_{f} \equiv u^{\prime}\left(c_{f}\right) / \lambda$, the union wedge $\tau_{i} \equiv \frac{u\left(\hat{c}_{i}\right)-u\left(c_{u}\right)}{\lambda w_{i}}$, as well as the wage elasticity $\kappa_{i}$ and the employment elasticity $\eta_{i}$ from equations (11)-(12):

$$
\left(\frac{t_{i}+\tau_{i}}{1-t_{i}}\right) \eta_{i}=\left(1-b_{i}\right)+\left(\frac{b_{i}-b_{f}+\left(1-b_{i}\right) t_{i}}{1-t_{i}}\right) \kappa_{i}
$$

If profit taxation is unrestricted, i.e., $b_{f}=1$, the result from Proposition 1 applies.

\section{C.3 Income effects}

If there are income effects, changes in the unemployment benefit $-T_{u}$ affect equilibrium employment $E_{i}$ and wages $w_{i}$ not only through their impact on participation tax rates $t_{i}$, but also via income effects at the union level. Therefore, we write $E_{i}=E_{i}\left(t_{i}, T_{u}\right)$ and $w_{i}=w_{i}\left(t_{i}, T_{u}\right)$. In this case, only the expression for the optimal unemployment benefit has to be modified. The first-order condition - the counterpart of equation (70) - reads as:

$$
\begin{aligned}
T_{u}: & -\sum_{i} N_{i} E_{i} \overline{u_{i}^{\prime}}-\sum_{i} N_{i}\left(1-E_{i}\right) u_{u}^{\prime}+\lambda \sum_{i} N_{i} \\
& +\sum_{i}\left(N_{i}\left(\hat{u}_{i}-u_{u}\right)+\lambda N_{i} t_{i} w_{i}\right) \frac{\partial E_{i}}{\partial T_{u}} \\
& +\sum_{i}\left(N_{i} E_{i} \overline{u_{i}^{\prime}}\left(1-t_{i}\right)-N_{i} E_{i} u_{f}^{\prime}+\lambda N_{i} E_{i} t_{i}\right) \frac{\partial w_{i}}{\partial T_{u}}=0 .
\end{aligned}
$$

To simplify this expression, divide by $\lambda \sum_{i} N_{i}$, and impose $b_{f}=1$. Furthermore, note that in equilibrium employment is on the labor-demand curve. Therefore, we can use the property

$$
\frac{\partial E_{i}}{\partial x_{i}}=\frac{\partial E_{i}}{\partial w_{i}} \frac{\partial w_{i}}{\partial x_{i}}
$$

for $x_{i} \in\left\{T_{u}, t_{i}\right\}$. Here, $\partial E_{i} / \partial w_{i}=1 / F_{i i}(\cdot)$ is the slope of the labor-demand curve. Then, combine equations (72), (74) and (75) to obtain:

$$
\sum_{i} \omega_{i} b_{i}+\omega_{u} b_{u}=1-\sum_{i} \omega_{i}\left(1-b_{i}\right) \iota_{i}
$$

where $\iota_{i} \equiv w_{i} \frac{\partial E_{i}}{\partial T_{u}} / \frac{\partial E_{i}}{\partial t_{i}}$. This expression generalizes equation (13) to the case with income effects. To obtain an expression for $\iota_{i}$, combine the union mark-up in equation (8), and the labor-demand equation (4) to find:

$$
\begin{aligned}
& \rho_{i} \int_{\underline{\varphi}}^{G^{-1}\left(E_{i}\right)} u^{\prime}\left(F_{i}(\cdot)\left(1-t_{i}\right)-T_{u}-\varphi\right) \mathrm{d} G(\varphi) F_{i i}(\cdot) \\
& +u\left(F_{i}(\cdot)\left(1-t_{i}\right)-T_{u}-G^{-1}\left(E_{i}\right)\right)-u\left(-T_{u}\right)=0 .
\end{aligned}
$$


We can then use implicit differentiation of equation (77) to obtain an expression for $\iota_{i}$ :

$$
\iota_{i}=1-\frac{u_{u}^{\prime}}{\hat{u}_{i}^{\prime}-\left(\hat{u}_{i}-u_{u}\right) \frac{\overline{u_{i}^{\prime \prime}}}{\overline{u_{i}^{\prime}}} .}
$$

Equation (76) is the analogue of the first result stated in Proposition 1. If income effects are absent, we have $\iota_{i}=0$, and equation (60) results. This is the case if the utility function $u(\cdot)$ is of the CARA-type, i.e., $u(c) \equiv-\frac{1}{\beta} \exp [-\beta c]$.

\section{Desirability of unions}

In this Appendix, we explicitly take the labor-market equilibrium conditions into account as constraints in the government's optimization problem, rather than deriving our results in terms of sufficient statistics. The reason for doing so is that this approach allows us to directly derive the welfare effect of an increase in union power. The maximization problem for the government then reads as:

$$
\begin{aligned}
\max _{T_{u}, T_{f},\left\{t_{i}, w_{i}, E_{i}\right\}_{i=1}^{I}} \mathcal{W}= & \sum_{i} N_{i}\left(\int_{\underline{\varphi}}^{G^{-1}\left(E_{i}\right)} u\left(w_{i}\left(1-t_{i}\right)-T_{u}-\varphi\right) \mathrm{d} G(\varphi)+\int_{G^{-1}\left(E_{i}\right)}^{\bar{\varphi}} u\left(-T_{u}\right) \mathrm{d} G(\varphi)\right) \\
& +u\left(F\left(K, E_{1} N_{1}, \cdots, E_{I} N_{I}\right)-\sum_{i} w_{i} N_{i} E_{i}-T_{f}\right), \\
\text { s.t. } & \sum_{i} N_{i}\left(T_{u}+E_{i} t_{i} w_{i}\right)+T_{f}=R, \\
& w_{i}=F_{i}\left(K, E_{1} N_{1}, \cdots, E_{I} N_{I}\right), \quad \forall i, \\
& \rho_{i} \int_{\underline{\varphi}}^{G^{-1}\left(E_{i}\right)} u^{\prime}\left(w_{i}\left(1-t_{i}\right)-T_{u}-\varphi\right) \mathrm{d} G(\varphi) F_{i i}(\cdot) \\
& +u\left(w_{i}\left(1-t_{i}\right)-T_{u}-G^{-1}\left(E_{i}\right)\right)-u\left(-T_{u}\right)=0, \quad \forall i .
\end{aligned}
$$

The corresponding Lagrangian is given by:

$$
\begin{aligned}
\mathcal{L}= & \sum_{i} N_{i}\left(\int_{\underline{\varphi}}^{G^{-1}\left(E_{i}\right)} u\left(w_{i}\left(1-t_{i}\right)-T_{u}-\varphi\right) \mathrm{d} G(\varphi)+\int_{G^{-1}\left(E_{i}\right)}^{\bar{\varphi}} u\left(-T_{u}\right) \mathrm{d} G(\varphi)\right) \\
& +u\left(F\left(K, E_{1} N_{1}, \cdots, E_{I} N_{I}\right)-\sum_{i} w_{i} N_{i} E_{i}-T_{f}\right)+\lambda\left(\sum_{i} N_{i}\left(T_{u}+E_{i} t_{i} w_{i}\right)+T_{f}-R\right) \\
& +\sum_{i} \vartheta_{i}\left(w_{i}-F_{i}\left(K, E_{1} N_{1}, \cdots, E_{I} N_{I}\right)\right) \\
& +\sum_{i} \mu_{i}\left(\rho_{i} \int_{\underline{\varphi}}^{G^{-1}\left(E_{i}\right)} u^{\prime}\left(w_{i}\left(1-t_{i}\right)-T_{u}-\varphi\right) \mathrm{d} G(\varphi) F_{i i}\left(K, E_{1} N_{1}, \cdots, E_{I} N_{I}\right)\right. \\
& \left.+u\left(w_{i}\left(1-t_{i}\right)-T_{u}-G^{-1}\left(E_{i}\right)\right)-u\left(-T_{u}\right)\right) .
\end{aligned}
$$

To examine how an increase in union power $\rho_{i}$ in sector $i$ affects social welfare, differentiate 
the Lagrangian (80) with respect to $\rho_{i}$, and apply the envelope theorem:

$$
\frac{\partial \mathcal{W}}{\partial \rho_{i}}=\frac{\partial \mathcal{L}}{\partial \rho_{i}}=\mu_{i} E_{i} \overline{u_{i}^{\prime}} F_{i i}
$$

Since $E_{i} \overline{u_{i}^{\prime}} F_{i i}<0$ (provided that labor demand is not perfectly elastic), the expression in equation (81) is positive if and only if $\mu_{i}<0$. To determine the sign of $\mu_{i}$, consider the first-order condition of equation (80) with respect to $t_{i}$ :

$$
N_{i} E_{i}\left(\overline{u_{i}^{\prime}}-\lambda\right)=-\mu_{i}\left(\rho_{i} E_{i} \overline{u_{i}^{\prime \prime}} F_{i i}+\hat{u}_{i}^{\prime}\right) .
$$

By concavity of the utility function $u(\cdot)$ and the production function $F(\cdot), \rho_{i} E_{i} \overline{u_{i}^{\prime \prime}} F_{i i}+\hat{u}_{i}^{\prime}>0$. Denoting by $b_{i}=\overline{u_{i}^{\prime}} / \lambda$, it follows that

$$
\mu_{i}<0 \quad \Leftrightarrow \quad b_{i}>1
$$

Hence, an increase in $\rho_{i}$ leads to an increase in social welfare if and only if $b_{i}>1$. Importantly, nowhere in the proof is it necessary to assume that income effects are absent, that labor markets are independent, or that profit taxation is unrestricted (i.e., $b_{f}=1$ ). Proposition 2 thus generalizes to settings with income effects, interdependent labor markets, and a binding restriction on profit taxation.

\section{D.1 Optimal union power}

Suppose that the government could optimally determine union power $\rho_{i}$. If we denote by $\underline{\chi}_{i} \geq 0$ the Kuhn-Tucker multiplier on the restriction $\rho_{i} \geq 0$, and by $\bar{\chi}_{i} \geq 0$ the multiplier on the restriction $1-\rho_{i} \geq 0$, the first-order condition for optimal union power $\rho_{i}$ in sector $i$ (obtained from differentiating the Lagrangian (80) augmented with the additional inequality constraints) is given by

$$
\mu_{i} E_{i} \overline{u_{i}^{\prime}} F_{i i}+\underline{\chi}_{i}-\bar{\chi}_{i}=0 .
$$

This expression should be considered alongside the other first-order conditions of the optimization program. In an interior optimum (i.e., where the optimal $\left.\rho_{i} \in(0,1)\right)$, the Kuhn-Tucker conditions require that $\underline{\chi}_{i}=\bar{\chi}_{i}=0$. Equations (84) and (82) then imply that in these sectors $b_{i}=1$. If the solution is at the boundary, then by the Kuhn-Tucker conditions it must be that either $\bar{\chi}_{i}=0$ and $\underline{\chi}_{i}>0$ or $\underline{\chi}_{i}=0$ and $\bar{\chi}_{i}>0$. If labor demand is not perfectly elastic, equation (84) implies that $\mu_{i}>0$ in the first case (in which case $b_{i}<1$ ) and $\mu_{i}<0$ in the second case (in which case $b_{i}>1$ ). Optimal union power thus equals $\rho_{i}=\min \left[\rho_{i}^{*}, 1\right]$ if $b_{i} \geq 1$, and $\rho_{i}=\max \left[\rho_{i}^{*}, 0\right]$ if $b_{i} \leq 1$, where $\rho_{i}^{*}$ is the bargaining power of the union for which $b_{i}=1$. 


\section{E Interdependent labor markets}

The Lagrangian is the same as in the proof of Proposition 1 in Appendix C.1:

$$
\begin{aligned}
\mathcal{L}= & \sum_{i} N_{i}\left(\int_{\underline{\varphi}}^{G^{-1}\left(E_{i}\right)} u\left(w_{i}\left(1-t_{i}\right)-T_{u}-\varphi\right) \mathrm{d} G(\varphi)+\int_{G^{-1}\left(E_{i}\right)}^{\bar{\varphi}} u\left(-T_{u}\right) \mathrm{d} G(\varphi)\right) \\
& +u\left(F\left(K, E_{1} N_{1}, \cdots, E_{I} N_{I}\right)-\sum_{i} w_{i} N_{i} E_{i}-T_{f}\right)+\lambda\left(\sum_{i} N_{i}\left(T_{u}+E_{i} t_{i} w_{i}\right)+T_{f}-R\right) .
\end{aligned}
$$

If labor markets are interdependent, we have to take into account that the wage and employment rate in sector $i$ are also affected by taxes levied in sector $j \neq i$. Ignoring income effects, these relationships can be written as $w_{i}=w_{i}\left(t_{1}, t_{2}, \cdots, t_{I}\right)$ and $E_{i}=E_{i}\left(t_{1}, t_{2}, \cdots, t_{I}\right)$. The case with income effects can be analyzed in analogous fashion as is done is Appendix C.1.

The first-order conditions read as:

$$
\begin{aligned}
& T_{u}:-\sum_{i} N_{i} E_{i} \overline{u_{i}^{\prime}}-\sum_{i} N_{i}\left(1-E_{i}\right) u_{u}^{\prime}+\lambda \sum_{i} N_{i}=0, \\
& T_{f}:-u_{f}^{\prime}+\lambda=0, \\
& t_{i}:-N_{i} E_{i} w_{i}\left(\overline{u_{i}^{\prime}}-\lambda\right)+\sum_{j}\left(N_{j}\left(\hat{u}_{j}-u_{u}\right)+\lambda N_{j} t_{j} w_{j}\right) \frac{\partial E_{j}}{\partial t_{i}} \\
& +\sum_{j}\left(N_{j} E_{j} \overline{u_{j}^{\prime}}\left(1-t_{j}\right)-N_{j} E_{j} u_{f}^{\prime}+\lambda N_{j} E_{j} t_{j}\right) \frac{\partial w_{j}}{\partial t_{i}}=0 .
\end{aligned}
$$

The first two results from Proposition 3 follow directly from equations (86)-(87). To arrive at the final result, divide equation (88) by $\lambda w_{i} \sum_{j} N_{j}$ and impose $b_{f}=1$ to find:

$$
\omega_{i}\left(1-b_{i}\right)+\sum_{j} \omega_{j}\left(t_{j}+\tau_{j}\right) \frac{w_{j}}{w_{i}} \frac{1}{E_{j}} \frac{\partial E_{j}}{\partial t_{i}}+\sum_{j} \omega_{j}\left(b_{j}-1\right) \frac{1-t_{j}}{w_{i}} \frac{\partial w_{j}}{\partial t_{i}}
$$

The latter can be rewritten as:

$$
\sum_{j} \omega_{j}\left(\frac{t_{j}+\tau_{j}}{1-t_{j}}\right) \eta_{j i}=\omega_{i}\left(1-b_{i}\right)+\sum_{j} \omega_{j}\left(b_{j}-1\right) \kappa_{j i}
$$

where the elasticities are given by

$$
\begin{aligned}
\eta_{j i} & \equiv-\frac{\partial E_{j}}{\partial t_{i}} \frac{1-t_{i}}{E_{j}} \frac{w_{j}\left(1-t_{j}\right)}{w_{i}\left(1-t_{i}\right)}, \\
\kappa_{j i} & \equiv \frac{\partial w_{j}}{\partial t_{i}} \frac{1-t_{i}}{w_{j}} \frac{w_{j}\left(1-t_{j}\right)}{w_{i}\left(1-t_{i}\right)} .
\end{aligned}
$$

Finally, as shown in Appendix D, the proof regarding the desirability of unions requires no assumption on the cross-derivatives $F_{i j}(\cdot)$ and hence, generalizes to a setting with interdependent labor markets. 


\section{F Inefficient rationing}

\section{F.1 Optimal taxation}

To prove Proposition 4, we start by characterizing some properties of the general rationing schedule, which satisfies, for all values of $E_{i}$ and $\varphi_{i}^{*}$

$$
\int_{\underline{\varphi}}^{\varphi_{i}^{*}} e_{i}\left(E_{i}, \varphi_{i}^{*}, \varphi\right) \mathrm{d} G(\varphi)=E_{i} .
$$

We can differentiate equation (93) with respect to $E_{i}$ and $\varphi_{i}^{*}$ to obtain:

$$
\begin{aligned}
& \int_{\underline{\varphi}}^{\varphi_{i}^{*}} e_{i E_{i}}\left(E_{i}, \varphi_{i}^{*}, \varphi\right) \mathrm{d} G(\varphi)=1, \\
& \int_{\underline{\varphi}}^{\varphi_{i}^{*}} e_{i \varphi_{i}^{*}}\left(E_{i}, \varphi_{i}^{*}, \varphi\right) \mathrm{d} G(\varphi)+e_{i}\left(E_{i}, \varphi_{i}^{*}, \varphi_{i}^{*}\right) G^{\prime}\left(\varphi_{i}^{*}\right)=0 .
\end{aligned}
$$

Rather than deriving labor-market equilibrium explicitly for a general rationing scheme, we instead assume that income effects at the union level are absent and labor markets are independent. In this case, the equilibrium wage and employment rate only depend on the participation tax rate: $E_{i}=E_{i}\left(t_{i}\right)$ and $w_{i}=w_{i}\left(t_{i}\right)$. To derive the social welfare function, first use equation (93) to derive an expression for the expected utility of the unemployed:

$$
\left(1-E_{i}\right) u\left(-T_{u}\right)=u\left(-T_{u}\right)-\int_{\underline{\varphi}}^{\varphi_{i}^{*}} e_{i}\left(E_{i}, \varphi_{i}^{*}, \varphi\right) u\left(-T_{u}\right)
$$

Consequently, the Lagrangian for maximizing social welfare is given by:

$$
\begin{aligned}
\mathcal{L} & =\sum_{i} N_{i}\left(u\left(-T_{u}\right)+\int_{\underline{\varphi}}^{\varphi_{i}^{*}} e_{i}\left(E_{i}, \varphi_{i}^{*}, \varphi\right)\left(u\left(w_{i}\left(1-t_{i}\right)-T_{u}-\varphi\right)-u\left(-T_{u}\right)\right) \mathrm{d} G(\varphi)\right) \\
& +u\left(F\left(K, E_{1} N_{1}, \cdots, E_{I} N_{I}\right)-\sum_{i} w_{i} N_{i} E_{i}-T_{f}\right)+\lambda\left(\sum_{i} N_{i}\left(T_{u}+E_{i} t_{i} w_{i}\right)+T_{f}-R\right) .
\end{aligned}
$$

The first-order conditions for $T_{u}, T_{f}$, and $t_{i}$ are given by:

$$
\begin{aligned}
& T_{u}:-\sum_{i} N_{i} E_{i} \overline{u_{i}^{\prime}}-\sum_{i} N_{i}\left(1-E_{i}\right) u_{u}^{\prime}+\lambda \sum_{i} N_{i}=0, \\
& T_{f}:-u_{f}^{\prime}+\lambda=0 . \\
& t_{i}:-N_{i} E_{i} w_{i}\left(\overline{u_{i}^{\prime}}-\lambda\right)-w_{i} N_{i} \int_{\underline{\varphi}}^{\varphi_{i}^{*}} e_{i \varphi_{i}^{*}}\left(u_{i}(\varphi)-u_{u}\right) \mathrm{d} G(\varphi) \\
& \quad+\frac{\partial w_{i}}{\partial t_{i}}\left(\lambda N_{i} E_{i} t_{i}+\left(1-t_{i}\right) N_{i} E_{i} \overline{u_{i}^{\prime}}+\left(1-t_{i}\right) N_{i} \int_{\underline{\varphi}}^{\varphi_{i}^{*}} e_{i \varphi_{i}^{*}}\left(u_{i}(\varphi)-u_{u}\right) \mathrm{d} G(\varphi)-N_{i} E_{i} u_{f}^{\prime}\right) \\
& \quad+\frac{\partial E_{i}}{\partial t_{i}}\left(\lambda N_{i} t_{i} w_{i}+N_{i} \int_{\underline{\varphi}}^{\varphi_{i}^{*}} e_{i E_{i}}\left(u_{i}(\varphi)-u_{u}\right) \mathrm{d} G(\varphi)\right)=0,
\end{aligned}
$$


where expected utility of the employed workers is given by:

$$
\overline{u_{i}^{\prime}} \equiv \int_{\underline{\varphi}}^{\varphi_{i}^{*}} \frac{e_{i}\left(E_{i}, \varphi_{i}^{*}, \varphi\right)}{E_{i}} u^{\prime}\left(w_{i}\left(1-t_{i}\right)-T_{u}-\varphi\right) \mathrm{d} G(\varphi)
$$

and $u_{i}(\varphi) \equiv u\left(w_{i}\left(1-t_{i}\right)-T_{u}-\varphi\right)$ is the utility of the worker with participation costs $\varphi \in\left[\underline{\varphi}, \varphi_{i}^{*}\right]$ who is employed in sector $i$.

Equations (98) and (99) lead to the first two results in Proposition 4. Next, divide equation (100) by $N_{i} E_{i} w_{i} \lambda$ and impose $b_{f}=1$. In addition, define the expected utility loss of labor rationing in sector $i$ for those workers who lose their job if the employment rate $E_{i}$ is marginally reduced as:

$$
\hat{\tau}_{i} \equiv \int_{\underline{\varphi}}^{\varphi_{i}^{*}} e_{i E_{i}}\left(E_{i}, \varphi_{i}^{*}, \varphi\right)\left(\frac{u\left(w_{i}\left(1-t_{i}\right)-T_{u}-\varphi\right)-u\left(-T_{u}\right)}{\lambda w_{i}}\right) \mathrm{d} G(\varphi) .
$$

Substitute equation (102) into equation (100) and rearrange to obtain:

$$
\left(\frac{t_{i}+\hat{\tau}_{i}}{1-t_{i}}\right) \eta_{i}=\left(1-b_{i}\right)+\left(b_{i}-1\right) \kappa_{i}+\frac{\kappa_{i}-1}{E_{i}} \int_{\underline{\varphi}}^{\varphi_{i}^{*}} e_{i \varphi_{i}^{*}}\left(E_{i}, \varphi_{i}^{*}, \varphi\right) \frac{\left(u_{i}(\varphi)-u_{u}\right)}{\lambda} \mathrm{d} G(\varphi) .
$$

Next, observe that $\kappa_{i}-1=\frac{\partial \varphi_{i}^{*}}{\partial t_{i}} \frac{\left(1-t_{i}\right)}{\varphi_{i}^{*}}$. In addition, use equation (95) to rewrite the last part of equation (103) as:

$$
\begin{aligned}
& \frac{\kappa_{i}-1}{E_{i}} \int_{\underline{\varphi}}^{\varphi_{i}^{*}} e_{i \varphi_{i}^{*}}\left(E_{i}, \varphi_{i}^{*}, \varphi\right) \frac{\left(u_{i}(\varphi)-u_{u}\right)}{\lambda} \mathrm{d} G(\varphi)= \\
& -\frac{\partial \varphi_{i}^{*}}{\partial t_{i}} \frac{\left(1-t_{i}\right)}{\varphi_{i}^{*}} \frac{e_{i}\left(E_{i}, \varphi_{i}^{*}, \varphi_{i}^{*}\right) G^{\prime}\left(\varphi_{i}^{*}\right)}{E_{i}} \int_{\underline{\varphi}}^{\varphi_{i}^{*}} \frac{e_{i \varphi_{i}^{*}}\left(E_{i}, \varphi_{i}^{*}, \varphi\right)}{\int_{\underline{\varphi}}^{\varphi_{i}^{*}} e_{i \varphi_{i}^{*}}\left(E_{i}, \varphi_{i}^{*}, \varphi\right) \mathrm{d} G(\varphi)} \frac{\left(u_{i}(\varphi)-u_{u}\right)}{\lambda} \mathrm{d} G(\varphi) .
\end{aligned}
$$

Finally, define

$$
\psi_{i} \equiv \frac{e_{i}\left(E_{i}, \varphi_{i}^{*}, \varphi_{i}^{*}\right)}{E_{i} / G\left(\varphi_{i}^{*}\right)} \int_{\underline{\varphi}}^{\varphi_{i}^{*}} \frac{e_{i \varphi_{i}^{*}}\left(E_{i}, \varphi_{i}^{*}, \varphi\right)}{\int_{\underline{\varphi}}^{\varphi_{i}^{*}} e_{i \varphi_{i}^{*}}\left(E_{i}, \varphi_{i}^{*}, \varphi\right) \mathrm{d} G(\varphi)}\left(\frac{u\left(w_{i}\left(1-t_{i}\right)-T_{u}-\varphi\right)-u\left(-T_{u}\right)}{\lambda w_{i}}\right) \mathrm{d} G(\varphi),
$$

and

$$
\gamma_{i} \equiv-\frac{\partial G\left(\varphi_{i}^{*}\right)}{\partial t_{i}} \frac{1-t_{i}}{G\left(\varphi_{i}^{*}\right)} .
$$

After substituting these definitions in equation (103), we arrive at:

$$
\left(\frac{t_{i}+\hat{\tau}_{i}}{1-t_{i}}\right) \eta_{i}-\left(\frac{\psi_{i}}{1-t_{i}}\right) \gamma_{i}=\left(1-b_{i}\right)+\left(b_{i}-1\right) \kappa_{i}
$$

\section{F.2 Desirability of unions}

To study the welfare effects of the reform described in Section 6.2, one can differentiate the Lagrangian in equation (97) with respect to $t_{i}$ and $T_{f}$ under the assumptions that the reform is budget neutral, and leaves wages and employment in sector $i$ (i.e., $w_{i}$ and $E_{i}$ ) unaffected. The 
welfare effect is then:

$$
\begin{aligned}
\frac{\mathrm{d} \mathcal{W}}{\lambda}= & -N_{i} E_{i} b_{i} w_{i} \mathrm{~d} t_{i}-b_{f} \mathrm{~d} T_{f} \\
& -N_{i} w_{i} w_{i} \int_{\underline{\varphi}}^{\varphi_{i}^{*}} e_{i \varphi_{i}^{*}}\left(E_{i}, \varphi_{i}^{*}, \varphi\right) \frac{u\left(w_{i}-T_{i}-\varphi\right)-u\left(-T_{u}\right)}{w_{i} \lambda} \mathrm{d} G(\varphi) \mathrm{d} t_{i} .
\end{aligned}
$$

The first term reflects the (direct) change in workers' utility in sector $i$ following the change in the participation tax rate, whereas the second term reflects the change in firm-owners' utility induced by a change in the profit tax. The third term reflects the utility loss due to a change in labor participation: if $t_{i}$ is lowered, more workers want to participate. If some of these workers find a job, and employment remains constant, then it must be that some other workers lose their jobs and thus experience a utility loss, since rationing is not fully efficient.

Under the balanced-budget assumption, we have $N_{i} E_{i} w_{i} \mathrm{~d} t_{i}+\mathrm{d} T_{f}=0$. In addition, if the government can levy a non-distortionary profit tax, then $b_{f}=1$. Substituting these results and equation (95) in equation (108), the change in social welfare can be written as:

$$
\begin{aligned}
& \frac{\mathrm{d} \mathcal{W}}{\lambda}=-N_{i} E_{i}\left(b_{i}-1-e_{i}\left(E_{i}, \varphi_{i}^{*}, \varphi_{i}^{*}\right) \frac{G^{\prime}\left(\varphi_{i}^{*}\right)}{E_{i}}\right. \\
& \left.\times \int_{\underline{\varphi}}^{\varphi_{i}^{*}} \frac{e_{i \varphi_{i}^{*}}\left(E_{i}, \varphi_{i}^{*}, \varphi\right)}{\int_{\underline{\varphi}}^{\varphi_{i}^{*}} e_{i \varphi_{i}^{*}}\left(E_{i}, \varphi_{i}^{*}, \varphi\right) \mathrm{d} G(\varphi)} \frac{u\left(w_{i}-T_{i}-\varphi\right)-u\left(-T_{u}\right)}{\lambda} \mathrm{d} G(\varphi)\right) w_{i} \mathrm{~d} t_{i} .
\end{aligned}
$$

Given that $t_{i}$ is lowered in the policy experiment (i.e., $\mathrm{d} t_{i}<0$ ), the welfare effect is positive provided that the term in between brackets is positive. Using the definitions for $\psi_{i}$ and $\gamma_{i}$ from equations (105) and (106), this is the case if:

$$
b_{i}>1+\left(\frac{\psi_{i}}{1-t_{i}}\right) \gamma_{i}
$$

\section{G Bargaining over multiple wages}

\section{G.1 Labor-market equilibrium}

We assume that there is one union with a utilitarian objective and denote union power by $\beta \in[0,1]$. The union bargains with the firm-owners over the wages all sectors $i$. Hence, the union affects the entire wage distribution. Under Nash-bargaining, the solution for wages and employment in all sectors $i$ follow from solving the following maximization problem:

$$
\begin{aligned}
\max _{\left\{w_{i}, E_{i}\right\}_{i \in \mathcal{I}}} \Omega & =\beta \log \left(\sum_{i} N_{i} \int_{\underline{\varphi}}^{G^{-1}\left(E_{i}\right)}\left(u\left(w_{i}-T_{i}-\varphi\right)-u\left(-T_{u}\right)\right) \mathrm{d} G(\varphi)\right) \\
& +(1-\beta) \log \left(u\left(F\left(K, E_{1} N_{1}, \cdots, E_{I} N_{I}\right)-\sum_{i} w_{i} N_{i} E_{i}-T_{f}\right)-u\left(F(K, 0, \cdots, 0)-T_{f}\right)\right) \\
\text { s.t. } & w_{i}-F_{i}\left(K, E_{1} N_{1}, \cdots, E_{I} N_{I}\right)=0, \quad \forall i, \\
& G\left(w_{i}-T_{i}+T_{u}\right)-E_{i} \geq 0, \quad \forall i .
\end{aligned}
$$


As in Appendix A, the payoffs of both parties are taken in deviation from the payoff associated with the disagreement outcome. The Lagrangian is:

$$
\begin{aligned}
\mathcal{L} & =\beta \log \left(\sum_{i} N_{i} \int_{\underline{\varphi}}^{G^{-1}\left(E_{i}\right)}\left(u\left(w_{i}-T_{i}-\varphi\right)-u\left(-T_{u}\right)\right) \mathrm{d} G(\varphi)\right) \\
& +(1-\beta) \log \left(u\left(F\left(K, E_{1} N_{1}, \cdots, E_{I} N_{I}\right)-\sum_{i} w_{i} N_{i} E_{i}-T_{f}\right)-u\left(F(K, 0, \cdots, 0)-T_{f}\right)\right) \\
& +\sum_{i} \vartheta_{i}\left(w_{i}-F_{i}\left(K, E_{1} N_{1}, \cdots, E_{I} N_{I}\right)\right)+\sum_{i} \mu_{i}\left(G\left(w_{i}-T_{i}+T_{u}\right)-E_{i}\right) .
\end{aligned}
$$

The first-order conditions are:

$$
\begin{aligned}
& w_{i}: \frac{\beta}{\sum_{j} N_{j} E_{j}\left(\overline{u_{j}}-u_{u}\right)} N_{i} E_{i} \overline{u_{i}^{\prime}}-\frac{1-\beta}{u_{f}-\underline{u}_{f}} N_{i} E_{i} \overline{u_{f}^{\prime}}+\vartheta_{i}+\mu_{i} G_{i}^{\prime}=0, \\
& E_{i}: \frac{\beta}{\sum_{j} N_{j} E_{j}\left(\overline{u_{j}}-u_{u}\right)} N_{i}\left(\hat{u}_{i}-u_{u}\right)-N_{i} \sum_{j} \vartheta_{j} F_{j i}-\mu_{i}=0, \\
& \vartheta_{i}: w_{i}-F_{i}=0, \\
& \mu_{i}: G_{i}-E_{i}=0 .
\end{aligned}
$$

where $\underline{u}_{f} \equiv u\left(F(K, 0, \cdots, 0)-T_{f}\right)$. These conditions characterize labor-market equilibrium, which has the following properties.

First, if the union has zero bargaining power $(\beta=0)$, the equilibrium coincides with the competitive outcome (i.e., $G_{i}=E_{i}$ and $w_{i}=F_{i}$ for all $i$ ). To see why, substitute $\beta=0$ in the first-order conditions for $w_{i}$ and $E_{i}$ in equations (113) and (114). Next, use (113) to substitute for $\vartheta_{i}$ in equation (114) and rearrange:

$$
\mu_{i} \underbrace{\left(N_{i} G_{i}^{\prime} F_{i i}-1\right)}_{<0}+N_{i} \sum_{j \neq i} \mu_{j} \underbrace{G_{j}^{\prime} F_{j i}}_{\geq 0}=N_{i} \underbrace{\frac{u_{f}^{\prime}}{u_{f}-\underline{u}_{f}}}_{>0} \underbrace{\sum_{j} N_{j} E_{j} F_{j i}}_{=-F_{K i} K<0} .
$$

The inequalities follow from the assumptions of co-operant factors of production and constant returns to scale. Non-increasing marginal productivity and co-operant factors of production imply $F_{i i} \leq 0 \leq F_{j i}$, whereas constant returns to scale implies $\sum_{j} N_{j} E_{j} F_{j i}=-F_{K i} K \leq 0 .{ }^{29}$ Suppose that there is a sector in which $G_{i}>E_{i}$, i.e., the wage is above the market-clearing level. Then, from the Kuhn-Tucker conditions, it must be that $\mu_{i}=0$. Because of the non-negativity of all multipliers, however, equation (117) cannot be satisfied unless all labor types would be perfect substitutes, i.e., $F_{i i}=F_{i j}=F_{K i}=0$ for all $i, j$. This is a contradiction. Therefore, $G_{i}=E_{i}$ for all $i$.

Second, if the union has sufficiently high bargaining power $\beta$, there is at least one sector $i$ for which the wage exceeds the market-clearing level, i.e., there exists a sector $i$ such that $G_{i}>E_{i}$. To see why, suppose $\beta=1$. In this case, the union is a monopoly union, and sets wages in order to maximize the expected utility of all workers, subject to the labor-demand

\footnotetext{
${ }^{29}$ This follows from differentiating $F(\cdot)=F_{K}(\cdot) K+\sum_{j} N_{j} E_{j} F_{j}(\cdot)$ with respect to $E_{\ell}$.
} 
equations $w_{i}=F_{i}\left(K, E_{1} N_{1}, \cdots, E_{I} N_{I}\right)$. Consequently, the union objective can be written as:

$$
\Lambda=\sum_{i} N_{i} \int_{\underline{\varphi}}^{G^{-1}\left(E_{i}\right)}\left(u\left(F_{i}\left(K, E_{1} N_{1}, \cdots, E_{I} N_{I}\right)-T_{i}-\varphi\right)-u\left(-T_{u}\right)\right) \mathrm{d} G(\varphi) .
$$

Now, suppose that, starting from the competitive equilibrium where $G\left(F_{i}-T_{i}-T_{u}\right)=E_{i}$ for all $i$, the union considers reducing the employment rate in the sector $\ell$ where the marginal utility of workers' consumption is highest (i.e., $\overline{u_{\ell}^{\prime}}>\overline{u_{j}^{\prime}}$ for all $j \neq \ell$ ). This reduction in employment increases the wage of the workers with the highest marginal utility of consumption and reduce the wages for all other workers. The impact of a reduction in employment in sector $\ell$ on the union's objective is:

$$
\mathrm{d} \Lambda=N_{\ell} \sum_{j} N_{j} E_{j} \overline{u_{j}^{\prime}} F_{j \ell} \times \mathrm{d} E_{\ell}=N_{\ell}\left(N_{\ell} E_{\ell} F_{\ell \ell} \overline{u_{\ell}^{\prime}}+\sum_{j \neq \ell} N_{j} E_{j} F_{j \ell} \overline{u_{j}^{\prime}}\right) \mathrm{d} E_{\ell} .
$$

This expression can be thought of as summing a weighted average of marginal utilities, with weights $N_{j} E_{j} F_{j \ell}$. The first term in brackets is negative (because $F_{\ell \ell}<0$ ), whereas the second term in brackets is positive (because $F_{j \ell} \geq 0$ for all $j \neq \ell$ ). The first term unambiguously dominates the second term. This is because the weights sum to less than zero (constant returns to scale implies $\sum_{j} N_{j} E_{j} F_{j \ell}=-F_{K i} K \leq 0$ ) and the only negative component (i.e., $N_{\ell} E_{\ell} F_{\ell \ell}$ ) is multiplied by the largest marginal utility (i.e., $\overline{u_{\ell}^{\prime}}>\overline{u_{j}^{\prime}}$ for all $j \neq \ell$ ). Consequently, the union objective unambiguously increases if - starting from the competitive equilibrium - the rate of employment for workers in the sector with the lowest wage is reduced (i.e., $d E_{\ell}<0$ ). Hence, a monopoly union $(\beta=1)$ always demands a wage above the market-clearing level in at least one sector.

\section{G.2 Optimal taxation}

In the absence of income effects and under the assumption that firm-owners are risk-neutral, the first-order conditions in equations (113) and (116) characterize equilibrium wages and employment rates as a function the participation tax rates: $w_{i}=w_{i}\left(t_{1}, . ., t_{I}\right)$ and $E_{i}=E_{i}\left(t_{1}, . ., t_{I}\right) .{ }^{30}$ These reduced-form equations can be used to derive the optimal tax formulas. This case is identical to the one with multiple unions and interdependent labor markets, which is analyzed in Appendix E. The optimal tax formulas (written in terms of elasticities) therefore remain unaffected.

\section{G.3 Desirability of unions}

To study the desirability of a national union, we analyze the welfare effects of a joint marginal increase in union power $\beta$ and a marginal change in participation tax rates, which leaves all labor-market outcomes unaffected. If the tax system is optimized, any change in welfare must then necessarily be the result of the change in union power.

\footnotetext{
${ }^{30}$ Risk-neutrality of firm-owners ensures that equilibrium wages and employment rates do not depend on the profit tax.
} 
Which tax reform offsets any impact of the increase in union power on equilibrium wages and employment. First, the tax reform cannot include a change in the participation tax rate for workers whose wage is at the market-clearing level. To see why, consider the labor-market equilibrium condition in a sector $i$ where the wage is at the market-clearing level:

$$
G_{i}\left(F_{i}(\cdot)\left(1-t_{i}\right)\right)=E_{i}
$$

A change in $t_{i}$ in this sector needs to be accompanied by a change in either $F_{i}(\cdot)$ or $E_{i}$. For this to be the case, employment in at least one sector $i$ needs to adjust. However, the tax change is intended keep employment in all sectors unaffected. Hence, in sectors where $G_{i}=E_{i}$ it must be the case that $\mathrm{d} t_{i}=0$. The tax reform thus changes taxes $\mathrm{d} t_{j}^{*}$ in all sectors $j$ where the wage is set above above the martket-clearing level, i.e., where $G_{i}>E_{i}$. The marginal tax reform should then satisfy:

$$
\forall i \in k(\beta): \quad \sum_{j \in k(\beta)} \frac{\partial w_{i}\left(t_{1}, . ., t_{I}, \beta\right)}{\partial t_{j}} \mathrm{~d} t_{j}^{*}+\frac{\partial w_{i}\left(t_{1}, . ., t_{I}, \beta\right)}{\partial \beta} \mathrm{d} \beta=0 .
$$

Here, $k(\beta) \equiv\left\{i: G_{i}>E_{i}\right\}$ is the set of sectors where the wage is raised above the marketclearing level. As before, assume that the government adjusts the profit tax to keep the budget balanced. Since the combined increase in union power $\beta$ and the tax reform $\mathrm{d} t_{j}^{*}$ for all $j$ leaves all labor-market outcomes unaffected, there is only a transfer of resources from firm-owners to the workers whose wage is higher than the market-clearing level (i.e., for whom $G_{i}>E_{i}$ ). The welfare effect is thus equal to:

$$
\frac{\mathrm{d} \mathcal{W}}{\lambda}=\sum_{i \in k(\beta)} N_{i} E_{i}\left(1-b_{i}\right) \mathrm{d} t_{i}^{*}
$$

where $\lambda$ is the multiplier on the government budget constraint. Divide the latter by $\sum_{i} N_{i}>0$. The remaining term is positive if and only if

$$
\sum_{i \in k \beta} \omega_{i}\left(1-b_{i}\right) \mathrm{d} t_{i}^{*}>0
$$

\section{H Efficient bargaining}

\section{H.1 Derivation elasticities}

Partial equilibrium in labor market $i$ is obtained by combining the contract curve from equation (34) and the rent-sharing rule from equation (35):

$$
\begin{aligned}
\overline{u^{\prime}\left(w_{i}\left(1-t_{i}\right)-T_{u}-\varphi\right)}\left(w_{i}-F_{i}\left(E_{i}\right)\right) & =u\left(w_{i}\left(1-t_{i}\right)-T_{u}-G^{-1}\left(E_{i}\right)\right)-u\left(-T_{u}\right), \\
w_{i} & =\left(1-\sigma_{i}\right) F_{i}\left(E_{i}\right)+\sigma_{i} \phi_{i}\left(E_{i}\right) .
\end{aligned}
$$

In the absence of income effects, these equations define $E_{i}=E_{i}\left(t_{i}\right)$ and $w_{i}=w_{i}\left(t_{i}\right)$. As before, the absence of income effects implies a change in $T_{u}$ does not affect equilibrium wages and employment if the participation tax rate $t_{i}$ remains constant. Hence, the derivative of equation 
(124) with respect $T_{u}$, while keeping $t_{i}$ constant, is zero:

$$
-\overline{u^{\prime \prime}\left(w_{i}\left(1-t_{i}\right)-T_{u}-\varphi\right)}\left(w_{i}-F_{i}\left(E_{i}\right)\right)=-u^{\prime}\left(w_{i}\left(1-t_{i}\right)-T_{u}-G^{-1}\left(E_{i}\right)\right)+u^{\prime}\left(-T_{u}\right) .
$$

To derive the elasticities of employment and wages with respect to the participation tax rate, we first linearize the rent-sharing rule:

$$
\frac{\mathrm{d} w_{i}}{w_{i}}=-\left(\left(1-m_{i}\right) \frac{\left(1-\sigma_{i}\right)}{\varepsilon_{i}}+m_{i}\right) \frac{\mathrm{d} E_{i}}{E_{i}}
$$

where $m_{i} \equiv\left(w_{i}-F_{i}\right) / w_{i}=1-F_{i} / w_{i}$ is the implicit subsidy on labor demand, as a fraction of the wage. If union power is zero, $\sigma_{i}=0, m_{i}=0$, and equation (127) reduces to the linearized labor-demand equation.

Second, linearizing the contract curve yields:

$$
\frac{\mathrm{d} \overline{u_{i}^{\prime}}}{\overline{u_{i}^{\prime}}}+\frac{\mathrm{d}\left(w_{i}-F_{i}\right)}{w_{i}-F_{i}}=\frac{\mathrm{d}\left(\hat{u}_{i}-u_{u}\right)}{\hat{u}_{i}-u_{u}} .
$$

Using equation (126), the linearized sub-parts are given by:

$$
\begin{aligned}
\frac{\mathrm{d} \overline{u_{i}^{\prime}}}{\overline{u_{i}^{\prime}}} & =\frac{\overline{u_{i}^{\prime \prime}} w_{i}\left(1-t_{i}\right)}{\overline{u_{i}^{\prime}}}\left(\frac{\mathrm{d} w_{i}}{w_{i}}-\frac{\mathrm{d} t_{i}}{1-t_{i}}\right)+\frac{\left(\hat{u}_{i}^{\prime}-\overline{u_{i}^{\prime}}\right)}{\overline{u_{i}^{\prime}}} \frac{\mathrm{d} E_{i}}{E_{i}}, \\
\frac{\mathrm{d}\left(w_{i}-F_{i}\right)}{w_{i}-F_{i}} & =\frac{1}{m_{i}}\left(\frac{\mathrm{d} w_{i}}{w_{i}}+\frac{\left(1-m_{i}\right)}{\varepsilon_{i}} \frac{\mathrm{d} E_{i}}{E_{i}}\right), \\
\frac{\mathrm{d}\left(\hat{u}_{i}-u_{u}\right)}{\hat{u}_{i}-u_{u}} & =\frac{\hat{u}_{i}^{\prime} w_{i}\left(1-t_{i}\right)}{\left(\hat{u}_{i}-u_{u}\right)}\left(\frac{\mathrm{d} w_{i}}{w_{i}}-\frac{\mathrm{d} t_{i}}{1-t_{i}}\right)-\frac{\hat{u}_{i}^{\prime} E_{i}}{g\left(\hat{\varphi}_{i}\right)\left(\hat{u}_{i}-u_{u}\right)} \frac{\mathrm{d} E_{i}}{E_{i}} .
\end{aligned}
$$

Solving for the relative changes in employment and wages yields:

$$
\begin{aligned}
\frac{\mathrm{d} E_{i}}{E_{i}} & =\frac{-u_{u}^{\prime} w_{i}\left(1-t_{i}\right)}{\frac{\hat{u}_{i}^{\prime} E_{i}}{g\left(\hat{\varphi}_{i}\right)}+u_{u}^{\prime} w_{i}\left(1-t_{i}\right)\left(\frac{\left(1-m_{i}\right)\left(1-\sigma_{i}\right)}{\varepsilon_{i}}+m_{i}\right)+\left(\hat{u}_{i}-u_{u}\right)\left(\frac{\left(1-m_{i}\right)}{m_{i}} \frac{\left(1-\sigma_{i}\right)}{\varepsilon_{i}}-1+\frac{\left(\hat{u}_{i}^{\prime}-\overline{u_{i}^{\prime}}\right)}{\overline{u_{i}^{\prime}}}\right)} \frac{\mathrm{d} t_{i}}{1-t_{i}}, \\
\frac{\mathrm{d} w_{i}}{w_{i}} & =\frac{u_{u}^{\prime} w_{i}\left(1-t_{i}\right)\left(\frac{\left(1-m_{i}\right)\left(1-\sigma_{i}\right)}{\varepsilon_{i}}+m_{i}\right)}{\frac{\hat{u}_{i}^{\prime} E_{i}}{g\left(\hat{\varphi}_{i}\right)}+u_{u}^{\prime} w_{i}\left(1-t_{i}\right)\left(\frac{\left(1-m_{i}\right)\left(1-\sigma_{i}\right)}{\varepsilon_{i}}+m_{i}\right)+\left(\hat{u}_{i}-u_{u}\right)\left(\frac{\left(1-m_{i}\right)}{m_{i}} \frac{\left(1-\sigma_{i}\right)}{\varepsilon_{i}}-1+\frac{\left(\hat{u}_{i}^{\prime}-\overline{u_{i}^{\prime}}\right)}{\overline{u_{i}^{\prime}}}\right)} \frac{\mathrm{d} t_{i}}{1-t_{i}} .
\end{aligned}
$$

The elasticities are now as given in Proposition 7. 


\section{H.2 Optimal taxation}

The derivation is similar as in Appendix C.1. Start with the Lagrangian for the maximization of social welfare:

$$
\begin{aligned}
\mathcal{L} & =\sum_{i} N_{i}\left(\int_{\underline{\varphi}}^{G^{-1}\left(E_{i}\right)} u\left(w_{i}\left(1-t_{i}\right)-T_{u}-\varphi\right) \mathrm{d} G(\varphi)+\int_{G^{-1}\left(E_{i}\right)}^{\bar{\varphi}} u\left(-T_{u}\right) \mathrm{d} G(\varphi)\right) \\
& +u\left(F(\cdot)-\sum_{i} w_{i} N_{i} E_{i}-T_{f}\right)+\lambda\left(\sum_{i} N_{i}\left(T_{u}+E_{i} t_{i} w_{i}\right)+T_{f}-R\right) .
\end{aligned}
$$

Differentiating with respect to $T_{u}, T_{f}$, and $t_{i}$ yields:

$$
\begin{aligned}
& T_{u}:-\sum_{i} N_{i} E_{i} \overline{u_{i}^{\prime}}-\sum_{i} N_{i}\left(1-E_{i}\right) u_{u}^{\prime}+\lambda \sum_{i} N_{i}=0 \\
& T_{f}:-u_{f}^{\prime}+\lambda=0 \\
& t_{i}:-N_{i} E_{i} w_{i}\left(\overline{u_{i}^{\prime}}-\lambda\right)+\frac{\partial E_{i}}{\partial t_{i}}\left(N_{i}\left(\hat{u}_{i}-u_{u}\right)+u_{f}^{\prime} N_{i}\left(F_{i}-w_{i}\right)+\lambda N_{i} t_{i} w_{i}\right) \\
& +\frac{\partial w_{i}}{\partial t_{i}}\left(N_{i} E_{i} \overline{u_{i}^{\prime}}\left(1-t_{i}\right)-N_{i} E_{i} u_{f}^{\prime}+\lambda N_{i} E_{i} t_{i}\right)=0
\end{aligned}
$$

The first two expressions from Proposition 8 are obtained by dividing equation (135) by $\lambda \sum_{i} N_{i}$ and equation (136) by $\lambda$, and imposing the definitions of the welfare weights $b_{i} \equiv \overline{u^{\prime}\left(c_{i}\right)} / \lambda$, $b_{u} \equiv u^{\prime}\left(c_{u}\right) / \lambda$ and the employment shares $\omega_{i} \equiv N_{i} E_{i} / \sum_{j} N_{j}$ and $\omega_{u} \equiv \sum_{i} N_{i}\left(1-E_{i}\right) / \sum_{j} N_{j}$. The second result can be found by dividing equation (136) by $\lambda$ and using $b_{f} \equiv u^{\prime}\left(c_{f}\right) / \lambda$. The expression for the optimal participation tax rate $t_{i}$ is obtained by substituting $u_{f}^{\prime}=\lambda$ in equation (137) and dividing the expression by $N_{i} E_{i} \lambda w_{i}$. After imposing the definitions of the union wedge $\tau_{i} \equiv \frac{u\left(\hat{c}_{i}\right)-u\left(c_{u}\right)}{\lambda w_{i}}$, the mark-up $m_{i}=\frac{w_{i}-F_{i}}{w_{i}}$ and the elasticities $\kappa_{i}$ and $\eta_{i}$ as defined in equations (40)-(41), we arrive at the final expression stated in Proposition 8.

\section{H.3 Desirability of unions}

To determine how a change in union power $\sigma_{i}$ affects social welfare, we formulate the Lagrangian by taking the labor-market equilibrium conditions explicitly into account, as in Appendix D:

$$
\begin{aligned}
\mathcal{L} & =\sum_{i} N_{i}\left(\int_{\underline{\varphi}}^{G^{-1}\left(E_{i}\right)} u\left(w_{i}\left(1-t_{i}\right)-T_{u}-\varphi\right) \mathrm{d} G(\varphi)+\int_{G^{-1}\left(E_{i}\right)}^{\bar{\varphi}} u\left(-T_{u}\right) \mathrm{d} G(\varphi)\right) \\
& +u\left(F(\cdot)-\sum_{i} w_{i} N_{i} E_{i}-T_{f}\right)+\lambda\left(\sum_{i} N_{i}\left(T_{u}+E_{i} t_{i} w_{i}\right)+T_{f}-R\right) \\
& +\sum_{i} \vartheta_{i} N_{i}\left(w_{i}-\left(1-\sigma_{i}\right) F_{i}(\cdot)-\sigma_{i} \phi_{i}(\cdot)\right) \\
& +\sum_{i} \mu_{i} N_{i}\left(\int_{\underline{\varphi}}^{G^{-1}\left(E_{i}\right)} u^{\prime}\left(w_{i}\left(1-t_{i}\right)-T_{u}-\varphi\right) \mathrm{d} G(\varphi)\left(F_{i}(\cdot)-w_{i}\right)\right. \\
& \left.+E_{i}\left(u\left(w_{i}\left(1-t_{i}\right)-T_{u}-G^{-1}\left(E_{i}\right)\right)-u\left(-T_{u}\right)\right)\right) .
\end{aligned}
$$


To determine how a change in the union power affects social welfare, differentiate the Lagrangian with respect to $\sigma_{i}$, and apply the envelope theorem:

$$
\frac{\partial \mathcal{W}}{\partial \sigma_{i}}=\frac{\partial \mathcal{L}}{\partial \sigma_{i}}=N_{i} \vartheta_{i}\left(F_{i}-\phi_{i}\right)
$$

Because the production function $F(\cdot)$ is concave in $E_{i}, w_{i}-F_{i}=\sigma_{i}\left(\phi_{i}(\cdot)-F_{i}(\cdot)\right)>0$ if $\sigma_{i}>0$.

Hence, $\frac{\partial \mathcal{L}}{\partial \sigma_{i}}$ is positive if and only if $\vartheta_{i}<0$. To determine the sign of $\vartheta_{i}$, use the first-order conditions of the Lagrangian with respect to $t_{i}, w_{i}$ and $T_{f}$ :

$$
\begin{aligned}
& t_{i}:-w_{i} N_{i} E_{i}\left(\overline{u_{i}^{\prime}}-\lambda\right)-\mu_{i} w_{i} N_{i} E_{i}\left(\overline{u_{i}^{\prime \prime}}\left(F_{i}-w_{i}\right)+\hat{u}_{i}^{\prime}\right)=0, \\
& w_{i}:\left(1-t_{i}\right) N_{i} E_{i} \overline{u_{i}^{\prime}}-N_{i} E_{i} u_{f}^{\prime}+\lambda t_{i} N_{i} E_{i}+\vartheta_{i} N_{i} \\
& +\mu_{i}\left(1-t_{i}\right) N_{i}\left(E_{i} \overline{u_{i}^{\prime \prime}}\left(F_{i}-w_{i}\right)+E_{i} \hat{u}_{i}^{\prime}\right)-\mu_{i} N_{i} E_{i} \overline{u_{i}^{\prime}}=0, \\
& T_{f}:-u_{f}^{\prime}+\lambda=0 \text {. }
\end{aligned}
$$

Combining equations (140) and (141) and substituting equation (142) yields:

$$
\vartheta_{i}=\mu_{i} E_{i} \overline{u_{i}^{\prime}}
$$

Substituting for $\mu_{i}$ using equation (140) and simplifying gives:

$$
\vartheta_{i}=E_{i}\left(\frac{\lambda \overline{u_{i}^{\prime}}\left(1-b_{i}\right)}{\overline{u_{i}^{\prime \prime}\left(F_{i}-w_{i}\right)+\hat{u}_{i}^{\prime}}}\right) .
$$

From equations (139) and (144), it follows that an increase in $\sigma_{i}$ increases social welfare if and only if the term on the right-hand side of expression (144) is negative:

$$
b_{i}>1 \text {. }
$$

\section{Simulations}

\section{I.1 Calculating optimal taxes}

This Appendix provides additional information regarding the simulations. we calculate the optimal tax-benefit system for varying degrees of union power $\rho_{i}$. In order to do so, we numerically solve the optimal tax expressions for the unemployment benefit and the participation tax rates. As explained in the main text, we ignore firm-owners and do not calculate the optimal profit tax. This only implies a slightly different cardinalization of the social preference for income redistribution via the revenue requirement of the government. Under Assumptions 1 and 2, the policy optimum is characterized by (see Proposition 1):

$$
\omega_{u} b_{u}+\sum_{i} \omega_{i} b_{i}=1
$$




$$
\left(\frac{t_{i}+\frac{\rho_{i} b_{i}}{\varepsilon_{i}}}{1-t_{i}}\right) \eta_{i}=\left(1-b_{i}\right)+\left(b_{i}-1\right) \kappa_{i},
$$

where we substituted for the union wedge using $\tau_{i}=\frac{\rho_{i} b_{i}}{\varepsilon_{i}}$. The government budget constraint is:

$$
\sum_{i} N_{i}\left(T_{u}+E_{i} t_{i} w_{i}\right)=R
$$

The labor-market equilibrium conditions and the welfare weights are:

$$
\begin{aligned}
E_{i} & =\zeta_{i}\left(w_{i}\left(1-t_{i}\right)\right)^{\gamma_{i}^{e}}, \\
E_{i} & =\xi_{i} w_{i}^{-\varepsilon_{i}}, \\
b_{i} & =\frac{1}{\lambda\left(w_{i}\left(1-t_{i}\right)-T_{u}\right)^{\nu}}, \\
b_{u} & =\frac{1}{\lambda\left(-T_{u}\right)^{\nu}} .
\end{aligned}
$$

We numerically solve the system (146)- (152) for the tax instruments $t_{i}$ and $T_{u}$, equilibrium wages $w_{i}$ and employment $E_{i}$, welfare weights $b_{i}$ and $b_{u}$, and the multiplier on the government budget constraint $\lambda$. Values for $R, \zeta_{i}$, and $\xi_{i}$ are calibrated using the Dutch statistics on observed wages, employment rates, and the tax-transfer system, see Table 1. Following Saez (2002) and Kroft et al. (2017), we set $\nu=1$ in our baseline simulations. We set the effective participation elasticity at $\gamma_{i}^{e}=0.16$ and the labor-demand elasticity $\varepsilon_{i}=0.3$. We then solve these equations for competitive labor markets without unions $\left(\rho_{i}=0\right.$ for all $\left.i\right)$, intermediate union power $\left(\rho_{i}=1 / 2\right.$ for all $\left.i\right)$, and monopoly unions $\left(\rho_{i}=1\right.$ for all $\left.i\right)$.

To solve for the optimal taxes with interdependent labor markets, we replace equation (147) with (21) and the labor-demand equations (150) with equation (46). 


\section{I.2 Sensitivity Analysis}

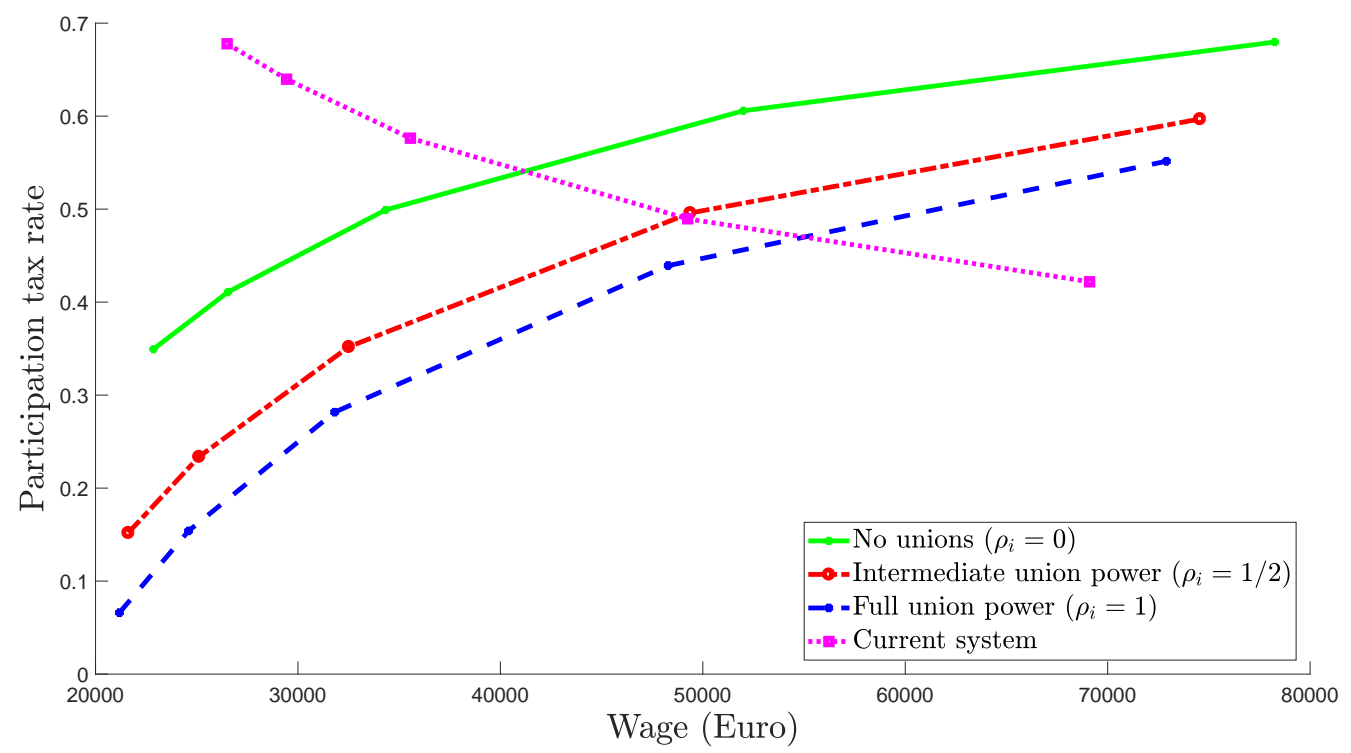

Figure 6: Optimal participation tax rates with higher labor-demand elasticity $\left(\varepsilon_{i}=0.6\right)$

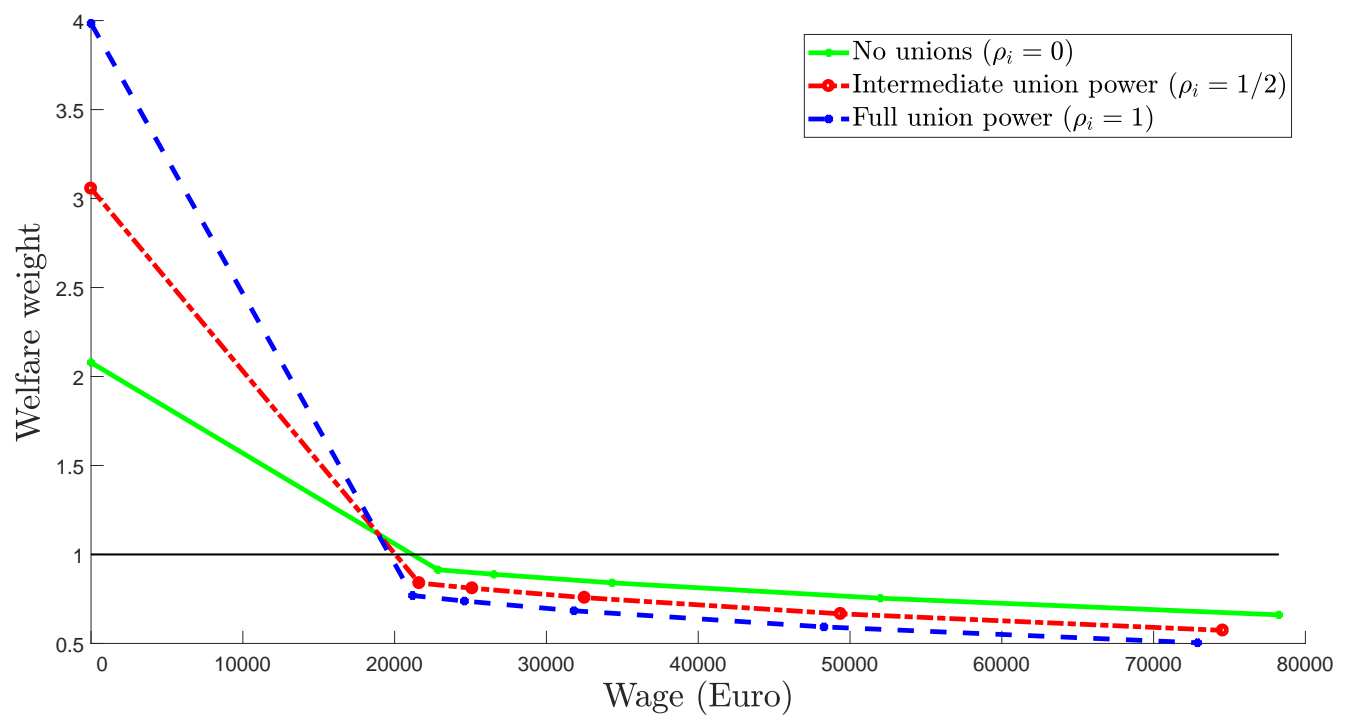

Figure 7: Social welfare weights with higher labor-demand elasticity $\left(\varepsilon_{i}=0.6\right)$ 


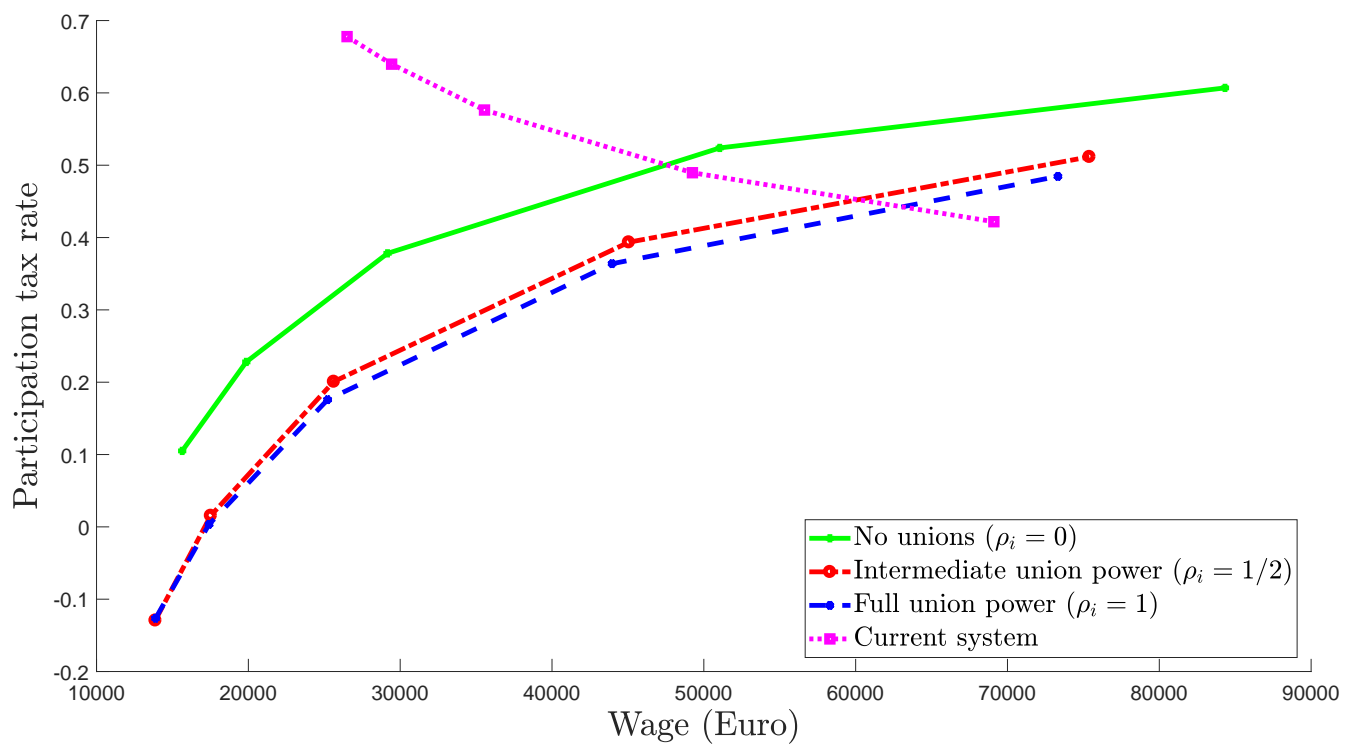

Figure 8: Optimal participation tax rates with higher participation elasticity $\left(\gamma_{i}^{e}=0.32\right)$



Figure 9: Social welfare weights with higher participation elasticity $\left(\gamma_{i}^{e}=0.32\right)$ 


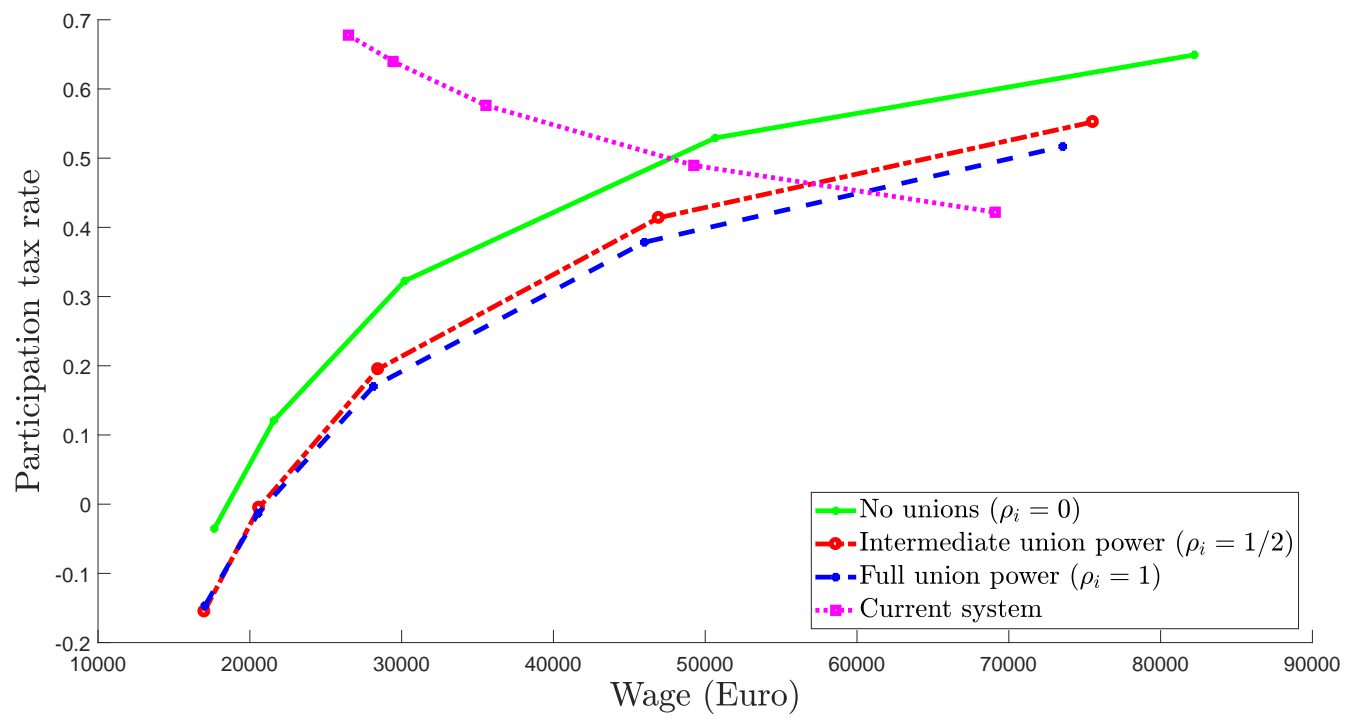

Figure 10: Optimal participation tax rates with lower social welfare weight of the unemployed $\left(b_{u}=1 /\left(2.25 \lambda\left(-T_{u}\right)^{\nu}\right)\right)$

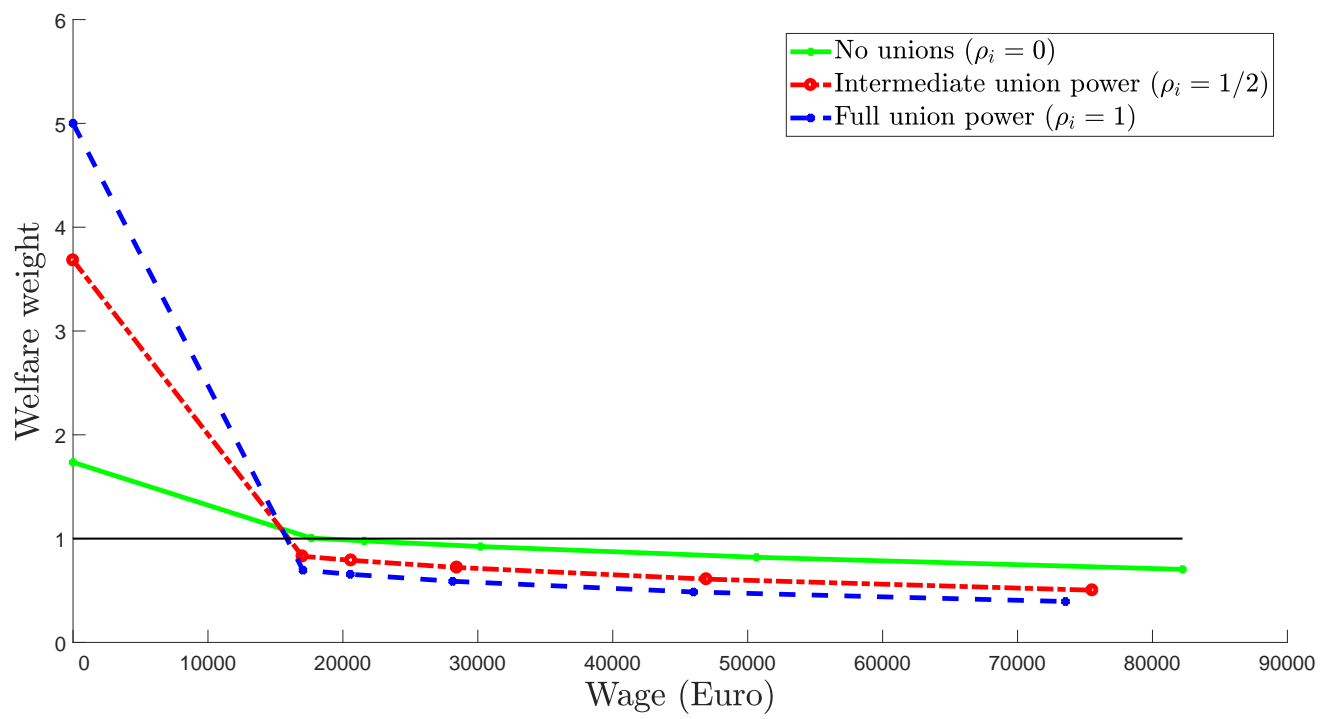

Figure 11: Social welfare weights with lower social welfare weight of the unemployed $\left(b_{u}=\right.$ $\left.1 /\left(2.25 \lambda\left(-T_{u}\right)^{\nu}\right)\right)$ 




Figure 12: Optimal participation tax rates with interdependent labor markets

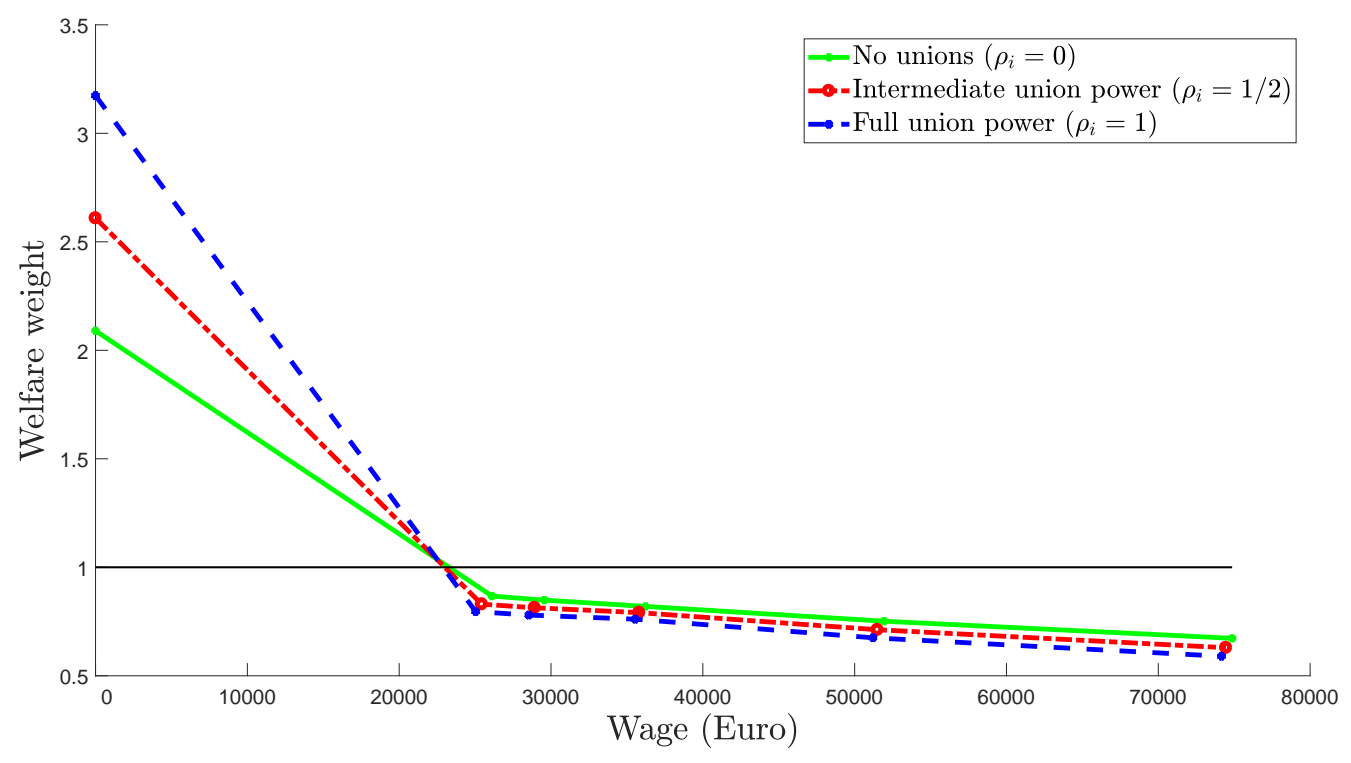

Figure 13: Social welfare weights with interdependent labor markets 